\title{
Instructor Guidelines and Group Size as Moderating Factors Affecting Quality and Quantity of Online Discussion Participation, Satisfaction and Learning
}

\section{Dr. Mohammed A. Farag Abstract :}

This study aimed at investigating the moderating effects of instructor guidelines and group size in online discussions on quality and quantity of learner participation, learning and satisfaction. Learners were randomly assigned to one of three treatment groups, which were defined by the amount of structure groups received: low, moderate, and high. Six sub-groups participated in six online discussion forums, with the three large groups ranged from 21-23 participants and the three small groups ranged from 6-8 participants. Learners participated in the discussions for five weeks; two weeks were used for training and actual study lasted three weeks. Quantity of participation was measured by participant number of responses whereas quality of postings was analyzed by a coding scheme dividing responses into on-topic and off-topic postings.Learningwas measured using an achievement test with 50-items. A survey was used to determine student satisfaction with the online discussion. Ninety-four $(n=94)$ undergraduate preparatory-year malestudents, studyingacommunication skills course, from Albaha University inSaudiArabia,betweentheagesof17-19yearsold,participatedinthestud yasaUniversityrequirement.Allstudytools (e.g.,studentcodingscheme, achievementmeasure, andsatisfactionquestionnair e) were administrated at the end of the study. The two way analysis of variance was used as a main tool for processing participant data, with the numeric measure of postings and percentageasa secondary tool.Theresultsof analysis of variance showed several significant differences. First, quality and quantity of learner postings were affected by levels of instructor guidelines and group size, with the high structure group being better and large size groups showed more postings but small size groups being better with the average means of postings. Second, high structure group outscored moderate and low structure groups in the on-topic responses. Third, small groups posted more on-topic responses than large groups but for the offtopic responses, the results showed no differences. Fourth, achievement was also affected by levels of structure and group size, with the high structure group being better whereas for the group size, the small groups' size showed better learning than large groups size. Fifth, satisfaction was also affected by structure and group size. Large groups were satisfied more with the online discussion than small groups. High structure groups were more satisfied with the online discussion than the other groups. Sixth, interaction between structure of online discussions and group sized were found to affect amount and types of participation, learning and satisfaction. The results of

\section{9}

\section{Journal of Arabic Studies in Education \& Psychology (ASEP)}


the study were discussed in terms of their implications for designing online discussion and leaning.

Keywords: Instructor Guidelines, Online Discussion Structure, Group Size, Quality and Quantity of Postings, Satisfaction, Participation, Amount and Types of Participation

\section{INTRODUCTION :}

Students are using the web in many facets of their lives, and they use it to interact with people in many ways. As a result of the growing use of the web, unique possibilities for educational use of the web have developed. Therefore, to capture the opportunity that the web presents, instructional designers must identify factors that make online learning effective to increase student participation and learning.

Online discussion is one of the most important asynchronous electronic communication tools via the Internet for the exchange of ideas, opinions and points of view and dialogue through contact with the possibility of attaching displayed illustrations and video to enrich the debate. Online discussion is one in which students participate via a website on the internet. A question or topic is posted to the discussion by the instructor or one of the students who participating in the debate and students log in, read the discussion postings and respond at their convenience. These responses are arranged according to the added time display where students can refer to them at any time from the start of the debate and to the end.

Such discussions are also called asynchronous discussion because each participant contributes to the discussion at his/her convenience. These discussions are part of asynchronous learning network and are examples of computer mediated communication. Asynchronous online discussions are a form of communication that can organize messages into "threads". A thread is a chain of messages that reply to each other, forming a discussion (DavidsonShivers \& Rasmussen, 2006). Because online discussion 
and threaded discussion were used interchangeably in the literature, both terms were used in the same manner in this study.

Online discussions are one of the widely used communication tools in a Learning Management System. Many educational institutions use them with different pedagogical aims - as an aid to classroom teaching in faceto-face institutions or as a teaching/learning tool and a communication medium among students, and students and instructors in online learning. The asynchronous medium of the online discussions environment provide great potential for promoting and building learning communities where students could interact with groups of students and engage in mutually exchanging messages about the content (Torrisi\& Steele, 2002). This has the potential to create new kinds of exciting possibilities for collaboration and satisfying the communicative needs of those who use them.

Despite the documented popularity and success of online discussions as good teaching and learning strategies, their use has not necessarily ensured high levels of learning, participation, or collaboration (Campbell, 2004). In fact, one of the most difficult challenges for instructors has been making online discussions interesting and motivating for students. Angeli, Valanides, and Bonk (2003) suggested that such discussions often did not maintain students' initial interests and participation beyond the first three weeks of a course. Xie, DeBacker and Ferguson (2006) reported that over time intrinsic motivation steadily dropped.

The instructor's challenge with online discussions, according to Kachel, Hebry, and Keller (2005), was to establish an atmosphere conducive to meaningful discourse that was founded on reflection and critical thinking, and student learning was best served when discussions

\section{1}


concentrated on questions related to course assignments and content. When such guidelines were followed, student participation, learning, and perceptions were more positive than when guidelines were not present.

A review of several studies that addressed online discussion and the factors that affected learner participation in online discussion have indicated that low student participation were found to be affected by many factors. One factor may limit student participation in online discussion is student views of the importance of the discussion (Xie et al., 2006; Zhao \& McDougall, 2005), or when there is no grading system exist (Dennen, 2005). Another Important factor limit student participation is the behavior of other participant (Cheung \& Hew, 2004), or when the discussion becomes emotional or rude ((Hewitt, 2005; Murphy \& Coleman, 2004). Further, information overload may prevent student from contributing to the discussion when multiple postings have to be processed at the same time (Stathakos, 2003; Clark \& Mayer, 2002; Kirk \& Orr, 2003; Peters, 2005; Wiley \& Bailey, 2006). Limited student contribution in asynchronous online discussions may also be due to students being at loss of what to contribute (e.g., Fung, 2004; Khan, 2005).

Previous research has indicated several manners in their trial to increase student participation in online discussion. One guideline was suggested by these studies was to select a discussion topic that directly related to the student's main curriculum (Dennen 2005; Hummel et al. 2005; Masters and Oberprieler 2004). Another technique used to add structure to online discussion was through providing instructor guidelines for participation. For example, researchers asked students to respond in a certain manner (Jeong\& DavidsonShivers, 2006), post a given number of responses (Kluwin\&Nortesky, 2005), defined guidelines for message

\section{2}


lengths and constructions (Jonassen\&Remidez, 2005) or added participation into a grading system as a requirement (Havard, Du, \&Olinzock, 2005; Kluwin\&Noretsky, 2005; Jeong\& Davidson-Shivers, 2006). Information overload may be overcome by splitting large discussion groups into subgroups or small ones that may increase the amount of participation. When the group size increases, the possibility of information overload may also decreases.

\section{BACKGROUND OF THE PROBLEM :}

There were several variables that factored into a student's participation (Davidson-Shivers \& Taylor, 2006), collaboration, and engagement in online courses (Beaudoin, 2002). Many instructors reported that requiring participation was fundamental to generating acceptable student participation in online discussions (Stemwedel, 2005). Khan (2005) confirmed this idea, finding that student participation increased when online discussions became mandatory rather than optional. These studies suggested that students were more active when they knew their participation was monitored than when it was not monitored. Stemwedel (2005) maintained that incorporating participation into students' grades was essential to ensure that students submitted high-quality contributions to online discussions. Khan (2005) suggested that mandatory assignments served as a catalyst for motivating students to participate and fostered student-centered discussions. Xie et al. (2006) suggested that when instructors placed greater value on online discussions and explicitly encouraged participation, student participation and participatory behaviors (e.g., number of login times and responses) increased. They added that when instructors emphasized the value of online discussions, had explicit expectations for discussions, and encouraged active participation, students participated more and perceived the discussions as valuable and interesting. Moreover, Wallace (2003) suggested that students

\section{3}


established a social presence through participation in online discussions, and, in turn, social presence seemed to be a key ingredient in satisfaction and learning. She also added that students valued online discussions with peers and instructors. Instructors, then, sought ways to outline participation requirements and approaches to evaluating student participation in online discussions; current methods were varied (Khan, 2005; Stemwedel, 2005).

Wallace (2003) agreed that students actively participated in online discussions when these discussions were valued. Xie et al. (2006) added that students were more likely to participate and continue participating in online discussions when they perceived the discussions as a useful and valuable way to communicate and receive information than when they did not find value in the discussions. Xie et al. (2006) also claimed that student participation was related to intrinsic motivation; and, if students perceived the discussions as valuable, interesting, and enjoyable, they were more likely to participate in online discussions.

While facilitation of online discussions was a factor which influenced student participation and learning, the use of facilitation varied. Some instructors did not facilitate course discussions (e.g., Ferdig\&Roehler, 2003-2004; Schrire, 2006); others actively interacted (Havard et al., 2005; Lu \&Jeng, 2006); still others were innovative in their facilitation methods. For example, Davidson-Shivers, Muilenburg, \& Tanner (2001) used students as facilitators for online discussions. Jugdev et al. (2004) used an academic coach, or mentor, to facilitate a threaded discussion debate; this coach was active in facilitating discussions through guiding, focusing, and initiating responses to the debate, while posting questions that fostered critical thinking and that extended discussions. Topper (2005) took a dual role as facilitator in online

\section{4}


discussions - instructor as participant and instructor as observer - which enabled the instructor to facilitate student discourse while analyzing discussions. As a participant, the instructor was able to incorporate discursive moves (methods for fostering a learning atmosphere) as facilitation mechanisms to foster student participation and improve the quality of participation. This type of facilitation increased the quality and level of student postings in course discussions and student learning.

Structure in online discussions was defined by Gilbert and Dabbagh (2005) as the instructional design components of a discussion that guided student participation in online discussions, such as number, type, and pace of postings. While these components have been commonly implemented, the ways in which discussion structure has been applied have varied (Jonassen\&Remidez, 2005). Despite how discussion structure was used, researchers suggested that it impacted student learning and satisfaction. Hew and Cheung (2003a) stated that student ideas often sound similar to one another. Therefore, students needed explicit guidelines (i.e., structure) in online discussions because without structure, students often participate at a surface level in online discussions. Angeli et al. (2003) indicated that students' participation in online discussions was mostly exchanges related to personal experiences, was not based on well-supported reasoning, did not show evidence of critical thinking related to studying course content, and was conversational and opinionated. The research of Hew and Cheung suggested that students, therefore, benefited from structure, such as guidelines, to help them participate at a deeper level in online discussions.

Elements of structure, or guidelines for participation, influenced student responses and student participation in online discussions. For example, Jonassen and Remidez 
(2005) suggested that some protocol items, such as limiting length of postings, could positively influence discourse; while others, such as choosing the type of message posting, may do the reverse. Gilbert and Dabbagh (2005) found that when the instructor presented guidelines, an increase in quality of responses and discussions was noted; participation guidelines increased the number of student postings, leading to more detailed and in-depth discussions and higher student interaction. Moore and Marra (2005) highlighted the notion that planning for the effective integration of structure in online discussions was an influential variable influencing student learning and was a task that was crucial for the online instructor to tackle, and the appropriate use of discussion structure directly influenced the quality of student learning. The present study was interested in investigating the influential effect of giving students instructions before participation in online discussion on the quality and quantity of postings. The manner used in the present study was to provide students with different levels of guidelines (high structure guidelines-moderate structure guidelines-low structure guidelines) on how to participate and amount of participation.

Another important issue related to the quality and quantity (amount) of participation in online discussion is the number of students participating in the debate. Online group size may in some way moderate students' participation and learning. In large group size, large number of students could use the environment at the same time or different time and so there is a great potential for information overload, overlap of similar messages, and shifting through large number of messages to get the required information could become an issue. In line with information overload, discussion generated in the forum would be useful to

\section{6}


students if the required information is easily located and quickly retrieved. This problem apparently arises because of the vast, unstructured and mixed amount of information available in the forum messages, and the inadequacy of the forum interface to support them. One solution to the information overload problem is controlling the size of the discussion group. Dividing large class into sub-classes with a total of 6-8 students in each group may decrease the possibility of information overload. The present study was interested in investigating to what extent the class size in the online discussion may change quality and quantity of participation and learning. The effect of different group sizes in online discussion is not clear and needs more investigation.

\section{STATEMENT OF THE PROBLEM}

Online Discussion Forums are considered as one of the most important electronic tools used in e-courses. With emergence of e-Learning Management Systems (LMS), several universities in developing countries have started to use them as platforms for electronic learning courses. An important interest in designing online discussion forums was to establish the conditions and terms which contribute and confirm learner participation in topics related to the course contents. Participation is a key issue in developing online discussion forums and has long been discussed in previous studies. Most previous studies discussed the manners and ways to enhance student participation in online discussion by using several strategies. One of the most important strategies used to increase learner participation in online discussion was to provide clear instructor guidelines for encouraging dialogue and participation. Using structure such as instructor guidelines with explicit instructions about the number of postings, quality of posting and the reasons for the selected post may be a good measure of participation. Based on this line of studies, the present

\section{7}


study was designed to investigate the effect of providing students with different levels of instructor guidelines (high structure guidelines, moderate structure guidelines, and low structure guidelines) in online discussion forum on learner participation in terms of amount and quality of postings. One could suggest that providing high structure guidelines may increase learner's quality and amount of postings. However, instructor guidelines may increase posting numbers; the quality of message posted may not show a similar increase. The study was also interested in investigating to what extent learning and satisfaction are affected by instructor guidelines.

The second important design element in online discussion structure is the size of the discussion group. Despite the possibility that increasing group size in online discussion may ensure an increase in participation and number of postings, this may not an indication also that increasing group size will result in an increase in the average post by learner or result in an increase in quality of postings. Previous studies have showed mixed and inconsistent results with relation to group size and participation. For example, Hewitt, Brett, \& Peters (2007) found that larger classes were associated with an increase in the number of notes written, a decrease in average note size, a decrease in the percentage of notes opened and an increase in note scanning. To overcome information overload, Hron and Friedrich (2003) argued that appropriate group sizes should be set up to ensure for each group a critical mass of participation, to reach the goals associated with collaborative learning, and to make it easier to establish social presence to encourage greater interactivity (Aragon, 2003; Tu\&McIsaac, 2002). As a basic precondition, online learners have to read the messages, ask questions, comment on messages, and answer questions (Hron\& Friedrich,

\section{8}


2003). Aragon (2003) pointed out that it was easier to establish social presence in smaller classes.

In summary of the class size, researchers have proposed a number of different optimal sizes for online classes. Some researchers suggested 30 as an upper limit on class size (Aragon, 2003) while others (e.g., Roberts \& Hopewell, 2003)suggested keeping the size of the class to 20 students, to allow for more "workable" loads, and to increase class effectiveness. It is more likely that small groups may bring pressure on members to participate. Larger groups, on the other hand, allow members to withdraw from active participation.

It is still unclear whether a large group size or a small group size may ensure more participation (amount and type of participation). Large group size may have many advantages such as exposure to a wide range of ideas and perspectives and have more chances for peer collaboration. However, increasing group size may have disadvantages. First, increasing group size may increase disparity among group members leading to ineffective behaviors. Second, with large group size, group members are less likely to see their own personal contribution to the group as being important to the group's success. Third, with larger group size, the average contribution per member may decrease. Group size, then, may be a moderate variable in learner participation and learning. Therefore, group size is a main variable in the present study.

Although structural elements such as guidelines and groups size have been reported as beneficial in online discussions, there is still a need to further information about the relationships between structure and other variables related to online discussions. For example, currently, it is not clear whether structure and participation lead to

\section{9}


improved student learning and positive student satisfaction with regard to online discussions. Structural elements, such as instructor guidelines and group size, in online discussion may be some of the factors that impact student participation, learning and satisfaction in online learning environment. The present study was designed to investigate these two factors that may affect student quality and quantity of participation, learning and satisfaction in an online learning environment.

\section{THE STUDY PURPOSES}

The overall purpose of this study was to determine the factors that are associated with student participation, learning and satisfaction in an online discussion. In supporting this purpose, the primary objectives are twofold. The first objective was to investigate the effect of the instructor guidelines (high structure, moderate structure, and low structure) on learner participation (in terms of quality and quantity of participation), learning and learner satisfaction in an online discussion. The second objective was to determine whether or not a large group size of the online discussion would produce different results in terms of student participation, learning, and satisfaction than a small group size.

\section{QUESTIONS}

The present study addressed the following seven questions:

- Research Q1: in terms of Quality and Quantity of Student Participation in Online Discussion, Can High Instructor Guidelines Structure Produce different results than moderate or low guidelines structure?

- Research Q2: in terms of Quality and Quantity of Student Participation in Online Discussion, Can Large Group Size in online discussion produce different results than Small Group Size?

\section{0}


- Research Q3: in terms of Achievement on the Course, Can High Instructor Guidelines structure in Online Discussion Produce different results than Moderate and Low Guidelines structure?

- Research Q4: in terms of Achievement on the Course, Can Large Group Size in online discussion produce different results than Small Group Size?

- Research Q5: in terms of Course Satisfaction, Can High Instructor Guidelines structure in Online Discussion Produce different results than Moderate and Low Guidelines structure?

- Research Q6: in terms of Course Satisfaction, Can Large Group Size in online discussion produce different results than Small Group Size?

- Research Q7: In terms of participation, learning and satisfaction, can the interaction (if exists) between instructor guidelines and group size produce different results outcomes?

\section{SIGNIFICANCE OF THE STUDY}

Since online discussions have become common in online courses because they offer a shared space for students to communicate and explore ideas (Davidson-Shivers \& Rasmussen, 2006; Johnson, 2005), continued examination of online discussions may assist in the development of online learning. While effective online discussions may enhance student learning as students examine ideas through discourse, designing effective online discussions is a challenge for instructors, and finding ways to encourage student participation adds to this challenge. Student participation in this process is imperative to the success of learning in online environments, and that online discussions increase class interaction.

Furthermore, Moore and Marra (2005) suggested that identifying appropriate participation protocols for online

\section{1}


discussions may have a direct influence on student participation and learning. This study sought to reveal ways to design online discussions to increase student participation for improved student learning and to extend the existing body of knowledge related to the use of discussions in online undergraduate courses. Information related to student satisfaction in online discussions was also investigated.

This study sought to fill a gap in the instructional technology literature about the effect of structuring online discussion based on instructor guidelines and group size on participation, learning and satisfaction. This study also provides University instructors with information that they can use to improve student participation in online learning particularly online discussion.

A great deal of research has been done on online discussions. Previous research has mainly focused on two topics: participation and online collaboration. A few researchers have studied class size and participation, with relation to instructor guidelines. This study is a trial in this respect.

\section{HYPOTHESES}

Null Hypothesis One: With respect to the instructor guidelines, there would be no significant difference at $\alpha=$ .05 level in amount and types of student participation as measured by the mean number of postings and participation rubric among the high structured online discussion group, moderate structured online discussion group and low structured online discussion group.

Null Hypothesis Two: With respect to the online discussion group size, there would be no significant difference at $\alpha=.05$ level in amount and types of student participation as measured by the mean number of postings and the participation rubric between large group size and small group size.

\section{2}


Null Hypothesis Three: With respect to the instructor guidelines, there would be no significant difference at $\alpha=$ .05 level in achievement as measured by achievement test among the high structured online discussion group, moderate structured online discussion group and low structured online discussion group.

Null Hypothesis Four: With respect to the online discussion group size, there would be no significant difference at $\alpha=.05$ level in achievement as measured by achievement test between of the large group size and small group size.

Null Hypothesis Five: With respect to the instructor guidelines, there would be no significant difference at $\alpha=$ .05 level in course satisfaction as measured by the satisfaction survey among the high structured online discussion class, moderate structured online discussion class and low structured online discussion class.

Null Hypothesis Six: With respect to the online discussion group size, there would be no significant difference at $\alpha=.05$ level in course satisfaction as measured by the satisfaction survey between the large group size and small group size.

Null Hypothesis Seven: with respect to instructor guidelines and group size, there would be no interaction effect at $\alpha=.05$ level in participation, learning and satisfaction.

\section{THE STUDY METHOD}

This study belongs to the type of experimental research, which aims to study the causal effects of selected variables, and the experimental method is the most appropriate research methods to achieve this purpose. Therefore, the present study follows the experimental method. Within this method the quasi- experimental design was used to study the effects of the independent on dependent variables.

\section{3}




\section{PARTICIPANTS}

The participants of this study $(\mathrm{N}=94)$ were preparatory year undergraduate students at Albaha University in Saudi Arabia. About 1800 to 2200 students join the preparatory year of the university each year. The age range of the participants was 17-19 years old. The mean age was 18.71 $(\mathrm{SD}=1.31)$. Participants were enrolled in the Communication Skills course for the first semester in the preparatory year. This course was web-based; thus, students possessed moderate technology skills. Because the course was required as part of the core curriculum for all majors, students joined the course had different majors such as engineering, medicine, pharmacy, education, computer science and so on. The Communication Skills Course is compulsory for females and males, but participants in the study were all male students. Participants had experience with online discussions in the course prior to participating in the actual study, that is, two weeks training were given to them to familiarize with the online discussion structures. These experiences helped students move beyond the learning threshold with discussions so that they could focus on the discussion content.

\section{THE STUDY VARIABLES}

This study included two independent variables and three dependent variables. The independent variables were, one was structure in online discussions, which had three levels high, moderate, and low, and the other was group size of the online discussion, which had two levels- large group and small group. The dependent variables were student participation, student learning, and participant satisfaction.

\section{The Independent Variables}

This study had two independent variables, structure (instructor guidelines) in online discussions, with three levels to this variable: (a) high, (b) moderate, and (c) low structure. Highstructure provided guidelines that required

\section{4}


students to respond to the question, offer support for their ideas, and elaborate on at least three peer messages. Moderate structure required students to provide an original response to the reflective question posed in the online discussion and to reply to at least three others' ideas. Lowstructure provided the discussion question but did not provide guidelines as to how or how often students must respond or reply. The second independent variable was group size in the online discussion, with two levels to this variable: (a) small group and (b) large group. Small group had between 8-10 participants. Large group had between 21-23 participants.

\section{The Dependent Variables}

This study included three dependent variables: student participation, student learning, and student satisfaction.

Student participation: this variable was based on the written messages students posted to online discussion and was measured in two ways: (a) amount of participation was calculated by the number of student responses, and (b) type of participation was measured using a modified coding scheme adapted from Davidson-Shivers et al. (2005) and Jeong and Davidson-Shivers (2006). Student responses were coded as on-topic and off-topic with relation to the discussion content based on a rubric. On-topic responses were related directly to the discussion content while offtopic responses were not related to the discussion content.

Student Learning: this variable was measured using a 50 question-achievement test, with (25) questions in the form of true and false, and (25) multi-choice questions. This test measure student knowledge and understanding of the course content.

Student Satisfaction: student satisfaction was defined as perceptions, attitudes, and opinions toward a given topic and online discussion. This variable was measured using a

\section{5}

Journal of Arabic Studies in Education \& Psychology (ASEP) 
25- Likert scale item survey of five responses ranging from strongly agrees to strongly disagree.

\section{EXPERIMENTAL DESIGN}

The quasi-experimental design was used to study the effects in the light of the independent variable levels, and this is represented in table below. The learners in the present study were blocked by structure guidelines and group size into 6 discussion forums.

Table 1: The study experimental design

\begin{tabular}{|c|c|c|c|c|c|}
\hline & & & \multicolumn{3}{|c|}{ Instructor Guidelines (Structure) } \\
\hline & & & High & Moderate & Low \\
\hline \multirow{3}{*}{ 苛芯 } & $\begin{array}{l}\text { Small } \\
\text { Group }\end{array}$ & 28 & 10 & 10 & 8 \\
\hline & $\begin{array}{l}\text { Large } \\
\text { Group }\end{array}$ & 66 & 22 & 21 & 23 \\
\hline & Total & 94 & 32 & 31 & 31 \\
\hline
\end{tabular}

Ninety four students participated in the present study. Of 94, 66 learners were assigned to the large group treatments while 28 participated in small groups. Larger group learners ranged in size between 21-23 students in each group, but with the small groups, 8-10 participants per group. 32 students were in the first treatment (e.g., high structure guidelines), 31 were in the moderate structure treatment, and 31 were in the low structure guidelines.

\section{THE STATISTICAL ANALYSIS}

The multivariate analysis of variance (MANOVA) was used in order to study the effects and interaction of the independent and dependent variables of the study.

\section{THE STUDY TOOLS}

- Frequency of Postings: a numeric count of student responses. This measure was used to measure number of postings.

- A type of response rubric: a 10-field scale measuring the quality of student postings. This measure was used to classify responses into two categories: off-topic responses and on-topic responses.

\section{6}


- An achievement test: a 50-item test, with 25 true and false questions and 25 multi-choice questions.

- Participant satisfaction Survey: a 25-item questionnaire for measuring student perception, attitudes, and opinions toward the online discussion forum.

\section{THE STUDY PROCEDURES}

- An analytical survey on the literature and related studies to the study topic and in the light of the independent variables. This survey method of literature aimed at form a theoretical framework for the study which was used in reasoning the study problem and helped in building the study hypotheses and discussing the study results.

- Content analysis of the units, followed by experts' judgment and rebuilding it in the light of the view of the experts. Then the instructional objectives were set to cover the content areas.

- Building the study tools (achievement test, a rubric for measuring type of participation, and student satisfaction survey), then gave it to a panel of specialists in curriculum and teaching methods and educational technology for judgment of congruency with treatment objectives and treatment contents.

- Designing scenario appropriate for e-learning technological environment.

- Development of the e-learning technological environment and gave it to the specialists and technologists in order to approve the design and development procedures.

- Conducting a pilot study to make sure that all tools and treatments are suitable for use with the main sample.

- Selecting the main sample and assigning them to the treatments based on the independent variable of the study.

- Conducting the experimental treatments on the main study sample based on the study experimental design.

\section{7}


- Post application of the study tools.

- Collecting and gathering data from the participants' achievement, participation rubric and their satisfaction survey.

- Statistical analysis of the data gathered and presenting the findings, discussing, and explaining the results in terms of their implications for designing online learning and online discussions.

\section{DEFINITION OF TERMS}

Online Discussion:A discussion format where the instructor posts a question or prompt and students respond. Students are also supposed to respond to each other. The online discussion shows different levels of responses, allowing students to respond to multiple ideas or "threads" through the discussion.

Quality of Participation:was defined as the type of response that students provide. There were two levels of student participation, on-topic and off-topic, which related to how connected student responses were to the discussion content. On-topic participation related directly to discussion content; off-topic participation did not.

Quantity of Participation: was defined as the number of times that students posted messages to discussions.

Instructor Guidelines: were defined as the instructions the instructor gave to the students before involvement in the online discussion, and these instructions directed participation in the online discussion.

Student Learning: For this study, student learning was defined as the acquisition of new information at a verbal information level and students' ability to use this information at an intellectual skills level of rules as defined by Gagne et al. (2005). Evidence of student learning was

\section{8}


obtained through a posttest of multiple choice and true-false items.

Student Satisfaction:Student satisfaction was defined as student opinions and beliefs about a given topic. For purposes of this study, satisfaction was related specifically to online discussions.

\section{THEORETICAL FRAMEWORK}

\section{Online Discussions}

Online discussion is one in which students participate via a website on the internet. A question or topic is posted to the discussion and students log in, read the discussion postings and respond at their convenience. Such discussions are also called asynchronous discussion because each participant contributes to the discussion at his/her convenience. These discussions are part of asynchronous learning network (ALN) and are examples of computer mediated communication (CMC). Asynchronous online discussions are a form of communication that can organize messages into "threads". A thread is a chain of messages that reply to each other, forming a discussion (Davidson-Shivers \& Rasmussen, 2006). Because online discussion and threaded discussion were used interchangeably in the literature, both terms were used in the same manner in this study.

Online discussions are one of the widely used communication tools in a Learning Management System. Many educational institutions use them with different pedagogical aims - as an aid to classroom teaching in faceto-face institutions or as a teaching/learning tool and a communication medium among students, and students and instructors in online learning. The asynchronous medium of the online discussions environment provide great potential for promoting building learning communities where students could interact with groups of students and engage in mutually exchanging messages about the content (Torrisi-

\section{9}


Steele, 2002). This has the potential to create new kinds of exciting possibilities for collaboration and satisfying the communicative needs of those who use them.

Online discussions offer several possibilities to support learning. They provide convenient and flexible medium to extend interactions in the online environment. This is in sharp contrast to traditional setting where opportunities for group working are constrained by time and place. Online discussions can be used within a course to serve several purposes ranging from providing a forum for social networking through to facilitating the construction of knowledge (McLoughlin\& Luca, 2002). The typical uses of Online discussions as identified by researchers include: a) providing flexible medium for students to make their perspectives, and questions visible and support collaboration or competition (Allan, 2004; Barker, 2003; Helic, Maurer, \&Scerbakov, 2004; Hoadley\& Linn, 2000; Thaiupathump, Dawant, \& Bourne, 1998), b) "develop critical thinking skills and teamwork"(Lawhead, Alpert, Bland, Carswell, Cizmar, DeWitt, Dumitru, Fahraeus, \& Scott, 1997, p.31), and c) enable "communities of learners to negotiate and co-construct meaning for problem solving and knowledge construction"(Barker, 2003, p.54).

One unique feature of an asynchronous online discussion forum is that there is no loss of data as the discussion forum allows records of an individual's written messages to be kept in the virtual space. Individuals can view the messages many times and long after the messages have been posted and respond to the messages posted at any time they prefer. The benefit of contributing at their own pace means that students have time to reflect on their own as well as other students' comments (Murphy \& Coleman, 2004). In addition, because individuals have to explicitly express their thoughts in writing, the very process of writing in itself helps them to carefully construct their ideas, as well as

\section{0}


encourages reflection which helps promote higher level learning such as analysis, synthesis, and evaluation (Newman \& Blitzer, 2003).

Although asynchronous online discussions can afford certain benefits, such benefits can only be achieved if students are willing to contribute in the discussions in the first place. As suggested by Mazzolini and Maddison (2003), a necessary, if not sufficient, condition for a discussion to aid learning is for it to contain a sizeable number of postings contributed by students. Dennen (2005) similarly suggested that although student contribution may not be a direct absolute measure of learning, student contribution is necessary in order for a discussion to occur in the first place. Student discussion has been identified as a key component of online learning, where learning takes place (Ertmer, Richardson, Belland, Gamin, Connolly, \&Coulthard, 2007). Richardson and Swan (2003) similarly identified online discussion as one of the activities that students found most beneficial to their learning. According to Dunlap (2005), a discussion provides the primary means for students to exchange ideas, share multiple perspectives, and clarify understandings; a notion consistent with the social constructivist learning perspective (Vygotsky, 1978). Unfortunately, prior research has suggested that limited student contribution in asynchronous online discussions appears to be a persistent and widespread problem (Hewitt, 2005; Campbell, 2004). In fact, one of the most difficult challenges for instructors has been making online discussions interesting and motivating for students. Angeli et al. (2003) suggested that such discussions often did not maintain students' initial interests and participation beyond the first three weeks of a course. Xie, DeBacker and Ferguson (2006) reported that over time intrinsic motivation steadily dropped.

The instructor's challenge with online discussions, according to Kachel et al. (2005), was to establish an

\section{1}


atmosphere conducive to meaningful discourse that was founded on reflection and critical thinking, and student learning was best served when discussions concentrated on questions related to course assignments and content. When such guidelines were followed, student participation, learning, and satisfaction were more positive than when guidelines were not present.

\section{Learner Participation in Online Discussion}

Student participation is a central issue in debates about online discussion. Kuboni and Martin (2004) suggest that two features are important in a definition of participation: exchanging messages and a quantitative dimension in which the number of postings are counted. A crucial problem was identified by researchers in asynchronous discussions is lack of student participation (Anderson, 2009; Brookfield \&Preskill, 2012; Conrad \& Donaldson, 2011; Hammond, 2005). Not all students relish the opportunity to make their views known or to engage in scholarly discourse. Coomey and Stephenson (2002) point out that "Instructors and course designers cannot assume that learners will be able to jump into group discussions, argue in online debates, or answer questions posed online, just because they are told to participate" (p. 39). Crucial to the success of online learning is active student participation and interaction both with peers and instructors (Sutton, 2001). Bruyn (2004) has found that student accessibility was often limited, levels of social presence were unequal and varying quality, and the degree of convergence was often low in student threaded discussions. Course co-ordinators employ various techniques for increasing and maintaining student participation in online courses. A common approach reported in the literature is some overt reward or punishment system (Masters \&Oberprieler, 2004). To guarantee participation, some researchers suggest that instructors require that everyone make a certain number of

\section{2}


comments in online discussions or require students to make contributions and comment on the contributions of others (Linn \&Slotta, 2006). In so doing, the low participation problem is often solved. However, with regard to large graduate online courses, students will face another problem - information overload.

In line with this idea, previous studies have measured student participation by the number of times a learner access an e-learning environment. Learners that access an elearning environment many times are assumed to participate more actively than learners who do not. A study of Davies and Graff (2005) used a student access to the group area and their access to the communication areas to represent the degree of participation. Another approach to measure participation was the number of written notes posted. In a study by Lipponen, Rahikainen, Lallimo, and Hakkarainen (2003), participation was defined in terms of active and inactive participant.; a participant was considered active if the participation rate (number of written notes) was in the upper quartile and inactive if it was in the lower quartile" (p. 492). Quality of postings was used as a technique to estimate participation. A learner that writes many contributions of high quality is assumed to participate more actively than a learner who does not. Davidson-Shivers, Muilenburg, and Tanner (2001) conducted a qualitative analysis and identified nine types of substantive and nonsubstantive comments. This was also considered in other studies as perceived importance of postings. In a study by Mazzolini and Maddison (2003), participation was estimated using importance of postings. A learner that posts many messages that are perceived of importance is assumed to participate more actively than a learner who does not. Vonderwell and Zachariah (2005) and Vonderwell, Liang, and Alderman (2007) define participation as taking part and

\section{3}


joining in a dialogue for engaged and active learning. A learner that feels that he or she is taking part and is part of a rewarding dialogue is assumed to participate more actively than a learner who does not.

\section{Measuring Participation in Online Discussion}

For the purpose of this study three types of measuring participation are discussed further; these are: quantity of postings, quality of postings and learner perception. One of the important common measure of online learner participation in online discussion has been the quantity of message or postings. Data gather from previous studies measured quantity of postings as: (1) the number of words, phrases or sentences posted (e.g., Bohlke, 2003), (2) the complete statements (e.g., Davidson-Shivers et al., 2001) or (3) ideas (e.g., Hakkarainen\&Palonen, 2003). The frequency of postings has been used to compare: (1) treatment groups, individual learners or groups; (2) groups of learners by characteristics (gender and learning styles); (3) types of postings (sent and received messages); (4) time-period; and (5) different discussion forums (academic and social forums).

The second important common measure of participation has been the quality of postings. Postings have been classified according to a coding system. Different studies used different coding schemes (Beuchot\&Bullen, 2005; Davidson-Shivers et al., 2000; Davidson- Shivers et al., 2005; Murphy, Mahoney, Chun-Ying, Mendoza-Diaz, \& Yang, 2005). The most important coding system has been used to measure quality of posting was the comparison between on-topic and of-topic messages (Davidson-Shivers et al., 2001; Lipponen et al., 2003). Another scheme was by measuring the type of interaction such as asking questions or providing information related/unrelated to the topic (Carr, Cox, Eden, \&Hanslo, 2004).

\section{4}


By coding online discussions in a graduate course, Beuchot and Bullen (2005) found that fostering interpersonal interaction resulted in increases in student participation, depth of discussion, and knowledge construction. In addition, Davidson-Shivers et al. (2001) used a coding system that identified student responses as either substantive or non-substantive. Substantive codes were defined as those that related directly to the discussion content, and non-substantive codes did not. Substantive codes were structuring, soliciting, responding, and reacting. Non-substantive responses were procedural, technical, chatting, uncodable, and supportive. Davidson-Shivers et al. (2001, pp356-357) define these codes as follows:

Structuring: "Statements that initiate a discussion and focus attention on the topic of the discussion"; (2) Soliciting: "Any content-related question, command or request which attempts to solicit a response or draw attention to something"; (3) Responding: "A statement in direct response to a solicitation"; (4) Reacting: "A reaction to either a structuring statement or to another person's comments, but not a direct response to a question"; (5) Procedural: "Scheduling information, announcements, logistics, listserv membership procedures, etc."; (6) Technical: "Computer-related questions, content, suggestions of how to do something not related to the topic directly"; (7) Chatting: "Personal statements, jokes, introductions, greetings to one, etc. to individuals or the group"; (8) Uncodable: "Statements that consist of too little information or unreadable to be coded meaningfully"; (9) Supportive - "Statements that although similar to chatting, there is an underlying positive reinforcement to the comment".

The coding system developed by Davidson-Shivers et al. (2001) was based on the literature and has been used and

\section{5}


modified over the last decade in studies such as those conducted by Jeong and Davidson-Shivers (2006) and Davidson-Shivers et al. (2005). Jeong and Davidson-Shivers (2006, 550) used codes based on traditional argumentation discourse, such as argue, evidence, critique, and elaboration. These authors defined these codes as follows: (1) Argue: "A main argument or assertion to support a position"; (2) Evidence: "To support argument and assertions with evidence, examples, studies, personal experiences"; (3) Critique: "Critique, test/question validity, request supporting evidence, identify flaw in argument, logic, evidence"; (4) Elaboration: "Elaborate/clarify without defending/challenging an argument or position". DavidsonShivers et al. (2005) added a code called "off topic" that meant students were discussing topics that were sidetracked or not germane to the main topic of the threaded discussion. These modified coding schemes provided the foundation for the coding scheme used in this present study.

For this present study, substantive codes based on Davidson-Shivers et al. (2005) were applied to discussion responses that related directly to the discussion question and topic. These codes were response, evidence, criticism/critique, elaborate, evaluation, and restate. Nonsubstantive codes were applied to discussion responses that were not directly related to the discussion question or topic. These codes included sidetracked, technical, chatting, and uncodable. The sidetracked code was similar to the "off topic" code used by Davidson-Shivers et al. (2005). Definitions and examples of codes for this present study are presented in Appendix C.

Students' participation and learning in online discussions can also impact their satisfactions of these discussions. Based on this, the most important measure of student participation in online discussion has been student

\section{6}


satisfaction. The approaches for studying participation satisfaction have included interviews (e.g., Bullen, 1998); reflective learner reports (Ellis, 2003) and, closed-ended (Hrastinski, 2006) and open-ended questions in surveys (Kuboni\& Martin, 2004). Olofsson (2007) examined how and why learners became participants in educational online learning communities. Ellis (2004) asked students to write reflective reports on their experience in online forums where they not only described but also attempted to explain their experiences. Hrastinski (2006) used closed-ended questions to map the social networks of students, in order to understand how students participate in communities. Finally, Kuboni and Martin (2004) included an open-ended question as a complement to closed items in a questionnaire.

\section{Low Course Participation}

Several previous studies have indicated that many factors may contribute to limited students' participation in online discussion. One factor may limit student participation in online discussion is student views of the importance of the discussion. In a study by Xie et al. (2006), indicated that students did not find it necessary to $\log$ on to a discussion forum and contribute in the online discussion as the students and instructors were already meeting face-to-face four times a week in class. Zhao and McDougall (2005) found that low student participation may result from students' feelings that the discussion topics not interesting and therefore not worthy of discussion. In addition, students have little interest in contributing to a discussion if no clear expectations are given or if no grades are awarded for their contribution in asynchronous online discussion. Dennen (2005) found that in cases where instructor expectations were not clear, student contribution floundered because students did not know how much they were to contribute or what their messages should look like. The results of Dennen's (2005) study also suggested that when no grade

\section{7}


was attached to using the discussion forum many students did not post any messages during the whole semester.

Previous research has also suggested that the behavior of other participants (e.g., other students, instructors) can limit student contribution in asynchronous online discussion (e.g., Bodzin and Park 2000; Hew and Cheung 2003a, b). Students cease contributing if they receive no immediate response or comments to their questions from other students. For example, Cheung and Hew (2004) found that some students procrastinated in responding to other people's questions, resulting in great frustrations for those students who were waiting for answers. The delay caused the students to feel that they were speaking into a vacuum; that no one was responding to them, so why bother writing messages. Studies also suggest that students stop contributing if they perceive that other students pontificate in the online discussion (e.g., giving their opinions about something as though they know everything about it), or if they feel threatened by other students or if the tone of the discussion becomes too emotional (Hewitt, 2005), or rude (Murphy \& Coleman 2004). Students may cease to contribute if the instructor does not show interest or involvement, such as giving encouragement or feedback. Xie et al. (2006), for example, reported that students decreased their motivation level to contribute if they perceived less involvement of their instructor in the online discussion.

An asynchronous online discussion allows multiple conversations, where many students can interact with many other students at the same time. However, such an attribute can also create confusion among students especially if the discussions are diverse. Students may find it difficult to keep track of the multiple threads of discussion in the asynchronous online discussion because some students

\section{8}

Journal of Arabic Studies in Education \& Psychology (ASEP) 
would post different ideas into one message posting. If other students respond to each of these various different ideas in the same posting, there is likelihood that one or more of the ideas will spawn various sub-discussions which can spawn even smaller fragments. Another reason for the difficulty in keeping up with the discussion is due to information overload on the part of the students. Information overload is considered one of the problems faced in a large class which is a main idea related to the present study. Bonk, Wisher, \& Lee (2004) pointed out that among the ten problems of elearning, one was too much data and information to read and respond to. Information overload has been defined as information presented at a rate too fast for a person to effectively process (Hiltz\&Turoff, 1985; Stathakos, 2003; Eisenberg \& Small, 1993). Coomey and Stephenson (2002) have discovered that "In almost all cases students say that effective procedures for instructor / tutor / peer feedback are the most important features of a successful online course" (p. 39). However, information overload may limit effective peer feedback if students have to skip notes or scan notes too often.

Students and instructors often complain that there are too many links or too many threads leading in all directions. This can confuse learners and distract them from the learning objectives (Clark \& Mayer, 2002). Klemm (2000) found that some participants lurked (just read but do not contribute), a few students dominated all the discussions in some courses, not all students read what were posted, and the huge number of notes was too overwhelming in large classes. The volume and pace of information can become overwhelming (Kirk \& Orr, 2003), especially since messages are not necessarily sequential and multiple topic threads are common, resulting in information overload. Information overload presents itself first as a problem, then

\section{9}

Journal of Arabic Studies in Education \& Psychology (ASEP) 
as a constant challenge to be overcome. Intensive interaction with a large number of communication partners results in the mushrooming of the absolute amount of information and the number of simultaneous discussions, conferences, and other activities. In her study, Peters (2005) echoes that "a common complaint among students was the amount of information there was to read, particularly in terms of the time required to read all of the notes in their online course" (p. 38). These demands exceed learners' normal coping abilities (Kerr \&Hiltz, 1982). Some studies suggest that working with others adds information that needs to be processed, because "Humans have a limited capacity for the amount of information they can simultaneously process" (Strijbos, Martens, \&Jochems, 2004, p. 315). The individual has less time to state his or her own thoughts out loud, and "others' contributions may interrupt the individual's own processing, knocking him off his train of thought" (Wiley \& Bailey, 2006, p. 300). Hiltz and Turoff (1985) list some results caused by information overload: individuals might fail to respond to certain inputs, respond less accurately than they would otherwise, respond incorrectly, store inputs and then respond to them as time permitted, systematically ignore (i.e., filter) some features of the input, recode the inputs in a more compact or effective form, or quit (in extreme cases).

Limited student contribution in asynchronous online discussions may also be due to students being at loss of what to contribute (e.g., Fung 2004; Khan 2005). Guzdial and Turns (2000) suggested that students may have a writer's block of what to write just as an empty word processing document can be intimidating to the beginning writer. In addition, the problem of students having difficulty in knowing what to contribute can also be due to the use of discussion prompts or questions that called for a single,

\section{0}


fact-based answer because after one student responds correctly there really is no need for further contribution from other students (Dennen, 2005). Students may exhibit surface level critical thinking in their contribution (Khine, Yeap, Lok, 2003). For example, Hew and Cheung (2003b) found that most of the surface level thinking was due to the fact that students lack critical thinking skills such as making conclusions or judgments without offering any justification; propose solutions with little details or explanations; and stating that one shares the conclusions or judgments made by others without taking these further. Students may also be content in merely answering questions. Cheung and Hew (2005), for instance, found that students were more interested in merely voicing their opinions to their classmates' queries - what Gunawardena et al. (1997) referred to as Phase I level of knowledge construction (sharing of information).

Finally, the technical aspects of the asynchronous online discussion software have also been identified as a factor that can limit student contribution. For example, in a study of 20 graduate students, Murphy and Coleman (2004) found that design elements such as the inability to flip back and read through discussion postings while composing a message, and the way the discussion software system constantly returns students to the top of the listings when they click to expand a thread resulting in students having to search through the entire postings to locate where they are frustrate students who want to contribute their ideas. Another technical aspect that limits the contribution of students is the inability to edit and delete messages (Murphy and Coleman 2004). Such an inability made some students feel like a fool throughout the entire course because they were unable to change a posting mistake. Furthermore, it caused students a lot of time and effort to rectify an error in a message - for

\section{1}


example, students had to explain what they said that was wrong, said what they actually meant to say, explained their arguments again, made the correction before someone else responded to it and confused the issue even more.

\section{AddressingLowStudentParticipationinOnline Discussion}

Previous research has indicted several manners in their trial to increase student participation in online discussion. One guideline was suggested by these studies was to select a discussion topic that directly related to the student's main curriculum (Dennen, 2005; Hummel et al. 2005; Masters \&Oberprieler, 2004). For example, Guzdial and Turns (2000) found that students were more motivated to contribute in the discussion when the discussion topics were tied to the curriculum. Examples of successful topics included exam reviews. Exam reviews were found to be valuable to students because studying for the exam can help improve their grades and because the online discussion enables students to explore solutions and critique other solutions. Connecting student participation with a grading system was another guideline suggested by researchers. For example, Yeh and Buskirk (2005) found that grading the discussion was found to be the best intervention to enhance student posting. When the student understands the purpose of the discussion, their participation may increase. Cheung and Hew (2005) found that if the purpose of the online discussion was not properly understood, students tended to lose interest and hence stopped contributing. Other researchers have found that expectations from instructor, such as students being told explicitly to share ideas and information were found to increase student contribution in online discussions (Jung, Choi, Lim, \&Leem, 2002).

Establishing ground rules for participation were also found to affect student contribution in online discussion. Ground rules may be used to establish appropriate behavior

\section{2}


or foster a respectful environment for learners to interact with one another and to avoid misbehaviors. One important guidelines used in previous studies has been instructor involvement in the discussion (Painter, Coffin, \&Hewings, 2003; Chen \& Chiu, 2006).

In order to help students contribute postings into correct threads, use discussion forums that represent the thread links visually to students rather than representing messages as a chronological list of message headers (Kear\& Heap, 2007). Threads are well-defined and easily identified artifacts; they make it easier for people to trace the evolution of a discourse (Hewitt, 2005). Specifically, a discussion thread is a hierarchically organized collection of messages in which all messages but the one that started the discussion are written as replies to earlier messages (Hewitt, 2005). Follow-up messages to the initial message are typically indented under the original message. A single simple discussion thread may remain a straight line or turn into a tree as participants post follow-up messages to replies. For example, Kear (2001) found that when a discussion forum fails to show the structure of threads, students often submit unthreaded messages, and other students find it hard to see how the messages fit into the different parallel discussions. This results in a confusing muddle where it is a struggle to keep track of what is going on in the discussion. Second, to alleviate the possibility of students introducing various different ideas into one posting that may later spawn increasingly smaller fragments of subdiscussions, use ground rules that explicitly specify students to post only one idea in one posting (Cheung \& Hew, 2007).

In order to address the problem of what to contribute in the discussion forum, scaffolding technique may be used. Choi et al. (2005) used a set of online scaffoldsclarification or elaboration questions, counterarguments,

\section{3}


and context- or perspective-oriented questions. Results suggested that the online scaffolds served as a starting point to help some students generate questions when they had difficulty asking questions. Also, students who received online scaffolds contributed significantly more questions than did students who did not receive the scaffolds (Choi, Land, Turgeon, 2005). Instead of using discussion prompts or questions that called for a single, fact-based answer, use open-ended questions where there may be more than one possible answer or solution. Asking open-ended questions has been found to result in more student contribution (Poscente\&Fahy, 2003).

To address students' surface-level critical thinking or students' low-level knowledge construction (i.e., being content to merely answer other students' queries), previous research has suggested that instructor should use a Socratic method to help students develop their critical thinking skills. Socrates did not teach; but according to Tucker (2007, p84) the tutor should model the use of Socratic questioning (e.g., questions of clarification, questions that probe assumptions, questions that probe reasons and evidence). For example, Yang, Newby, \& Bell (2005) found that teaching and modeling of Socratic questioning helped students demonstrate a higher level of critical thinking skills. Yang, Newby, \& Bell (2008) found that if the instructor modeled and challenged students' critical thinking skills at the beginning of the discussion rather than in the middle of the semester, students seemed to be more motivated to contribute and students maintained their critical thinking skills after the instructor discontinued the critical thinking questioning facilitation.

Finally, to address the technical aspects, two guidelines were reported in previous empirical studies. First, ensure that students have adequate technical preparation to use the

\section{4}


asynchronous online discussion system. For example, Cifuentes, Murphy, Segur, \&Kodali (1997) found that the all-encompassing requirement for a successful asynchronous online discussion is adequate technological preparation such as setting a password, accessing the discussions, and posting messages on the part of the students. Certain facilitator interventions, such as providing students with written instructions on how to add and delete a message, and face to- face demonstrations of how to access the discussion and post messages were found to be effective in overcoming the students' technical difficulties. Second, use asynchronous discussion systems that have easy navigation functions. For example, Xie et al. (2006) found that discussion board with easy navigation functions was reported to have increased the interest of students to contribute in the online discussion.

\section{Instructor Guidelines in Online DiscussionsNeeds for Instructor Guidelines}

Structure in online discussions was defined by Gilbert and Dabbagh (2005) as the instructional design components of a discussion that guided student participation in online discussions, such as number, type, and pace of postings. While these components have been commonly implemented, the ways in which discussion structure has been applied have varied (Jonassen\&Remidez, 2005). Despite how discussion structure was used, researchers suggested that it impacted student learning. Hew and Cheung (2003) stated that student ideas often sound similar to one another. Therefore, students needed explicit guidelines (i.e., structure) in online discussions because without structure, students often participate at a surface level in online discussions. Angeli et al. (2003) indicated that students' participation in online discussions was mostly exchanges related to personal experiences, was not based on well-supported reasoning, did not show evidence of critical

\section{5}

Journal of Arabic Studies in Education \& Psychology (ASEP) 
thinking related to studying course content, and was conversational and opinionated. The research of Hew and Cheung suggested that students, therefore, benefited from structure, such as guidelines, to help them participate at a deeper level in online discussions. Elements of structure, or guidelines for participation, influenced student responses and student participation in online discussions. For example, Jonassen and Remidez (2005) suggested that some protocol items, such as limiting length of postings, could positively influence discourse; while others, such as choosing the type of message posting, may do the reverse. Gilbert and Dabbagh (2005) found that when the instructor presented guidelines, an increase in quality of responses and discussions was noted; participation guidelines increased the number of student postings, leading to more detailed and in-depth discussions and higher student interaction. Moore and Marra (2005) highlighted the notion that planning for the effective integration of structure in online discussions was an influential variable influencing student learning and was a task that was crucial for the online instructor to tackle, and the appropriate use of discussion structure directly influenced the quality of student learning.

Several terms were associated with discussion structure. For example, Gilbert and Dabbagh (2005) used the term, protocols, and Moore and Marra (2005) used the term, scaffolded discussions. Both definitions related to structuring online discussion. Structuring online discussions outlined parameters for student participation (Gilbert \&Dabbagh, 2005); or, according to Moore and Marra (2005), structuring imposed constraints on communication systems and types of student responses. Moore and Marra (2005) pointed out that structure explained the rules and guidelines of participation by providing common expectations of the quantity and quality of student

\section{6}


responses. Based on this information, a common definition would suggest that discussion structure was the specific instructor guidelines and expectations for student participation in online discussions. The definition of discussion structure is further clarified by identification of the methods for imposing structure.

\section{Methods for Implementing Guidelines}

Current methods for imposing structure in online discussions vary. In fact, the research literature included a variety of structural elements in online discussions (Jonassen\&Remidez, 2005; Moore \&Marra, 2005). For example, Gilbert and Dabbagh (2005) imposed specific discussion protocols, guidelines for students as facilitators, and evaluation rubrics to foster meaningful online discourse. One of the most common ways to add structure to online discussions was through providing instructor guidelines for participation. For example, researchers asked students to respond in a certain manner (e.g., argue and defend; Jeong\& Davidson-Shivers, 2006) or post a given number of responses (Kluwin\&Nortesky, 2005). According to Fisher, Thompson, and Silverberg (2004-2005), form of dialogue, resource access, scaffolding, student-student versus instructor-student orientation, and group formation and support were structural elements, as well. Jonassen and Remidez (2005) added that guidelines for message lengths and constructions were structural elements.Xie et al. (2006) maintained that such guidelines for participation must be clearly stated. Branon and Essex (2001) added that providing students in online courses with clear guidelines could foster meaningful student experiences and possibly reduce the risk of students feeling disconnected or isolated. These guidelines offered structure to student participation and learning experiences in online discussions. Other instructors used structure to articulate the amount of responses for students to post.

\section{7}


Just as the methods of imposing structure in online discussions varied, so, too, did the amount. Some online instructors required participation in online discussions (Cifuentes et al., 1997; Fisher et al., 2004-2005; Schrire, 2006); others did not (Larkin \&Belson, 2005; Mazzolini\&Maddison, 2003). For instance, Cifuentes et al. (1997) included discussion participation into the course grading system as a requirement; whereas, Larkin and Belson (2005) informed students that online discussions were optional. Some instructors simply posted questions for students to respond to with no guidelines or structure (Bailey \& Wright, 2000); others imposed structure by requiring students to post their own responses and also respond to peers' ideas (e.g., Havard et al., 2005; Kluwin\&Noretsky, 2005); and still others used a debate format in which students were asked to post their own positions with support for their statements (Jeong\& Davidson-Shivers, 2006).

The structure imposed by Gilbert and Dabbagh (2005) was presented in levels based on the amount of structure provided, ranging from low to high. Although the other researchers cited previously used structure to specify the amount of responses for students to post, the structure defined by Gilbert and Dabbagh articulated both the number of responses for students to post in well-defined levels that built upon one another. Structuring kinds of student responses could be embedded into Gilbert and Dabbagh's levels, as well. Therefore, the levels of structure in this study were based on the framework defined by Gilbert and Dabbagh.

Gilbert and Dabbagh (2005) integrated online discussions into multiple semesters of a course. During the first semester of the course, low levels of structure were provided for students. With each successive section,

\section{8}


increasing levels of structure were added. For the low structure treatment students were not given formal or specific guidelines for how to participate in the discussions. No explanation for the number, type, or quality of responses was offered. During the second semester of their study, Gilbert and Dabbagh (2005) amended the structural guidelines for their low structure group and added further structural guidelines for student participation in the discussions. This amended set of guidelines outlined the participation expectations for the medium structure treatment. Hence, these guidelines were more specific, and protocols for participation were added. For example, the instructor outlined expectations for the frequency and pacing of postings. During the last semester of their study, Gilbert and Dabbagh (2005) built upon the participation guidelines specified for the medium structure treatment to create their high structure group. A well-defined, comprehensive framework for participation was outlined for this group, and additional participation requirements were expected of students in this group. This group was given a comprehensive weekly discussion rubric. Using the rubric, students were evaluated on criteria such as timely contributions, responsiveness to peers' postings, and knowledge of the discussion content.

Moore and Marra (2005) defined constrained, or scaffolded, discussions as "prestructured forms of conversation systems that require participants to label each of their postings from a pre-defined set of message types" (p. 194). Jonassen and Remidez (2005) used constrained discussions to foster more structured and focused discussions because they believed that online discussions lacked focus; these authors imposed strict structural elements on problem-based online discussions by limiting initial responses to proposed solutions to the problem. Responses to solutions were restricted to the following

\section{9}


types: reason to support, reason to reject, and modify proposal. Subsequent responses were confined to information or facts, personal opinion or belief, personal experience, and research findings.

Similarly, Du, Havard, \& Li (2005) imposed structure by requiring students to post specific types of responses. Students were asked to formulate and post responses, critique peers' responses, and assist peers in developing their ideas. Students were also asked to include information such as details about learners, instructional context, and content matter. In addition, students were required to submit a rationale for their ideas. The purpose of these structural elements was to help students develop ideas and a foundation for research papers and to positively impact student participation and learning. Jeong and DavidsonShivers (2006) structured the types of responses that students posted in online debates. Students were asked to present, support, and refute ideas by posting responses that included arguments, evidence, explanations, critiques, and evaluations. Davidson-Shivers et al. (2001) also structured the types of responses that students posted by providing guidelines for responding. Students were asked to draw from course materials, and they were encouraged to include certain kinds of information in their responses. For example, students were asked to include their own experiences, knowledge, and skills in responses. Davidson-Shivers et al. then used a coding scheme to examine how students responded in these structured discussions. The coding system identified student responses as either substantive (directly related to discussion content) or nonsubstantive (not directly related to discussion content). Substantive codes were structuring, soliciting, responding, and reacting. Nonsubstantive responses were procedural, technical, chatting, uncodable, and supportive.

Although structure has been reported as beneficial in online discussions, there is still a need to further

\section{0}


information about the relationships between structure and other variables related to online discussions. For example, currently, it is not clear whether structure and participation lead to improved student learning and positive satisfaction with regard to online discussions.

Discrepancies about Using Guidelines There are three potential guideline stressed for and against using instructor guidelines in online discussion need to be discussed further. First, using a grading system or marks associated with online discussions did not necessarily result in positive outcomes because some students responded to the marks but not necessarily with enthusiasm. Their contributions were not particularly original or insightful, but often a rehash of what others had said in order to get the marks. This was echoed by Oliver and Shaw (2003) who found that students were merely "playing the game" of assessment (p. 64). Students simply made postings to earn marks but rarely contributing otherwise. Interestingly, Brewer and Klein (2006) found that groups of students who were given specific incentive or reward (e.g., bonus points for the week's assignment) had more off-task behaviors (i.e., statements about topics not related to the course) than those who did not have it. In line with idea, the mere giving of marks to increase contribution may not be a good strategy. Perhaps one solution is to employ an evaluation rubric that spells out different marks for different specific categories of contributions. Another option might be to use other forms of incentives to motivate student contribution. For example, in Hummel et al.'s (2005) study, the incentive mechanism allowed individual students to gain personal access to additional course-related information through the accumulation of points earned by making postings to discussion forums. Results suggested that the level of contribution was indeed increased by the introduction of the incentive system. 
Second, using number of postings as instructor guidelines did not also contribute to student levels of participation. Although Dennen (2005) found that students needed to know how many messages they were to post (i.e., number of posting guideline) so that they would be interested to contribute in the discussion, other researchers disagree about the efficacy of such an approach. For example, Murphy and Coleman (2004) found the quality of the discussion declined when students were forced by the course requirement to post messages in relation to a number of posting guideline. Students, for instance, found the forced responses to be incredibly dull, or superficial (e.g., making very general comments and "me too" additions) unlike other forums that had no requirement to post a certain number of messages. Again, perhaps the use of an evaluation rubric that clearly explained how the postings should entail (e.g., provide reasons or explanations for your "I agree" statements) might be a better alternative, rather than the mere use of number of posting guideline.

Third, instructor involvement in the online discussion was not ensured by previous research to be an effective strategy of guideline. Not all researchers agree that an instructor should facilitate the online discussion. Mazzolini and Maddison (2003), for example, found that involvement by instructors did not lead to more student postings on average. Also, instructors who were active in starting up discussion threads on average ended up with shorter discussion threads than did instructors who largely left it to the students to initiate discussions. This was echoed by Fauske and Wade (2003-2004) who found that students preferred not having the instructor involved in the online discussion. Students felt that the instructor's involvement could be inherently oppressive to certain students and ideas. Because of this, some researchers (e.g., Poole, 2000) have

\section{2}


suggested the possibility that students should facilitate their own discussions. We posit that student-facilitation is different from instructor-facilitation. Student facilitation is based on lateral or peer relationships while instructorfacilitation is typically seen as a hierarchical relationship (e.g., expert-novice). Because of this expert-novice relationship, an instructor's postings can prevent students from posting messages as students tend to think that the instructor's note must be the final authoritative one (Zhao \& McDougall, 2005). Furthermore, Mazzolini and Maddison (2003) noted that some instructor-facilitation techniques, such as instructor questioning, may be more likely seen by students as an assessment tool. Hence, student may be more hesitant in responding to them.

\section{Information Overload in Large Group Online} Discussion

Class size and information overload are related. Information overload is a phenomenon that is commonly reported by students in computer conferencing courses. In online conferencing, larger class sizes increase the amount of material that students are expected to read. This amplifies information overload. One student in Peters' (2005) study complains, "Too many students in one large group; making for a more superficial discussion of many issues, rather than a deeper discussion of a few issues" (p. 38). Bender (2003) states that one of the reported feelings in CMC was being overwhelmed brought on by a large class, lengthy lectures or online responses, or numerous responsibilities. Harasim (1990) pointed out that the larger the class size in the online environment, the greater the likelihood that students will become frustrated and anxious with the emerging pressures of keeping up with the readings and stored messages. Potentially, according to Hewitt and Brett (2007), the perception of information overload could have a number of negative consequences, such as heightened student anxiety,

\section{3}


which can interfere with the amount of attention that participants dedicate to online learning. Lipponen (2001) has found that group work (especially larger groups) could actually increase the processing load on individuals. Wiley and Bailey (2006) point out that "In the end, individuals may be more burdened and enjoy less intact cognitive processing than when working alone" (p. 300). Often students will split up a task, work separately, and later pool their ideas together (Paulus, Larey, \& Ortega, 1995).

Information Overload can produce frustration and disappointment (Kimball, 1995). Bonk et al. (2004) pointed out that among the ten problems of e-learning, one was too much data and information to read and respond to. Hiltz (1990) believed that online courses often involved greater time expenditure and effort than traditional face-to-face courses. In particular, online courses with an enrolment of over 20 students often generate a large number of notes for students to read and respond to, in addition to required reading materials and corresponding assignments. Information overload has been defined as information presented at a rate too fast for a person to effectively process (Hiltz\&Turoff, 1985; Stathakos, 2003; Eisenberg \& Small, 1993). Coomey and Stephenson (2002) have discovered that "In almost all cases students say that effective procedures for instructor / tutor / peer feedback are the most important features of a successful online course" (p. 39). However, information overload may limit effective peer feedback if students have to skip notes or scan notes too often.

Students and instructors often complain that there are too many links or too many threads leading in all directions. This can confuse learners and distract them from the learning objectives (Clark \& Mayer, 2002). Klemm (2000) found that some participants lurked (just read but do not

\section{4}


contribute), a few students dominated all the discussions in some courses, not all students read what were posted, and the huge number of notes was too overwhelming in large classes. The volume and pace of information can become overwhelming (Kirk \& Orr, 2003), especially since messages are not necessarily sequential and multiple topic threads are common, resulting in information overload. Information overload presents itself first as a problem, then as a constant challenge to be overcome. Intensive interaction with a large number of communication partners results in the mushrooming of the absolute amount of information and the number of simultaneous discussions, conferences, and other activities. In her study, Peters (2005) echoes that "a common complaint among students was the amount of information there was to read, particularly in terms of the time required to read all of the notes in their online course" (p. 38). These demands exceed learners' normal coping abilities (Kerr \&Hiltz, 1982).

Some studies suggest that working with others adds information that needs to be processed, because "Humans have a limited capacity for the amount of information they can simultaneously process" (Strijbos, Martens, \&Jochems, 2004, p. 315). The individual has less time to state his or her own thoughts out loud, and "others' contributions may interrupt the individual's own processing, knocking him off his train of thought" (Wiley \& Bailey, 2006, p. 300). Hiltz and Turoff (1985) list some results caused by information overload: individuals might fail to respond to certain inputs, respond less accurately than they would otherwise, respond incorrectly, store inputs and then respond to them as time permitted, systematically ignore (i.e., filter) some features of the input, recode the inputs in a more compact or effective form, or quit (in extreme cases). 


\section{Strategies to Cope with Information Overload}

Although individuals are overloaded at different levels (Hiltz\&Turoff, 1985), most students in large classes cannot perceive and deal with all information cognitively and effectively. To cope with information overload and large class discussions, students have to find ways to meet instructors' expectations and to achieve satisfactory marks for participation. As early as 1962, Miller found that individuals tended to focus on filtering and omitting (ignoring) information as the most effective ways of coping with information overload in face-to-face classes. In their research, Hewitt, Brett, and Peters (2007) have found that CMC students habitually engaged in practices like scanning, skimming, and reading new notes. Atack's (2003) findings are consistent with this research which suggested skimming was a common strategy for coping with workload demands. Hewitt, Brett, and Peters (2007) have also found that larger classes had higher scan rates due to increased information overload. Less scanning occurred in small group configuration. However, skimming and scanning may lead to shallow superficial learning (Hewitt \& Brett, 2007). In reality, many of these strategies are adopted to fulfill course participation requirements (Peters, 2005).

Peters and Hewitt (2005) conducted research to examine the online practices and "survival strategies" of 57 students enrolled in graduate-level distance education programs. They identified a number of common habits and strategies that online learners typically employed. Many of these strategies helped learners meet course requirements more efficiently and cope with information overload. However, some of these strategies may undermine learning (Peters \& Hewitt, 2005). Learners in this study often complained about information overload and the lack of time to read all notes. Peters and Hewitt (2005) also found "To compensate, they often took shortcuts such as skimming notes or

\section{6}


ignoring some discussion threads" (p. 6). The findings from this study revealed that learners tended to respond to notes with questions, notes with familiar topics, and the beginning of long notes. They also tended to read notes once only and scanned notes to find the ones that they were interested in. They did not always participate in a manner that maximized their learning. By adopting such time-saving habits, important issues, ideas and discussion topics in the later sections of long notes and notes with unfamiliar titles may be missed. As a result, some important issues and topics may lose their potential for influencing the discussions.

Students' efforts seemed focused on ways to most easily meet course participation requirements. Students often participated in a manner that emphasized course efficiency over advancing their own understanding about course topics. The findings from their research investigation suggested that "students are not always benefiting from the educative advantages afforded by computer conferencing" (p. 8). In their conclusion, Peters and Hewitt (2005) pointed out the need to restructure the design of computer-mediated conferencing courses and to rethink the nature of online participation to foster true online collaboration. Hewitt (2003) found a tendency for computer conference users to focus on recently introduced notes and a reduced tendency to re-visit older, more established notes. He argued that "Consequently, the most recent notes in each thread are the ones most likely to drive the next round of responses" (p.31). He also pointed out that "Educationally, this situation can be problematic if an excessive focus on new notes unintentionally shifts attention away from important issues" (p. 31). Findings from Hewitt, Brett, and Peters (2007) research revealed that scan rates increased when the note size increased. Students were more likely to scan the notes of their peers than notes written by their teachers.

\section{7}




\section{Debates For and Against Group Size}

Individuals learn through interaction with others (Scardamalia\&Bereiter, 1999). As Bender (2003) observes, "group work, when carefully designed and carried out, can include high level tasks and can encourage students to think at a very deep level" (p. 122). The group has the advantage of multiple frames with which students can select relevant or important information to attend to, multiple long-term memory depots from which students can retrieve relevant knowledge, and multiple temporary storage that may allow for more elaborate processing in a group (Wiley \& Bailey, 2006). In a group, the learning objective is not solely to produce a good group work, but to ensure that every member in the group contributes effectively toward the group learning outcomes (Lea, Rogers, \&Postmes, 2002). Wayne and Cohen (2001) believe "The contributions of any group to its members will vary in nature and intensity with group purpose and model" (p. 6). All approaches to group work in FTF classroom teaching and learning utilize small group theory and involve an understanding of individual development and strategies for working with others (Garvin, 1981).

Online learning environments offer new opportunities to observe group dynamics and instructional design in unobtrusive ways (Kukulska-Hulme, 2004), and support information exchange (Kadushin, 1992) and flexible group interactions (Bodzin\& Park, 2000; Graham \&Misanchuk, 2004). One of the important factors in understanding the potential effects of online collaborative learning is group size, especially in larger groups (Mullen, Johnson, \& Salas, 1991), "because the balance of process gains and losses changes dramatically depending on the size of the group" (Dennis \& Williams, 2003, p. 168). Online discussions offer more flexibility in group size and group composition.

\section{8}


Individuals can participate in both small groups and larger groups (Linn \&Slotta, 2006). The reasons for dividing large whole classes into groups vary from class to class and from instructor to instructor. For some, the purpose is to vary the learning activities in online conferencing (Bender, 2003) so that different groups discuss different subtopics. For others, the purpose is to overcome information overload and to stimulate online discussion and effective learning. Many researchers have studied how groups develop into functional teams (e.g., working on projects) and organize group processes to accomplish their tasks (Johnson, et al, 2002). However, there has been little research aimed at exploring the efficacy of classes of different sizes.

Class size has long been recognized as a factor affecting achievement in face-to-face contexts and has recently been identified as a factor in online conferencing as well (Hewitt $\&$ Brett, 2007). Hewitt and Brett pointed out that there appeared to be both advantages and disadvantages to large classes. Larger computer conferencing courses offer educational advantages. They can expose individual students to a wider range of ideas and perspectives. There are also more opportunities for peer collaboration. However, large classes also increase the amount of information that students have to process, and may reduce the amount of time that an instructor can spend working with individual learners (Hewitt \& Brett, 2007). In their quantitative analyses of note production, average note size, note opening and note reading percentages, they found a significant positive correlation between class size and notes generated in each course, a significant negative correlation between class size and average note size, and a significant negative correlation between class size and percent of notes opened. The findings of their research suggested that students tended to write more notes in larger classes than their peers in

\section{9}


smaller classes. However, the notes in larger classes had smaller word counts. Hewitt and Brett (2007) also noticed that class size was associated with student note reading behaviors. The larger the class size, the less likely that the students would open all of their peers' notes. Additionally, students tended to scan more frequently in large classes than in small classes. Students in large classes read notes the quickest, often reaching or exceeding reading speeds of 8 words per second, while, students in small classes read notes more slowly. Scan rates varied with class size and class configuration (Hewitt, Brett, \& Peters, 2007). Their research results also suggested that larger classes were associated with an increase in the number of notes written, a decrease in average note size, a decrease in the percentage of notes opened and an increase in note scanning. Hewitt and Brett (2007) developed three hypotheses exploring why students in larger classes tended to write more notes. The first hypothesis was that larger classes increase the number of opportunities for participation, such as more discussion topics. The second hypothesis was that students in larger classes feel uncertain about their place in the class and compensate by participating more often. The third hypothesis was that well designed, interesting courses taught by skilled instructors attracted a larger number of students and also inspired higher levels of participation.

To overcome information overload, Hron and Friedrich (2003) argued that appropriate group sizes should be set up to ensure for each group a critical mass of participation, to reach the goals associated with collaborative learning, and to make it easier to establish social presence to encourage greater interactivity (Aragon, 2003; Tu\&McIsaac, 2002). As a basic precondition, online learners have to read the messages, ask questions, comment on messages, and answer questions (Hron\& Friedrich, 2003). Aragon (2003) pointed

\section{0}


out that it was easier to establish social presence in smaller classes. In Davie's (1988) case study, he divided the students into small groups of four to five members. He found that during both of his courses, each of the small groups succeeded in producing a good-to-excellent analysis of a case study. Dennis and Williams (2003) stated that instructors needed to be keenly aware of group processes and dynamics that developed both in the threaded discussion as well as in class. They may need to reassign students to new groups or increase or decrease group size throughout the semester, to expose students to new interpersonal relationships and viewpoints. This limitation can also be overcome by changing groups during the semester or by opening a temporary idea exchange forum for the whole class (Dennis \& Williams, 2003; Weasenforth, Lucas, \&Meloni's, 2002).

\section{Inappropriate Group Size}

The effect of different group sizes in online conferences is not clear. Considerable research has been conducted on the effects of different group sizes in face-to-face settings. For example, an inappropriate group size may interfere with effective group discussions or with group work on projects. Johnson et al. (1994) listed a number of ways that group size can interfere with group effectiveness. First, the greater the disparity between effective group size (the most productive size) and actual group size, the more ineffective the group will be. As a group gets larger, not all its members are active and try to solve the problem (Johnson, et al., 1994). In groups with more than ten people, there is often considerable process loss occurring. In groups of more than eight or nine members, a few students are likely to dominate the discussion and others are likely to remain passive (Watson \& Johnson, 1972). Second, the less group members see their contributions as essential for group success (e.g. in large classes), the less effective the group

\section{1}


will be. As the group size gets larger and larger, group members are less likely to see their own personal contribution to the group as being important to the group's success (Kerr, 1989). As the size of the group increases, social loafing and free-riding also increases. Third, the greater the complexity of group structure and the more time it takes to organize its joint efforts (e.g. to be collaborative in large classes), the less effective the group will be. Additional time is needed to organize a group; such organization is unnecessary for individuals (Bales $\&$ Strodtbeck, 1951). The larger the group, the more time is needed to organize it. Fourth, the less effort invested by each member (e.g. lurking in large classes), the less effective the group will be. As group size increases, the average contribution per member decreases. Fifth, the less the members identify with the group, the less effective the group will be. Kramer and Brewer (1986) have shown that a strong sense of belonging or social identity leads to cooperative behavior. They suggest that the more a learner feels part of the group, the less strongly he distinguishes between his personal welfare and the group's welfare. Small groups are easier to identify with than large groups. Sixth, the fewer members that follow the group's norms (e.g. engaging in inappropriate behavior in large classes), the less effective the group will be. Reducing group size makes it easier to monitor members' behavior and strengthen members' adherence to the group.

Researchers have proposed a number of different optimal sizes for online classes. Based on their own online teaching experience, Rovai (2002) and Aragon (2003) proposed 30 as an upper limit on class size. This matches Bi's (2000) suggestion that to optimize and allow for effective feedback, fewer than 30 students should be enrolled in each class. Roberts and Hopewell (2003) suggested that faculty keep

\section{2}


the size of the class to 20 students, to allow for more "workable" loads. This size is manageable without overwhelming the instructor or minimizing his effectiveness. Hiltz (1990) recommended that a class conference be divided into subgroups when the number of students reach or exceed 30. Even with 20 students in graduate level discussions, the reading and writing load is still very heavy. However, a class with less than 5 or 6 students is less overwhelming but not encouraging in participation. Rovai (2002) argued that to guarantee effective online engagement and interactions, 8-10 students were required. However, in general, students in smaller classes tended to learn more (Glass \& Smith, 1979). As Garvin (1981) explains: "Small groups, such as those of about four to eight members, demand and produce more intimacy than larger groups. Such small groups are likely to bring pressure on members to participate. Larger groups, on the other hand, allow members to withdraw from active participation. The tendency in such groups is for a polarization to occur with some members talking a great deal while others seldom speak." (p. 79).

Some researchers argued that a group larger than five presented problems for participation in interaction. Cohen (1994) pointed out that "for group discussion, I have always found that four or five is an optimal size. Cohen stated that as the group gets larger, there is more of a chance that one or more members will be left out of the interaction almost entirely" (p.73). A group of three has some special problems (Cohen, 1994). There is a strong tendency for two persons to form a coalition, leaving the third feeling isolated and left out. Groups should be mixed as to academic achievement, sex and any other status characteristic such as race or ethnicity (Cohen, 1994). In summary, successful online learning depends on which group size is best suited to the

\section{3}


learning objective, the expected level of interaction, task type and level of pre-structuring (Strijbos, et al., 2004).

\section{Theoretical Basis for Group Learning}

Collaborative learning is discussed more often than cooperative learning in the online learning literature. Among studies of collaborative learning in educational contexts, advantages of the performance of a group over individuals have been reported (Webb, Troper, \& Fall, 1995). The theoretical framework relating to collaborative learning is underpinned by the theory of Constructivism based on the works of Piaget (1952), Bruner (1985) and Vygotsky (1978). In this context, students must play an active part in their learning process and not remain as passive learners as in teacher-led instruction, whereby the teacher is the sole authority and distributor of knowledge (Neo, 2003). In classrooms that adopt a collaborative approach, the basic challenge shifts from learning in the conventional sense to the construction of collective knowledge (Scardamalia\&Bereiter, 1999). With collaborative learning, the control of learning is turned over to the students and the learning environment is studentcentric. Learning takes place in a meaningful, authentic context and is a social, collaborative activity, where peers play an important role in encouraging learning (Neo, 2003). Collaboration is more than the exchange of information and ideas. It is the creation of new insights among group members during online discussions (Ingram \&Hathorn, 2004). Indeed, collaboration ideally engages learners in a kind of interactive problem solving in which the product of groupwork is more than the sum of its parts (Brown, Collins, \&Duguid, 1989). Collaborative learning approaches engage students in active learning and give them access to the shared knowledge, experience, and insights of other members of the learning team (Golas, 2000). It is particularly important for higher-order, critical thinking

\section{4}


skills that must move beyond the passive memorization of facts to a more "constructivist" engagement in which students comprehend, assess, and apply information in ways that lead to new insights and understanding. Collaborative learning processes encourage knowledge construction by prompting learners to articulate their own understanding and trying to negotiate a shared understanding (McAlpine, 2000). Researchers have found that collaborative discussions (competitive or cooperative) do facilitate learning (Cohen, 1994).

In his review of collaboration and task design in higher education, Rodriguez Illera (2001) focuses on exploring tasks that have genuinely interdependent components. He concludes that we should make use of the "many strategies of co-operative learning not mediated by computers" ( $p$. 492) in rethinking ways of organizing online groups, the division of tasks and the role of the teacher. Vygotsky (1978) argued that all learning begins from a social context, which is in alignment with Dewey's (1901) vision. Collaborative learning practices are often a liberating and democratic influence, creating new freedoms in the classroom. They transform a classroom from the normal "one authority/many listeners" mode of learning to a "one facilitator / many active participants" mode of learning (Hubscher-Younger \& Narayanan, 2003). A peer discussion is a useful way of encouraging the kind of social interaction that leads to learning. Through interaction with others (Knowles \& Knowles, 1959), learners jointly construct and instantiate knowledge structures for themselves (Wiley \& Bailey, 2006), and their learning is prompted by conflict with others (Piaget, 1932) and being introduced to varying and discrepant points of view (Oliver, 2000). Collaboration is especially important in online learning (Klemm, 1998; Naidu, 1997; Pena, 2004; Puntambekar\&Luckin, 2003)

\section{5}


where distance learners tend to be isolated, without the usual social support systems found in on-campus or classroom-based instruction.

Classic instructional design (e.g., Dick \& Carey, 2004) focuses on individual learning outcomes and tries to control instructional variables to create a learning environment that supports the acquisition of a specific skill or specific knowledge (Kirk \& Orr, 2003). Hiltz (1986) has found that people who engaged in online collaboration with their peers became more actively engaged with the course content and thus developed deep personal understandings. Through interaction with their classmates and instructors, students advanced their understanding because multiple new perspectives and ideas emerged during collaborative learning (Harasim, 1990).

Newman, Johnson, Webb, and Cochrane (1997) evaluated computer-mediated-communication in a group learning context as a means of promoting deep learning and critical thinking. They believed that critical thinking was a key skill required in deep learning. Depth or quality of learning may therefore depend on how online collaboration is managed (Kukulska-Hulme, 2004). In collaborative learning environments, students can critique, link, reformulate, and combine ideas (Linn, 1995; Harasim, 1997; Smith \& Winking-Diaz, 2004) with the objective of developing understanding (Hewitt, 1996).

In order to establish and maintain an online learning community, a dynamic learning environment (Stathakos, 2003), the learning environment needs to be effectively designed to provide students with opportunities to practice collaboration, critical thinking, and teamwork skills that are increasingly valuable in the information age (Kerka, 1996).

With the development of new technologies, new instructional strategies capitalize on the social constructivist 
nature of learning. One of the most prominent features of a computer mediated conferencing classroom is "the provision of a collaborative and peer-supported learning environment" (Peters, 2005, p. 10). The introduction of more flexible approaches to learning and greater use of online tools offer new opportunities for student collaboration and new challenges for teachers supporting group work (Palloff\& Pratt, 1999) to produce and manage shared knowledge (Hubscher-Younger \& Narayanan, 2003). However, CMC, if not well designed, leads to depersonalization and deindividuation (Bordia, 1997). Those students that are quiet thinkers may benefit from sharing their ideas with classmates if they perceive an electronic format to be more conducive for them to "talk" (Larson \&Keiper, 2002).

Research suggests that even when individuals come to a discussion with similar kinds of understanding, they spark responses in each other that can increase the total number of ideas shared (Hoadley, 2004). Knowledge is constructed in these collaborated conversations and interactive communication (M. D. Gall \& J. P. Gall, 1976) through the process of social negotiation among the discussions' participants (Grady, 2003).

Collaborative forums can support argumentation by motivating individuals to build coherent and cohesive explanations in the process of negotiating meanings with peers (Duschl\& Osborne, 2002), by involving learners in a collective effort of understanding and shared values (Bielaczyc\&Colins, 1999; Ng \& Hung, 2003), by engaging students in knowledge-building processes (Peng, 2004), and by extracting useful resources on students' demand (Dringus, 2002). However, the pedagogical approaches used are, in many cases, more important than the technical features of the applied technology (Lehtinen, 2003). Today the benefits of collaborative learning are widely known but

\section{7}


rarely practiced, particularly at the university level (Roberts, 2004). Students and teachers are not the same as experts; they have special needs that require consideration in designing technology for collaborative learning (Lipponen\&Lallimo, 2004).

\section{METHODOLOGICAL PROCEDURES}

This step includes the following:

- Designing and Developing the Treatments.

- Building the Study Tools

\section{Designing and Developing the Treatments}

The present study was designed to investigate the effects of two structural elements in online discussion forum (instructor guidelines and group size) in an online communication course on student participation, learning and satisfaction. To achieve the study objective, the researcher reviewed several instructional design models in general and models that interested in designing and developing online courses in particular. Based on this review, the researcher reached a conclusion that all instructional design models agree in the general stages and the general framework of the phases of the fundamental processes of design and development of instructional program and software. However, these models differed in the view of the details of these processes so that every user of these models may develop elements consistent with his/her study goals and the basic needs required to achieving success. In the light of reviewing previous models, the researcher did not adopt any of them but followed the general framework of these models in designing and developing the instructional treatments. Three phases (Analysis, design, and development) of these models are described below.

\section{Analysis Phase}

Analysis is the starting point in the instructional design process and must be completed before the start of the design process, and this stage includes: problem analysis and needs

\section{8}


assessment, analysis of instructional tasks, analysis of the characteristics of learners and their entry behaviors, and analysis of resources and constraints.

\section{Problem Analysis and Need Assessment:}

Problem or need is a gap between the current level of performance and the required level of performance; this process aims to identify problems and instructional needs, and formulated in the form of general objectives or goals. The need is the objective or the overall goal. The instructional needs were defined in the present study based on three aspects. First, the researcher observation that undergraduate student in the preparatory year-Albaha University in Saudi Arabia had low participation in online courses developed by the University. A communication skill course is one of the courses developed by the university to be taught online for different students with different majors, but a complaint was submitted to the university showing that most students did not participate in online discussion about the course content to achieve the course requirements. Second, student overall scores in the final exam of the course showed that students had difficulty in knowledge and understanding of the topics discussed in the course. Third, most students were not satisfied with the communication skills course, which might have affected their performance.

Based on this analysis, the minimum basic requirements for performance and participation in the communication course were not available for preparatory year students. Therefore, the researcher defined the instructional needs based on two levels; the current level and the required level. Students' current levels showed that they had difficulty in understanding and achievement in the communication course in general, as well as the low level of participation in online discussion activities related to the course. As for the required level, the analysis showed that students should

\section{9}


have minimum basic knowledge and understanding in communication as a requirement for all majors, as well as participating in online discussion as a requirement for getting scores during the course period.

In order to solve the problem, the researcher hypothesized that creating online discussion forums and linked them with a grading system may solve part of the problem. Further, leaving students to choose to participate or not without providing them with clear instructions on amount and type of postings might have not been an effective strategy whereas providing them with clear instructions to participate may result in higher participation rates. Another important solution to the problem is dividing the students in groups and not leaving all students in only one group. The e-Learning Management System (Blackboard) enabled instructors to create several subgroups for discussion the course topic. This strategy of dividing larger groups of participants into small ones may encourage more participation.

\section{Analysis of Learners' Characteristics:}

Analysis of learners' characteristics aims to identify the students who the instructional e-course or the experimental treatments directed to them. This analysis is very important especially for the design of learning environment which is suitable for learners unknown by the teacher or instructional designer. One of the information which is important for the designer is the information about the general developmental characteristics of learners, their own special abilities, and their entry behavior levels. In the present study, the experimental online discussion forums designed for preparatory year students at Albaha University in Saudi Arabia who are studying a communication skills course. Those students were all around the same age, from the same area, and studied the same course. All students have

\section{0}


completed their study of secondary school and just joined the university. Students studied the communication skills course as a university requirement. Students have different majors such as education, computer science, engineering, medicine and so on. Students came from secondary schools with some basic computer experience enabled them to deal with computer Microsoft office software, internet, and information technology. Further, students had no problems with respect to public health, which may have had an impact on the course of the study. They also showed positivemotivation toward studying using the course online.

\section{Analysis of Resources and Constrains:}

At this stage, the available resources are analyzed to determine the necessary requirements for the development of the e-course with discussion forums. This was done by analyzing the resources, financial obstacles, instructional constrains, physical constrains, and human and administrative constrains. In terms of the technical requirements, the researcher has sufficient expertise in programming, design, and some of the necessary skills needed to complete the development of the experimental treatments. In terms of physical requirements, the researcher had to check the availability of the following physical requirements: Some desktop computers with following specifications and extensions: IBM compatible, processor with $2.7 \mathrm{GH}$ speed, operating system (Window XP or Windows 7), 12GB Memory, Speaker, Mouse, Keyboard, printer, and DSL internet line with 4GB speed for upload and download files, and a Host and URL. Based on this, the researchers checked the availability of these requirements in the labs chosen for application of the study in the Preparatory Year of Deanship-Albaha-University. Labs in the Preparatory Year Building at Albaha University were equipped with computer labs with 15 Dell compatible computers in each lab. All labs were equipped with all the

\section{1}


necessary requirements for conducting the experiment. Financial obstacles were represented in the cost of the development of the e-course. The University e-Learning Management System (Blackboard) was used as a platform for the e-course and the discussion activities were done using the Blackboard Shell.

\section{Analysis of Instructional Tasks}

This stage of the analysis is concerned with analyzing the general goals and objectives into their main components and sub-components. The instructional tasks are not the objectives and goals, rather they are more similar to the subjects, concepts, skills, main titles and sub-titles related the subject matter. In this stage, the researcher chose the unit of instruction that the students would be asked to learn. The Communication Skills Course taken from the textbook for undergraduate Preparatory Year developed by the Albaha University was the unit of instruction. This unit is a compulsory unit for all majors of students who studying a one-year preparation for joining the university as undergraduate student.

\section{Design Phase}

The design stage aims to establish and set up the conditions and specifications of the learning resources and operations.

\section{Designing Instructional Objectives:}

The instructional objective or the instructional aim is accurate words that are observable and measurable, describing the conditions that must be met by the learner after the completion of the learning lesson, unit of instruction or the course. Design the instructional aim required the designer to follow some practical sets as follow: translating the instructional tasks into instructional aims and wording them in a good format based on a suitable model. ABCD model used to word the instructional aims. This model helped the researcher to set the learner

\section{2}


behaviors and the behaviors required to be done by the learners. In the light of content analysis to be explained next and the general goal of the course, the instructional aims were set for the course based on the conditions and principles of wording the aims.

A preliminary list of the instructional aims was presented to a panel of experts and specialists in curriculum and teaching methods and instructional technology for judgment of congruency with the behaviors intended to achieve and the accuracy of the wording of each aim in the list. Then, the researcher statistically analyzed the data based on specialists' responses to the list, and calculated the percentage of how each aim related and covered the intended behavior. The aim which had less than $80 \%$ agreement was amended and reformed in accordance with the view of judges. Finally, final list of the instructional aims achieved more than $90 \%$ of agreement based on the judges' contributions.

\section{Designing Criterion Measurement Tools:}

In order to measure students' participation (amount and type of participation), learning and satisfaction, the researcher designed three criterion measurement tools, and these tools are:

- A Coding Scheme (Rubric) was prepared by the researcher to measure the type of student postings. This measure was a modified version of the coding scheme developed by Davidson-Shivers et al. (2005) and Jeong and Davidson-Shivers (2006).

- An achievement test: a 50-item test, with 25 true and false questions and 25 multi-choice questions. This measurement was created to measure learning.

- Participant satisfaction Survey: a 25-item questionnaire for measuring student perception, attitudes, and opinions

\section{3}


toward the online discussion forum. More details about this step will be presented later in this section.

\section{Content Design:}

In this study, online discussions were integrated as part of the undergraduate course entitled Communication Skills. The course was designed to assist Preparatory Year Students in Albaha University in Saudi Arabia in developing the skills and competencies needed for their professional life. As part of the course content, students were exposed to five weeks online discussion forums to enhance their skills in communication.

Content design is known as defining the content elements that will be used to cover the instructional aims. These elements should be put in an order suitable for achieving the aims. There are several manners in sequencing the content. In the present study, the content was sequencing in a hierarchical organization by the subjects would be studied from top to down (from general to specific). The subjects of the content included four main topics: Introduction to communication, verbal and non-verbal communication, communication and the art of persuasion, and electronic communication. These four main topics were covered in the syllable in five weeks period. Hierarchical organization was selected as a suitable way to present the content so as to connect the main concepts with sub-concepts. The four main topics were divided into 29 sub-topics. Each main topic had several other sub-topics. For example, the first main topic (introduction to communication) included 6 minor sub-topics and these were: the concept of communication, the importance of communication skills in professional success, communication process elements, principles of communication process, types of communication, and common communication errors. The second main topic had nine minor sub-topics, including verbal and non-verbal communication. The third and fourth main topics included 14 minor sub-topics, with 7 sub-topics

\section{4}


in each main one. The course overall included 29 subtopics. It was important to build and represent the content concepts, facts, and information through a chart showing information sequences in content area. Fig. 1 shows a flowchart for four main topics detailed in minor sub-topics.

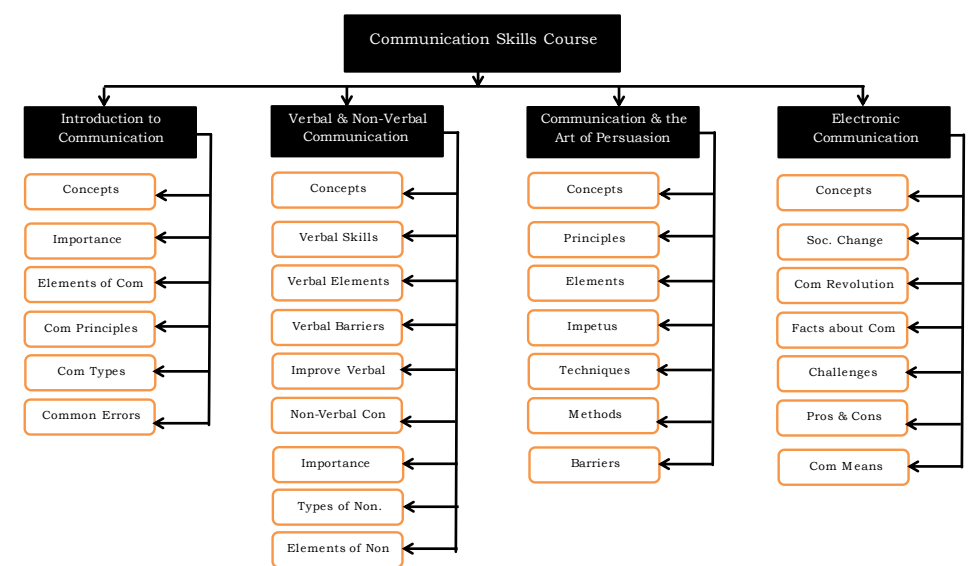

Fig. 1: Flow chart shows course content and sub-contents

The researcher requested a panel of specialists in curriculum and teaching methods and educational technology to judge the content with accompanied instructional aims. The aim was to verify to what extent the content topics covered the instructional aims as well as to what extent the content and aims were related. Further, specialists were asked to estimate the clarity and accuracy of the content. Based on experts' judgment, the percentage of agreement, in terms of content congruency with the aims and content sufficiency, was more than $88 \%$. After this procedure, the researcher conducted all the changes and amendments requested and the final form of content was built.

\section{Designing learning and instructional Strategies:}

The present study used multiple learning strategies which mostly were based on the nature of the online learning environment being designed. Within the online learning

\section{5}


environment, the main instructional methods were used were the self-learning and collaborative methods.

\section{Designing Interactive Strategies for Delivering Instruction:}

An essential part of strategies to provide instruction in the current study was how to implement the various interactions and strategies in the online learning environments. Because participation was basically dependent variable of the study it was important to take into account the interactive contents and the social constructivism components. One component was the interactive content, which made the learner interact with the learning task, peers and the instructor. Interaction with content was designed to let the learner engage in reading the topics of the contents provided as modules in the Learning Management System (Blackboard). Contents were also available in PPT format, video clips. Links to other websites, quizzes, concepts comparison were available within the contents modules. Interaction with peers was also an important feature of the interactive strategies provided through the Blackboard. Because the present study was dependent on the discussion forum as a main tool to achieve the objective of the study, a detailed explanation of this tool is given next.

\section{Online Discussion Forums:}

A website was designed and created with the purpose of learning and enhancing student participation. The researcher had to design, develop, and publish a website using Blackboard as e-Learning Management System, and provided the website with the tools and media to promote the interaction between the learner and content, and among learner one another. For enhancing participation and interaction among learners six separate discussion forums were created using the features of the Blackboard. The asynchronous discussion and dialogue Forums via the

\section{6}


internet were mainly created to promote discussion and dialogue between the learner and the instructor and among the students each other. For the purpose of this study and the independent variable, an interaction between the learner and the instructor was not available, only student to student discussions were of main interest of this study. The discussion Forum does not require the presence of more than one student at a time (other than a chat room which requires the presence of a student at the same time with another participant).

Online discussions took place using the university's Blackboard system through the "Groups" function. The instructor began each discussion using the same questions for all treatments groups.

Participants were given minimum participation expectations at the beginning of the semester (see Appendix C). These expectations set forth the minimum number of original posts as well as response posts that each participant should produce. Participants were encouraged to engage in the online discussions beyond these minimal expectations; however, very few participants posted more than the minimum number of responses.

Blackboard provided participants the option to "subscribe" to discussion threads. With this feature enabled, the system would send e-mail messages to participants each time a response was posted to the discussion board. In order to promote active participation in online discussions, the researcher requested that participants subscribe to group threads.

The online discussion expectations also outlined the timelines for each discussion. Participants were asked to complete their online interactions for each article discussion over one week period. The researcher collected online

\section{7}


transcripts two weeks following the completion of the discussion to ensure that all participants had adequate time to post final comments. Since these discussions were less interactive than face-to-face discussions and participants had the opportunity to post complete thoughts without interruption, the statements captured during online discussions were fewer, 658 posts, but also typically much longer than verbal statements that occurred during face-toface discussions. The researcher coded each complete statement in its entirety. If different parts of one statement could be coded at different levels, the researcher assigned the entire statement the highest category that was evidenced.

For this study, threaded discussions were integrated into a unit of the Communication Skills Course. The course content developed by Albaha University and amended by the researcher to suit the purpose of the study. The course lasted 14 weeks, only four main topics were selected to be included in the present study. These four main topics were taught for a five weeks period. Of the five weeks period, the first two weeks were used in the experiment as a training period, with the last three weeks being used for the actual study.

Six separate discussion forums were created to assign participants into six sub-groups. Assigning subjects to the treatment groups whether high structure guidelines group, moderate structure guidelines group or low structure guidelines group was blocked by their group size as small group or large group. This arrangement was done to control for the independent variables of the study. The first independent variable was the structure guidelines; the second was the group size. Students divided into three groups based on the instructions they received before participating in the discussion forums. Group one $(\mathrm{N}=32)$ received high structure guidelines, group two $(\mathrm{N}=31)$

\section{8}


received moderate structure and group three $(\mathrm{N}=31)$ received low structure. High structure group were divided into two sub-groups based on size; with 10 participants joined the first forum (high structure - small size) and the 22 participants comprising the second subgroup were placed in the second forum (high structure-large group). Moderate structure group also divided into two sub-groups joining the third and fourth forums $(n=10$, moderate structure small group and n21, moderate structure large group). For the low structure group, two sub-groups were created, to be placed in forums five and six) comprising 31 participants ( $n=8$, low structure small group, and $n=23$, low structure large group).

Students in all three treatment groups received the same discussion questions, but the instructor guidelines for student participation, or the level of structure, differed for the groups. Five questions were placed in the discussion forums for five successive weeks, with the first two weeks being used for training students in participating in the online discussions. Questions three to five were used for the actual study (see Appendix B-Instructor guidelines). The five questions used in the online discussions were all required participants to generate, apply, analyze, synthase, and evaluate ideas, because they were open-ended type. The questions were in the types of "Why and Why Not". For example, question designed for week one stated that: "In your opinion, do you think that communication skills are necessary for professional success? Why? And Why Not?". Students in all the three groups (six sub-groups) received that same five discussion questions, but the instructor guidelines for student participation, or the level of structure, differed for the groups. Participants only participated in the discussion forum with those in their treatment groups (based on level of structure and group size), and not with the class as a whole. Following the treatment, which lasted for five

\section{9}


weeks, a post achievement test was administrated to help measure the influence of the structure and group size on learning, and a satisfaction survey was given to assess student satisfaction of their experiences participating in the online discussions.

High structure guidelines: in the high structure guidelines treatment groups, students were given detailed guidelines for participating in the online discussion forum and responding to the discussions. The high level of structure included the questions to which students were to respond; students were also required to provide support for their ideas and elaborate of at least three peers' idea. For example, in week one, they were asked, "In your opinion, do you think that communication skills are necessary for professional success? Why? and Why Not? Dear students, you are required to discuss the answer to this question from your personal point of view including the following elements in your responses: mention two reasons why you answered the way you did, give evidence or example to support your answers. You may refer to the textbook of the course to cite examples and evidence or you may visit the electronic links and website in the course shell to support your point of view and your answers. In addition to your view point about the question posted, you have to reply to the comments of three other peers in your discussion forum to comment on, evaluate, elaborate, or criticize their ideas. Also, your answer, viewpoints, and your responses to the colleagues' comments is evaluated and considered by the instructor as scores points within the semester evaluation".

Moderate structure guidelines: in the moderate structure guidelines, students were given less structure than the high structure group. They were asked to provide an original response to the same discussions questions and to respond to other students' responses. No additional directions about

\section{0}


the quantity, type, or quality of responses were provided. They were asked: "Answer the following question with your opinion and respond to at least three other students' postings. In your opinion, do you think that communication skills are necessary for professional success? Why? and Why Not?"

Low structure guidelines: Students in the low structure treatment group were not given instructor guidelines for participation in the online discussions. For this group, the instructor posted only the threaded discussion questions (the same questions provided to the other treatment groups) and allowed students to respond in any way they find appropriate. They were asked, "In your opinion, do you think that communication skills are necessary for professional success? Why? and Why Not?"

\section{Help and Guidance}

Because the present study was concerned with studying the moderating variables of levels of structure and group size as conditions for participation, learning and satisfaction in online discussions, so it was important to provide learners with a range of assistance instructions, guidelines and supports that would help them to be active participation. The discussion forums were a tool used with an online learning environment; therefore, the assistances and supports were all related to the content and the discussions. Instructions about content included: the nature of the study, the aims, importance of effort exerted to achieve success in the environment, modules and content organization in the course, media available to interact with the content, how to use the e-learning management system (Blackboard), activities and quizzes used within the environment. Instructions also directed subjects on how to visit links and websites to enhance the learning experience in the content area. As for instructions about the online discussions,

\section{1}


participants were directed to participate within the online group defined and do not participate in other discussion groups. Further, they were asked to manage the discussion within the time defined by the instructor and were told that their participation would be compulsory for collecting scores. All instructions about the contents and discussion were detailed in a lecture before the study to begin in a computer lab equipped with internet, projector and data show.

\section{Selecting Instructional Media}

The learning resources included written text, photos, PDF files, PPT presentation and video files. All these resources were means of support for the instructional modules which covered the topics content. Criteria for using the instructional media were considered in order to facilitate learning within the online learning environment. The written texts were included in every page of the module pages and every online learner could easily read them. The video files were recorded as a series of clips with the accompanied sound to show the learners every part of the content. Videos were collected and edited using Camtasia software. The PowerPoint presentations were also available for all topics. The only tools available for discussion were the online discussion forums. There were six discussion forums used for investigating the effect of the independent variables of the study.

\section{Designing Scripts}

Script is a procedural map includes executive steps for the development of a certain instructional source. This map should contain all the conditions, descriptions and details of the media such as the audio-visual elements, and describe the final shape of the production process on a sheet of paper. Designing a script is varied on accordance with differences in the nature of the product and required details. However, in general, there should be some basic details

\section{2}


included. In developing computer software and web-based sites, details such as screen numbers, content of the screens, the screen text and audio, static pictures and videos, sketch of the screen and the transition between screens should be available in the script. The researcher designed the instructional script in steps and stages with a general outline being drawn first followed by detailing of each main screen. Each screen included the following details: Screen number: each screen in the script was identified with a serial number. This was done for each main and sub-screen. Screen type: there were different types of screens such as main lesson screens, sub-lesson screens, exercises screens, additional or extra screens, and multimedia screens Description: a description of the screen content in terms of main topics, background, fonts, order of appearance of multimedia, control buttons, and control type. Screen elements: screen elements may be called sketch of screen which included all types of multimedia elements included in each screen. Based on these details, a script was created. After building the script for online environment, they were given to the experts and specialists in educational technology and computer fields for judging. In the light of the view of the experts, final forms of the scripts were produced.

\section{Development Phase}

The development stage refers to the processes by which the conditions and standards built within the design stage would be transformed into complete and ready for use instructional products. The instructional development stage includes the following phases:

\section{Development of Content elements}

In the light of what was determined in the design stage, multimedia elements were collected from different sources. The following procedures were conducted to collect media:Texts: Microsoft Word software was used to write texts with the consideration being taken to suit the font size

\section{3}


with the size of the screen and the space available for presenting the onscreen text. Still pictures: Adobe Photoshop 8 CS ME was used for producing and editing the pictures and photos that had been collected. The researcher collected several photos and pictures related to the contents of the lessons. These photos were edited and deleted the irrelevant parts and retain the required parts. Enlarging and minimizing the photos upon need were done, as well as comments were added to some photos when needed. All photos were saved as "GIF" extension because this type of extension is more suitable, in terms of clarity and size, for publishing online. Sound: editing and processing sound is an easy task with the use of COOL Edit software. Videos: getting video footage with small sizes is an important task for publishing these video on the internet. The videos in the present study were recorded and edited using two programs, one was the Camtasia Studio 8 and the other was the Screen Cast software.

\section{Website and Course SCORMS Development}

The website pages were created using FrontPage Software in the light of the site script. Development of course SCORMs were based on using Reload Editor 202_win software, which was used to compress pages of each unit of the course and changing these units into zip packages compatible with the SCORM standard.

Development of Activities and Blocks and Uploading the Site

There were a range of activities and blocks being in the Blackboard LMS. During this phase, the researcher build several blocks as essential requirements for any website and blocks included: modules blocks, activities block, formative evaluation block, forums blocks, chat rooms, glossary block, site registration block, site calendar block, people block, site administration block, forum search block, upcoming events block, recent activities block, and test results block. An important block was created for the

\section{4}


purpose of the study is the forum block in which six online forums were created to be the main tool for achieving the objectives of the study. After creating the blocks, the website was uploaded and the course became available through the internet.

\section{Building the Study Tools}

\section{Posttest for Student Learning:}

The posttest was a 50-item measure that evaluated students' understanding of the four units' content and their applications of the course content discussed in the online discussion forums (i.e., introduction to communication, verbal and non-verbal communication, communication and the art of persuasion, and electronic communication). Before designing the test, a content analysis was conducted and the four basic units of the course were divided into 29 sub-units. These sub-units were the target of the test questions. The test included 25 multiple-choice items and 25 true and false items (see Appendix A). The five questions placed in the online discussion covered the entire topic discussed in the course, and the test questions covered all topics and content studied. The test was given at the end of the fifth week of the discussion forums, and was administrated online at the conclusion of the four units. The test items (multiple choice and true and false questions) were graded by the instructor using the learning management system in which the course was delivered. Each of the 50 item questions was worth one point when the corrected answer was given. The total scores were 50, meaning that each question was given a point on the scale. Five content experts in the area of teaching methods and instructional technology evaluated the posttest for content validity. The five experts agreed that the posttest measured students' knowledge of communication skills, verbal and non-verbal communication, persuasion and electronic communication. A test was said to be valid if it can be

\section{5}


shown to adequately represent the content of an area or domain. The experts also agreed that the test also measured students' ability to use this information at an intellectual skills level of higher order rules. A Cronbach's Alpha was calculated to determine reliability of the posttest, and the Cronbach's Alpha was 0.83.

\section{Online Discussion Rubric}

Participant responses to discussions for all the treatment groups were coded. Codes were divided into the following two sections: related substantive on topic and unrelated nonsubstantive off topic (See Appendix C). Substantive related on topic responses codes were applied to students' responses that were related directly to the discussion content and topic. Non-substantive unrelated off topic responses were not relevant to the discussion topic or content. The codes were adapted from Davidson-Shivers et al. (2005) and from Jeong and Davidson-Shivers (2006). Originally, the substantive related codes were response, evidence, criticism/critique, elaborate, and evaluation. Nonsubstantive codes were technical, chatting, and uncodable. During the analysis of the coding process, however, the researcher found the need for two additional codes. One code was substantive (restate); one was nonsubstantive (sidetracked/deviation). In many occasions, participants would respond to peers' postings by restating the peers' ideas. Although these responses were related to the discussion topic and were new postings, they did not extend the original idea or add anything significant to the discussion. These responses were coded as restate. Therefore, restate responses were defined as restating another's idea but not extending the idea. In other instances, students would post a response that was related to a comment in peer's posting that was related to the discussion but was not directly related to the discussion question. These types of responses were coded as deviations or sidetracked. Therefore, sidetrack responses were defined as making a comment that was related to the communication or

\section{6}


the topic of discussion but was not directly related to the original discussion question (See Appendix $\mathrm{C}$ for descriptions and examples). These two new codes were added and applied to all discussions and were used to research hypotheses one, two, and seven.

\section{Satisfaction for Online Discussion Survey:}

The survey instrument for this study was the online discussion questionnaire for measuring participant satisfaction. The survey was developed by the researcher to identify the participant levels of satisfaction in online discussion within the communication course. The survey was administrated at the conclusion of this study to obtain student satisfaction and their experiences in the online discussions and if their participation in the discussion affected their achievement on the course (see Appendix D). Students were also asked how they perceived the impact of the online discussions on the learning process and how valuable they were in the online classroom. The questionnaire consisted of 25-Likert-type scale of five possible responses, ranging from strongly agree to strongly disagree was used. High responses on the survey items reflected positive satisfaction for all but three items. The scale for these three items (item thirteen, fifteen, and sixteen) were reversed to maintain consistency in the scales. Cronbach's alpha scores range from 0 through 1 , with a coefficient closer to 1 indicating higher reliability. Reliability coefficients should be at least 0.70 or higher to be considered reliable for affective instruments. The Cronbach's Alpha for the questionnaire items was 0.92, which indicates a high degree of internal constancy in a multi-item scale. The $95 \%$ confidence interval for the mean of the questionnaire was 3.60 to 3.90 .

\section{Study Procedures}

Before starting the experiment, a standard set of procedures was used for this study. Permission to complete this study was obtained from the Deanship of Preparatory Year at Albaha University in Saudi Arabia. Permission was

\section{7}


requested from the sample to participate in the study and this permission was attained through participant informed consent forms. Prior to implementing this study, proposal was submitted to the Deanship of the Preparatory Year of the Albaha University. Approval from the Deanship was obtained prior to conducting this study. Following approval, participant consent was obtained. An explanation of this study and a request for participation was submitted to students. Students were informed that participation in the study was voluntary and refusal to participate in the study neither would not negatively affect their course grades or withdrawal from the study. However, participants would earn extra credits for participation. An electronic consent form was used and delivered via the Blackboard, and students who chose to participate were asked to submit their letter of consent via a drop box in the LMS. Immediately on sending the consent forms, students were provided their user name and password for the system.

Before the study to begin, a pilot study was conducted prior to the actual study. The pilot provided the opportunity to conduct a trail of the treatment, procedures, and instruments. The formative findings were used to make minimal modifications to instruments and procedures. Based on the pilot study, several modifications were made before implementing the actual study. Some problems were emerged from the pilot study.

The actual study began two weeks following the pilot study in Fall term 2014. The actual study lasted five weeks and occurred during the middle of the semester. Participants were randomly assigned to one of the three treatment groups and were blocked by group size to become six sub-groups. This assignment was completed using the Blackboard feature that randomly assigned students into a given number of groups and informed students of their respective treatment groups. All the instruction and instruments were

\section{8}


presented in the online course in the Blackboard. The posttest and satisfaction survey were administrated through the testing features of the system, and online discussions relied on the discussion features within the Blackboard.

During the instruction, students were given with each unit the following: a unit overview, list of learning outcomes, PowerPoint presentation, videos, a lecture with embedded web links, a reading assignment with embedded photos, a unit summary, and quizzes after the unit. Students navigated through the units' components independently at their own pace. Students also participated in their respective online discussion forums related to the unit topics; each group of the six groups in one forum. Students were presented with the same threaded discussion questions. Student participation in the online discussions was monitored without interference or interaction from the researcher. At the conclusion of the course units, students completed the posttest was given to students. During the instruction, participant responses were not confidential to the researcher and the peers. However, responses were made confidential during analysis and processing data.

\section{RESULTS \& FINDINGS}

This section presents the data analysis and results for the research questions of the study. The purpose of the current study was to examine the influence of discussion structure and group size on student learning, satisfaction and participation in online discussions. Data collection of the study involved both quantitative and qualitative data.

The results of the present study will be presented in terms of the determined questions and the hypotheses. The present study was designed to answer seven main questions divided into seven hypotheses. The results are presented in two sections:SECTIONONE:EFFECTSOFINDEPENDENTVA RIABLESSECTIONTWO:EFFECTSOFINTERACTION

\section{9}

Journal of Arabic Studies in Education \& Psychology (ASEP) 


\section{SECTIONONE:EFFECTSOFINDEPENDENT VARIABLES}

\section{Answering the First Question}

The first question of the study states: in terms of quality and quantity of student participation in online discussion, can high instructor guidelines structure produce different results than moderate or low guidelines structure? Question one addressed whether online discussion structure in terms of instructor guidelines impacted the amount and types of participation. Three groups received the same question in the online discussion, but the level of instructor guidelines varied. Because this question addressed two types of results: amount of responses and types of responses, therefore the results will be presented in two sections as follows:

\section{Quantity of Participation by Instructor Guidelines}

Ninety four students participated in the study. Of the 94 , 32 students received high instructor guidelines before participating in the discussion forum, 31 received the moderate instructor guidelines, and 31 received the low instructor guidelines. Descriptive statistics, presented in Table 2, shows that the high structure group posted more responses than the moderate structure group, and the low structure group posted less than the high and moderate structure groups.

Table 2: Frequencies and percentages of discussion responses by instructor guidelines

\begin{tabular}{|c|c|c|c|}
\hline $\begin{array}{c}\text { Instructor } \\
\text { Guidelines }\end{array}$ & $\mathrm{N}$ & $\begin{array}{c}\text { Response } \\
\text { Frequency }\end{array}$ & $\begin{array}{c}\text { Percentage of Total } \\
\text { Responses }\end{array}$ \\
\hline High & 32 & 247 & $37 \%$ \\
\hline Moderate & 31 & 223 & $34 \%$ \\
\hline Low & 31 & 195 & $29 \%$ \\
\hline
\end{tabular}

Descriptive statistics presented in Table 3 show that the mean number of responses posted by the high structure group is 8.586 responses. The mean number of responses

\section{0}


posted by the moderate structure group is 7.771 . The mean number of responses posted by the low structure group is 6.644.

Table 3: Means and standard deviations of discussion responses by levels of instructor guidelines

\begin{tabular}{|c|c|c|c|}
\hline $\begin{array}{c}\text { Instructor } \\
\text { Guidelines }\end{array}$ & $\mathrm{N}$ & $\mathrm{M}$ & $\mathrm{SD}$ \\
\hline High & 32 & 8.586 & 2.84 \\
\hline Moderate & 31 & 7.771 & 2.01 \\
\hline Low & 31 & 6.644 & 1.99 \\
\hline
\end{tabular}

It was hypothesized that the level of instructor guidelines would not affect the amount of student responses. In order to test this hypothesis, an ANOVA was conducted followed by post hoc comparison. Results of the one-way analysis of variance of structure guidelines showed that on amount of postings, there was a main effect of structure guidelines $(F=8.222 ;$ df 2, 91; $P<0.001 ; \eta 2=0.157)$. Table 4 shows the between subject effect of the structure guidelines on student mean number of postings.

Table 3: The between subject effect of instructor guidelines by amount of postings

\begin{tabular}{|r|l|l|l|r|r|}
\hline & \multicolumn{1}{|c|}{$\begin{array}{c}\text { Sum of } \\
\text { Squares }\end{array}$} & \multicolumn{1}{c|}{ Df } & Mean Square & F & Sig. \\
\hline Between & 32.784 & 2 & 16.392 & 8.222 & 0.001 \\
\hline Within & 489.695 & 91 & 5.381 & & \\
\hline Total & 522.479 & 93 & & & \\
\hline
\end{tabular}

A Post hoc comparison of Scheffe test (based on an alpha of .05) revealed that the high structure group $(\mathrm{m}=8.586)$ scored significantly higher than both the low structure group $(m=6.644)$ but no significant difference was found between the high structure group and the moderate structure group $(m=7.771)$. Moreover, the scheffe test showed that the moderate structure group scored also significantly higher than the low structure group, and this is shown in Fig.2. 


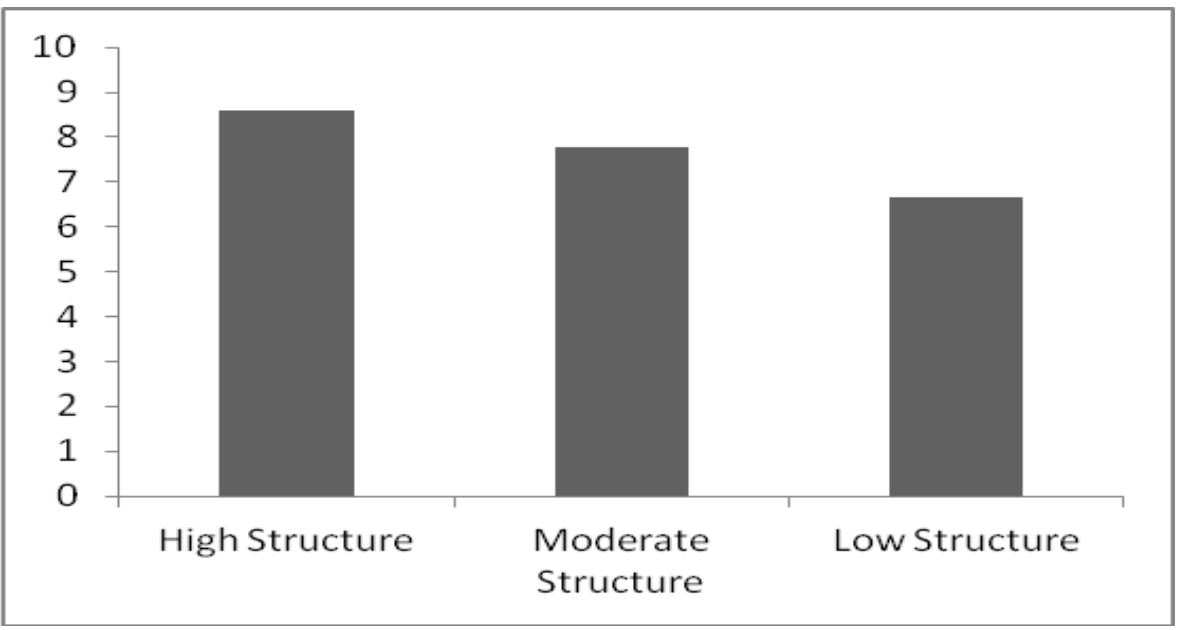

Fig.2: Main effect of instructor guidelines by amount of participation in online discussion

\section{Quality of Participation by Instructor Guidelines}

The analysis of question one also involved examining the quality of student responses in online discussion. In order to investigate this section of question one, online student postings were calculated in terms of how the response was related or unrelated to the question and topic of the discussion. Related responses were named as on-topic responses while unrelated responses were named as offtopic responses. Responses were analyzed as on-topic or off-topic responses according to a rubric designed for this purpose (see Appendix 3).

Question one addressed whether the level of discussion structure (instructor guidelines) impacted the types of student participation (quality of participation) in online discussion. Six related on-topic and four unrelated off topic codes were used to analyze the discussion. Responses were coded phrase by phrase. Overall participants in each treatment group posted more on-topic responses than off topic responses, and this is shown in Table 4. A total of 248 codes appeared with the high structure group discussions. Of these responses, about three times more responses were 
on topic responses than off topic responses. A total of 223 codes appeared with the moderate structure group discussions. Of these responses, also about three times more responses were on topic responses than off topic responses. A total of 195 codes appeared with the low structure group discussions. Of these responses, more than two times more responses were on topic responses than off topic responses.

Table 4: Number of responses and percentage of on topic and off topic codes by instructor guidelines

\begin{tabular}{|l|l|l|l|l|l|}
\hline $\begin{array}{l}\text { Instructor } \\
\text { Guidelines }\end{array}$ & $\begin{array}{l}\text { No. of On } \\
\text { Topic } \\
\text { Responses }\end{array}$ & $\begin{array}{l}\text { No. of Off } \\
\text { Topic } \\
\text { Responses }\end{array}$ & $\begin{array}{l}\text { Percentage of } \\
\text { No. of On } \\
\text { Topic } \\
\text { Responses }\end{array}$ & $\begin{array}{l}\text { Percentage of } \\
\text { No. of Off } \\
\text { Topic } \\
\text { Responses }\end{array}$ & N \\
\hline High & 177 & 71 & $71.4 \%$ & $28.6 \%$ & 32 \\
\hline Moderate & 166 & 57 & $74.4 \%$ & $25.6 \%$ & 31 \\
\hline Low & 131 & 64 & $67.2 \%$ & $32.8 \%$ & 31 \\
\hline
\end{tabular}

Summary of the descriptive statistics demonstrated that the percentage of on topic responses posted by the high structure group and moderated structure group was slightly greater than $71 \%$ and $74 \%$ respectively. The percentage of on topic response for the low structure group also demonstrated greater than $67 \%$. In order to see whether the percentage differences indicate a difference in mean scores, an ANOAV was conducted on the on/off topic postings with the structure guidelines as the independent variable. The analysis of variance showed that there was an effect of structure on on-topic but there was no significant effect of structure on off-topic responses. This finding is presented in Table 5.

Table 5: The between subject effect of the on-topic/off topic responses by instructor guidelines

\begin{tabular}{|r|r|l|l|l|l|l|}
\hline \multicolumn{2}{|c|}{} & \multicolumn{1}{|c|}{$\begin{array}{c}\text { Sum of } \\
\text { Square }\end{array}$} & \multicolumn{1}{c|}{ Df } & \multicolumn{1}{c|}{$\begin{array}{c}\text { Mean } \\
\text { Square }\end{array}$} & F & Sig. \\
\hline On & Between & 31.345 & 2 & 15.672 & 3.690 & .029 \\
\cline { 2 - 7 } Topic & Within & 386.485 & 91 & 4.247 & & \\
\cline { 2 - 7 } & Total & 417.830 & 93 & & & \\
\hline Off & Between & 2.297 & 2 & 1.148 & .738 & .481 \\
\cline { 2 - 7 } Topic & Within & 141.533 & 91 & 1.555 & & \\
\cline { 2 - 7 } & Total & 143.830 & 93 & & & \\
\hline
\end{tabular}


A Post hoc comparison of Scheffe test (based on an alpha of .05$)$ revealed that the high structure group $(M=5.53$, $S D=2.37)$ produced more substantive responses than the low structure group $(M=4.23, S D=1.85)$. But for the moderate structure group $(M=5.35, S D=1.91)$, substantive responses showed no significant difference than the high structure group but the responses were slightly difference than the low structure group. For the off-topic responses, the scheffe test showed no significant differences of the high structure $(M=2.22, S D=1.24)$, moderate structure $(M=1.84$, $S D=0.93)$, and low structure $(M=2.06, S D=1.24)$. The findings related to on-topic and off-topic postings are presented in Fig. 3

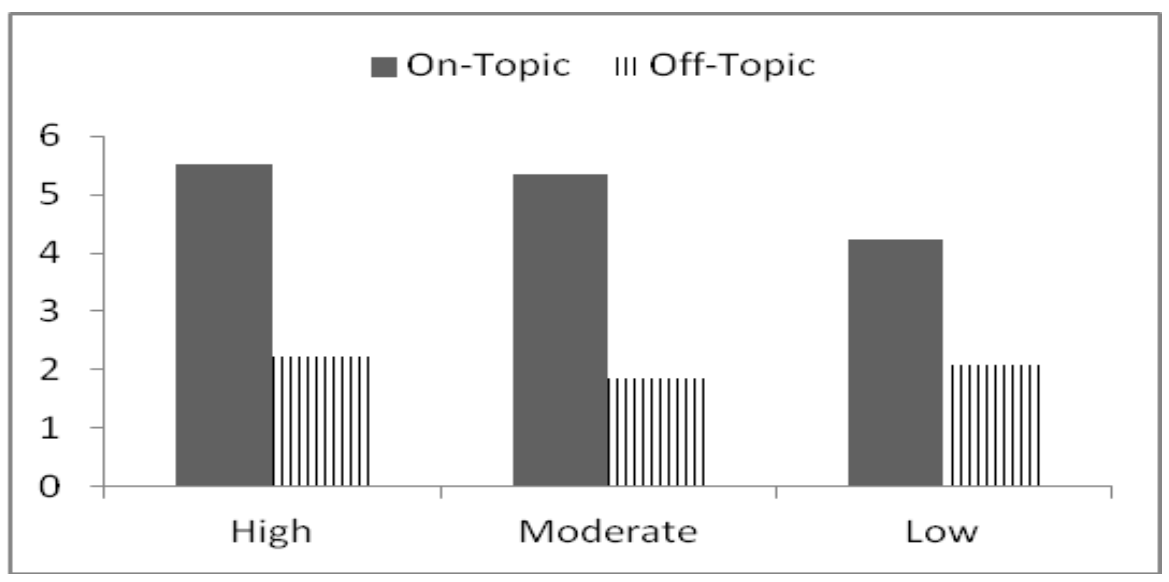

Fig.3: Main effect of instructor guidelines by quality of participation (ontopic versus off-topic responses) in online discussion

\section{Answering the Second Question}

The second question of the study states: in terms of quality and quantity of student participation in online discussion, can large group size in online discussion produce different results than small group size? Question two addressed whether online group size impacted the amount and types of participation in online discussion. 
Three large groups of 21 to 23 participants were presented with an online discussion question while the three other subgroups of 6-8 students were also participated in online discussion with the same online question. Because this question addressed two types of results: amount of responses and types of responses, therefore the results will be presented in two sections as follows:

\section{Quantity of Participation by Group Size}

Ninety four students participated in the study. Of the 94, 28 students participated in three small sub-groups: 10 were in sub-group one, 10 were in sub-group two, and 8 were in sub-group three. Of the 94, 66 participated in three large sub-groups, with 22 being in sub-group one, 23 in subgroup two, and 21 in sub-group three. When involved the group size as the independent variable and quantity of responses as the dependent variable, the descriptive statistics showed a difference in the number of postings, with the large groups posting more responses than the small groups. The percentage of posting by the large group was $60.6 \%$ while for the small group was $39.4 \%$. This result is shown in Table 6.

Table 6: Frequencies and percentages of discussion responses by group size

\begin{tabular}{|c|c|c|c|}
\hline Group Size & N & Response Frequency & $\begin{array}{c}\text { Percentage of Total } \\
\text { Responses }\end{array}$ \\
\hline Large & 66 & 403 & $60.6 \%$ \\
\hline Small & 28 & 262 & $39.4 \%$ \\
\hline
\end{tabular}

Descriptive statistics presented in Table 7 shows that the mean number of responses posted by the small group participant in online discussion is 9.36 responses. The mean number of responses posted by the large discussion group is 6.110 .

Table 7: Means and standard deviations of discussion responses by group size

\begin{tabular}{|c|c|c|c|}
\hline Group Size & $\mathrm{N}$ & $\mathrm{M}$ & SD \\
\hline Large & 66 & 6.110 & 1.8 \\
\hline Small & 28 & 9.36 & 1.9 \\
\hline
\end{tabular}


It was hypothesized that the group size would not affect the amount of student responses. Results of the one-way analysis of variance of group size indicated that on amount of postings, there was a main effect of group size $(F=60.75$; df 1 , 92; $P<0.001 ; \eta 2=0.423)$, with the small group being better. Table 8 shows the between subject effect of the group size on student mean number of postings. Fig. 4 shows this finding.

Table 8: The between subject effect of group size by amount of participation

\begin{tabular}{|r|l|l|l|c|c|}
\hline & Sum of Squares & \multicolumn{1}{|c|}{ Df } & Mean Square & F & Sig. \\
\hline Between & 207.792 & 1 & 207.793 & 60.75 & 0.000 \\
\hline Within & 314.686 & 92 & 3.4206 & & \\
\hline Total & 522.4787 & 93 & & & \\
\hline
\end{tabular}

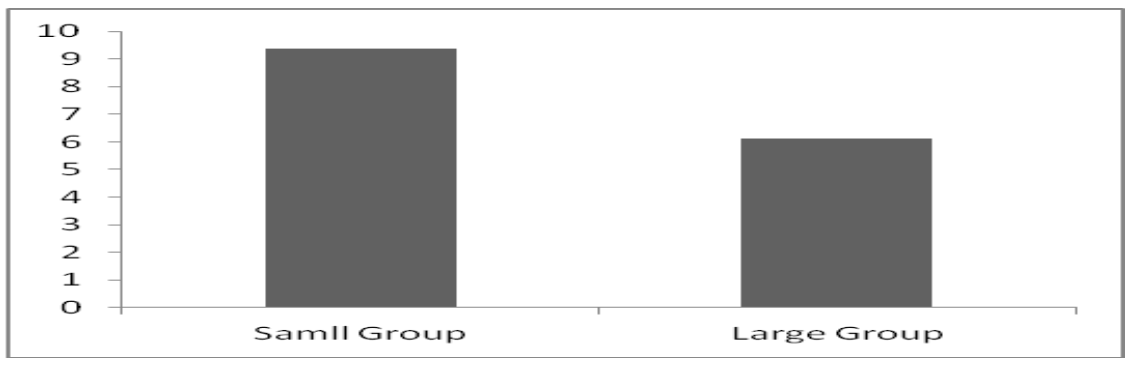

Fig.4: Main effect of group size by amount of participation of individual student

\section{Quality of Participation by Group Size}

The analysis of question two also involved examining the quality of student responses in online discussion. In order to investigate this part of question two, online student postings were calculated in terms of how the response was related or unrelated to the question and topic of the discussion. Related responses were named as on-topic responses while unrelated responses were named as off-topic responses. Responses were analyzed as on-topic or off-topic responses according to a rubric designed for this purpose (see Appendix 3). 
Question two addressed whether the group size impacted the types of student participation (quality of participation) in online discussion. Six related on-topic and four unrelated off topic codes were used to analyze the discussion. Responses were coded phrase by phrase. Overall, participants in each treatment group posted more on-topic responses than off topic responses, and this is shown in Table 9.

Table 9: Number of responses and percentage of on topic and off topic codes by group size

\begin{tabular}{|l|l|l|l|l|l|}
\hline $\begin{array}{l}\text { Group } \\
\text { Size }\end{array}$ & $\begin{array}{l}\text { No. of On } \\
\text { Topic } \\
\text { Responses }\end{array}$ & $\begin{array}{l}\text { No. of Off } \\
\text { Topic } \\
\text { Responses }\end{array}$ & $\begin{array}{l}\text { Percentage of } \\
\text { No. of On } \\
\text { Topic } \\
\text { Responses }\end{array}$ & $\begin{array}{l}\text { Percentage } \\
\text { of No. of } \\
\text { Off Topic } \\
\text { Responses }\end{array}$ & N \\
\hline Large & 261 & 142 & $64.8 \%$ & $35.2 \%$ & 66 \\
\hline Small & 213 & 50 & $81 \%$ & $19 \%$ & 28 \\
\hline
\end{tabular}

Summary of the descriptive statistics demonstrated that the percentage of on topic responses posted by the small group is greater than $80 \%$ but for the large group the percentage of on topic response demonstrates greater than $64 \%$. In order to see whether the percentage differences indicate a difference in mean scores, an ANOAV was conducted on the on/off topic postings with the group size as the independent variable. The analysis of variance showed that there was main effect of group size on on-topic but there was no significant effect of group size on off-topic responses. This finding is presented in 10 .

Table 10: The between subject effect of the on-topic/off topic responses by group Size

\begin{tabular}{|r|r|l|l|l|c|c|}
\hline \multicolumn{2}{|c|}{} & Sum of Squares & \multicolumn{1}{c|}{ df } & Mean Square & F & Sig. \\
\hline On & Between & 262.288 & 1 & 262.288 & 155.138 & .000 \\
\cline { 2 - 7 } Topic & Within & 155.542 & 92 & 1.691 & & \\
\cline { 2 - 7 } & Total & 417.830 & 93 & & & \\
\hline Off & Between & 2.631 & 1 & 2.631 & 1.714 & .194 \\
\cline { 2 - 7 } Topic & Within & 141.199 & 92 & 1.535 & & \\
\cline { 2 - 7 } & Total & 143.830 & 93 & & & \\
\hline
\end{tabular}

Table 10 shows that more on topic responses were recorded in the small group than in the large group. This can be seen in Fig.5. 


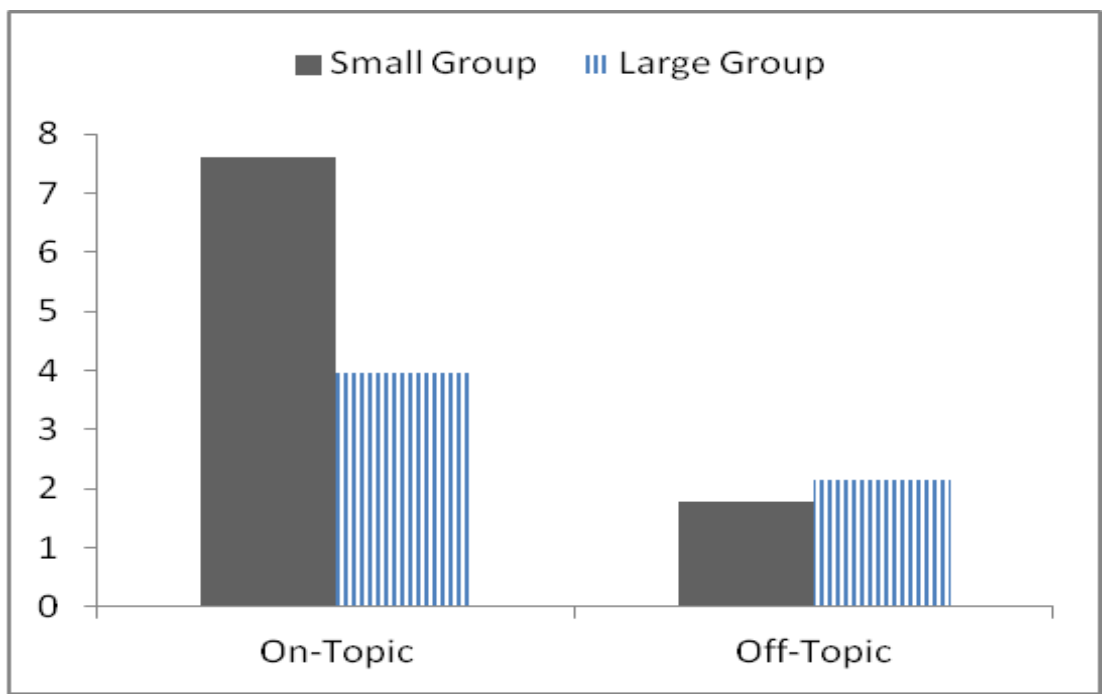

Fig.5: Main effect of group size by quality of participation (on-topic versus off-topic responses) in online discussion

\section{Answering the Third Question}

The third question of the study states: in terms of achievement on the course, can high instructor guidelines structure in online discussion produce different results than moderate and low guidelines structure? Question three addressed whether the instructor guidelines given to students in online discussion impacted learning. Learning was measured using an achievement test. This test consisted of 25 true and false questions plus 25 multi-choice questions. The test questions were given to student online after the five week discussions, and then scores were calculated, with each corrected answer being given one point and the wrong answer being given no point. Data from the achievement test was analyzed using ANOVA, with the structure guidelines as the independent variable. The results of analysis of variance revealed that on the achievement test, there was a main effect of instructor guidelines $(F=111.136 ;$ df 2, 91; $P<0.000 ; \eta 2=0.707)$, and this finding is shown in Table 11.

\section{8}




\section{Number 72, April , 2016}

Table 11: The between subject effect of the achievement by levels of structure in online discussion

\begin{tabular}{|r|l|l|l|l|c|}
\hline & \multicolumn{1}{|c|}{$\begin{array}{c}\text { Sum of } \\
\text { Squares }\end{array}$} & \multicolumn{1}{c|}{ df } & Mean Square & F & Sig. \\
\hline Between & 1845.628 & 2 & 922.814 & 111.136 & .000 \\
\hline Within & 755.617 & 91 & 8.303 & & \\
\hline Total & 2601.245 & 93 & & & \\
\hline
\end{tabular}

A Post hoc comparison of Scheffe test (based on an alpha of .05$)$ revealed that the high structure group $(M=45.56$, $\mathrm{SD}=1.88)$ scored significantly higher than the moderate structure group $(M=41.58, S D=2.67)$ and the low structure group $(M=34.84, S D=3.79)$. Further, the results showed that the moderate structure group outperformed the low structure group. These findings are presented in Fig. 6.

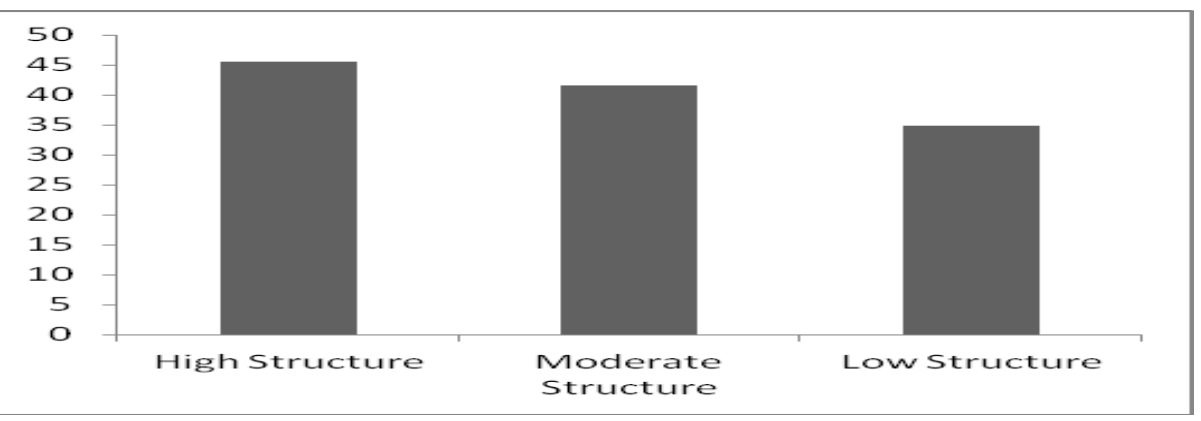

Fig.6: Main effect of instructor guidelines by mean scores on achievement test

\section{Answering the Fourth Question}

The fourth question of the study states: in terms of achievement on the course, can large group size in online discussion produce different results than small group size? In order to answer this question, an analysis of variance was conducted on the achievement test scores with the online discussion group size as the independent variable. The analysis showed that there was a significant main effect of group size, $(F=10.702 ; d f 1,92 ; P=0.219 ; \eta 2=0.108)$, with the large group size $(\mathrm{M}=41.251, \mathrm{SD}=5.4)$ outperforming the small group size $(\mathrm{M}=39.203, \mathrm{SD}=5.2)$. This is shown in Table 12, and Fig.7. 
Table 12: The between subject effect of the achievement by group size in online discussion

\begin{tabular}{|r|l|l|l|l|c|}
\hline & \multicolumn{1}{|c|}{$\begin{array}{c}\text { Sum of } \\
\text { Squares }\end{array}$} & \multicolumn{1}{c|}{ Df } & Mean Square & F & Sig. \\
\hline Between & 42.653 & 1 & 42.653 & 10.702 & 0.002 \\
\hline Within & 2558.592 & 92 & 27.811 & & \\
\hline Total & 2601.245 & 93 & & & \\
\hline
\end{tabular}

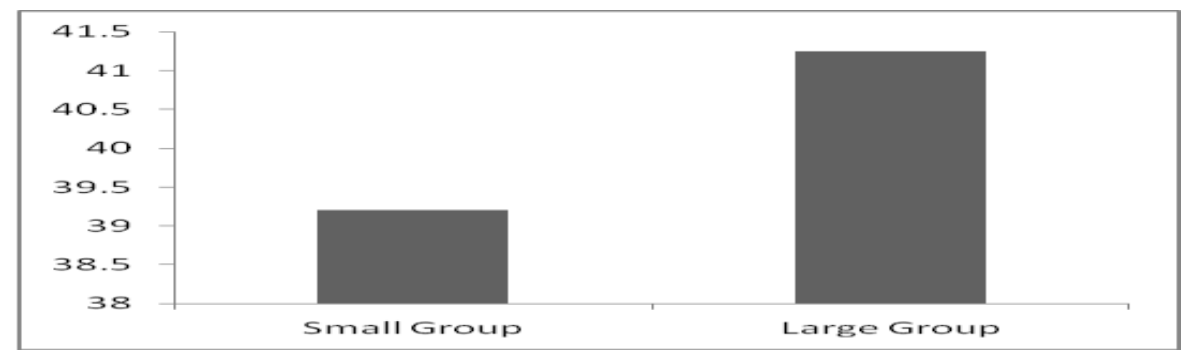

Fig. 7: Mean differences of group size by achievement scores

\section{Answering the Fifth Question}

Study question five addressed student satisfaction of online discussion. Participants were given a 25-item satisfaction questionnaire after participating in an online discussion. A Likert-type scale of five possible responses, spanning from strongly agree to strongly disagree, was used. The scale for three questionnaire items (item thirteen, fifteen, and sixteen) were reversed to maintain consistency in the scales of the variables. The Cronbach's Alpha for the questionnaire items was 92 .

The average mean score for the satisfaction questionnaire $(\mathrm{M}=3.75, \mathrm{SD}=0.73)$, showed that overall, participants had positive satisfactions of online discussions. The 95\% confidence interval for this mean was 3.60 to 3.90 . Therefore, overall participant satisfaction would be positive.

It was hypothesized that participant's satisfaction would not vary based on the treatment condition (structure guidelines). Question five states: in terms of satisfaction with online discussion, can high instructor guidelines

\section{0}


structure in online discussion produce different results than moderate and low guidelines structure? To answer this question and test hypothesis five, a one-way ANOVA was conducted to determine whether participant's satisfaction differed based on treatment condition. The mean and standard deviations for the overall satisfaction scores by structure guidelines (instructor guidelines) are presented in Table 13. The results of the ANOVA suggested that instructions given to participants before joining the online discussion had a significant impact on satisfaction $(F=55.70 ;$ df 2 , 91; $P=0.000 ; \eta 2=0.882)$. Table 14 shows the ANOVA results.

Table 13: Means and standard deviations of participant's satisfaction by levels of instructor guidelines

\begin{tabular}{|c|c|c|c|}
\hline Structure & N & M & SD \\
\hline High Structure & 32 & 4.43 & 0.32 \\
\hline Moderate Structure & 31 & 3.67 & 0.70 \\
\hline Low Structure & 31 & 3.13 & 0.38 \\
\hline
\end{tabular}

Table 14: The between subject effect of the satisfaction by instructor guidelines in online discussion

\begin{tabular}{|c|r|l|l|l|c|c|}
\hline \multicolumn{2}{|c|}{} & Sum of Squares & Df & Mean Square & F & Sig. \\
\hline Satisfaction & Between & 27.184 & 2 & 13.592 & 55.701 & .000 \\
\cline { 2 - 8 } & Within & 22.205 & 91 & .244 & & \\
\cline { 2 - 7 } & Total & 49.389 & 93 & & & \\
\hline
\end{tabular}

The fifth hypothesis that satisfaction would not vary based on instructor guidelines was not supported. The results showed that there was a significant mean effect of structure guidelines on participant's satisfaction. In order to see which structure group had the greater effect, a post hoc comparison was conducted. A Scheffe test (based on alpha of 0.05) revealed that the high structure group scored significantly higher than the moderate structure group, and the low structure group. The post hoc also showed that the moderate structure group significantly outperformed the low structure group. These results are presented in Fig. 8. 


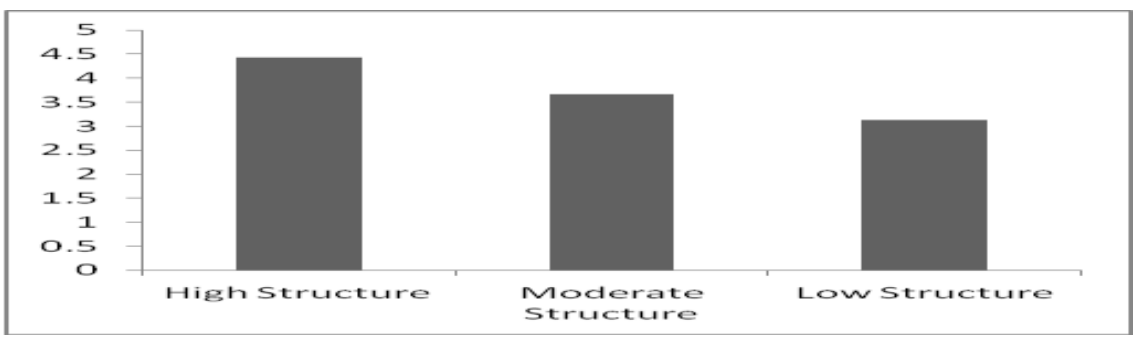

Fig. 7: Mean differences of instructor guidelines by participant satisfaction

\section{Answering the Sixth Question}

Question six of the present study states: in terms of course satisfaction, can large group size in online discussion produce different results than small group size? Participants were also given the same 25-item satisfaction questionnaire used to investigate the effect of structure guidelines on satisfaction. It was hypothesized that participant's satisfaction would not vary based on the group structure condition (group size).

To answer this question and test hypothesis six, a oneway ANOVA was conducted to determine whether participant's satisfaction differed based on group size of the online discussion. The mean and standard deviations for the overall satisfaction scores by group size (small versus large group size) are presented in Table 15. The results of the ANOVA suggested that group size (large vs. small) had a significant impact on satisfaction $(F=3.939$; $d f 1,92$; $P=0.05 ; \eta 2=0.541)$. Table 16 shows the ANOVA results.

Table 15: Means and standard deviations of participant's satisfaction by group size

\begin{tabular}{|c|c|c|c|}
\hline Group Size & N & M & SD \\
\hline Small Group & 28 & 3.52 & 0.68 \\
\hline Large Group & 66 & 3.85 & 0.73 \\
\hline
\end{tabular}

Table 16: the between subject effect of the satisfaction by group size in online discussion

\begin{tabular}{|r|l|l|l|l|l|}
\hline & \multicolumn{1}{|c|}{$\begin{array}{c}\text { Sum of } \\
\text { Squares }\end{array}$} & \multicolumn{1}{c|}{ Df } & Mean Square & F & Sig. \\
\hline Between & 2.028 & 1 & 2.028 & 3.939 & .050 \\
\hline Within & 47.361 & 92 & .515 & & \\
\hline Total & 49.389 & 93 & & & \\
\hline
\end{tabular}




\section{SECTION TWO: EFFECTS OF INTERACTION}

The seventh question of the study states: in terms of participation, learning and satisfaction, can the interaction (if exists) between instructor guidelines and group size produce different results outcomes? In order to answer this question, an analysis of variance of instructor guidelines (high-moderate-low) by group size (small-large) by participation by learning by satisfaction, was conducted. The results showed several significant differences, and these are presented in four parts as follows:

- Effects of Structure by Group Size by Quantity of Participation

- Effects of Structure by Group Size by Quality of Participation

- Effects of Structure by Group Size by Learning

- Effects of Structure by Group Size by Satisfaction

Effects of Structure by Group Size by Quantity of Participation

The analysis of variance of structure in online discussion (high - moderate-low), group size (large versus small) with the quantity of participation as dependent variable, the analysis showed that there was an interaction effect $(\mathrm{F}=5.451 ; \mathrm{df} 2,88 ; \mathrm{P}=006)$. The analysis also showed that there was an effect of structure $(\mathrm{F}=8.222$; df2, 88; $\mathrm{P}=000)$, with the high structure group being better and of group size $(\mathrm{F}=64.571$; df2, 88; $\mathrm{P}=000)$, with the small group showing increase in amount of postings. Fig. 8 shows this interaction.

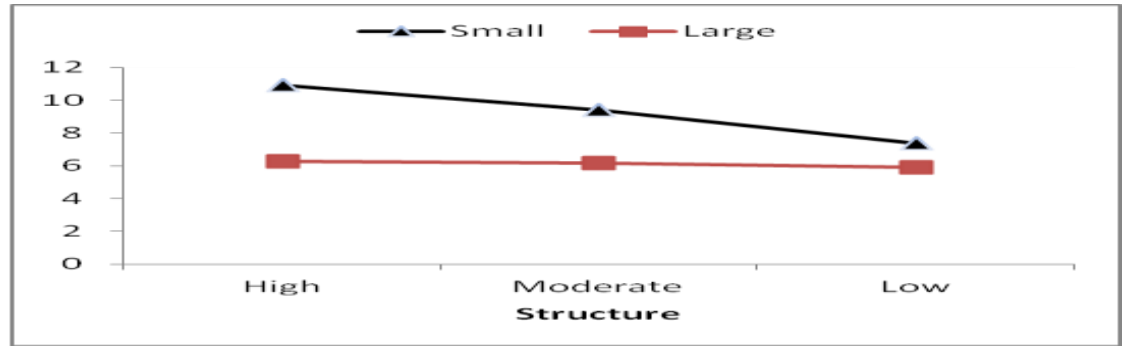

Fig. 8: Interaction of amount of participation per participant by instructor guidelines by group size 
Looking at Fig. 8 indicates that the amount of student postings increase with the high structure guidelines when the group size is small. Amount of participation per participant increases from low to moderate to high when the group size is small. When there are no instructor guidelines (low structure), small and large groups show little differences. The differences between small and large group size appear with the high structure in online discussion. The overall postings for small groups are greater than large groups.

\section{Effects of Structure by Group Size by Quality of}

\section{Participation}

The analysis of variance of structure in online discussion (high - moderate-low), group size (large versus small) with the quality of participation as dependent variable, the analysis showed that there was an interaction effect of structure by group size by off-topic responses $(\mathrm{F}=8.80$; df2, $88 ; \mathrm{P}=000$ ), with the small group performing better when participants received high structure but when no instructions were given, large groups doing better. The analysis also showed no interaction of group size by structure by on topic responses $(\mathrm{F}=0.68 ; \mathrm{df} 2,88 ; \mathrm{P}=0.51)$. The effect on offtopic responses is displayed in Fig.9, and Fig. 10 presents the effect on on-topic responses.

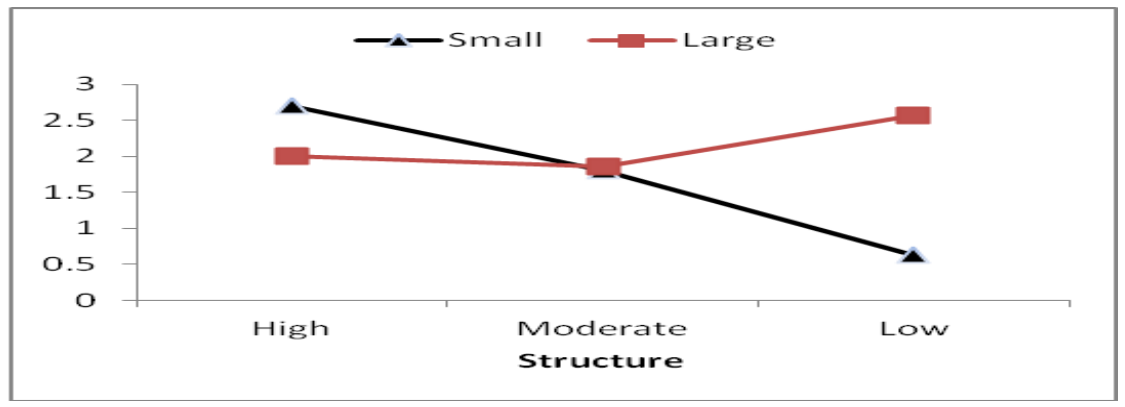

Fig. 9: Interaction of off-topic responses by structure by group size 
Number 72, April , 2016

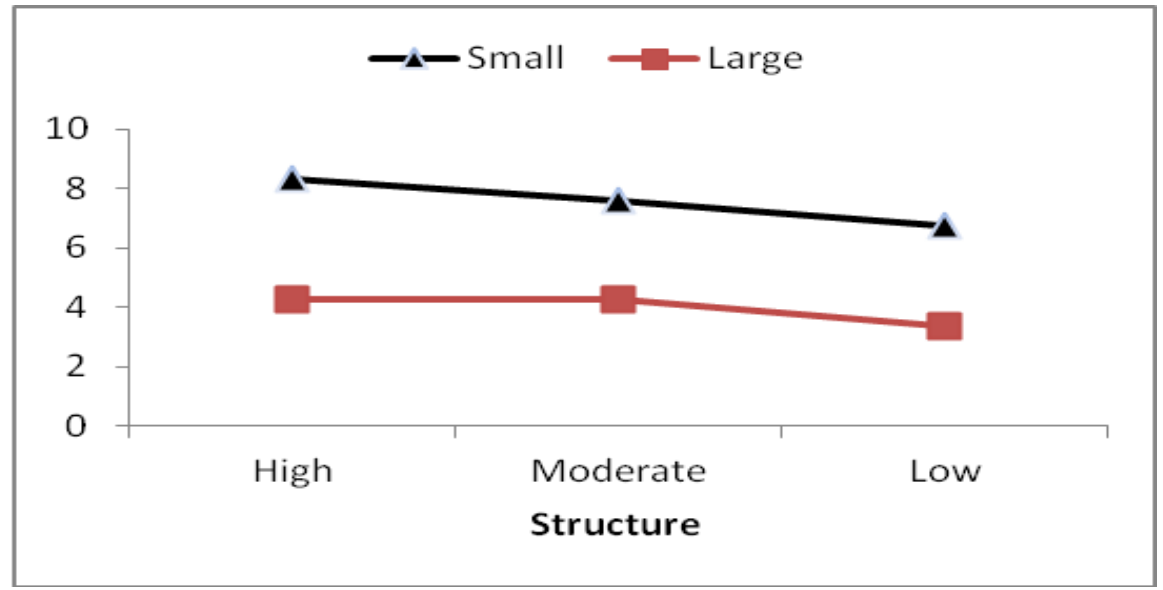

Fig.10: Interaction of on-topic responses by structure by group size Effects of Structure by Group Size by Learning

When the analysis of variance involved structure (highmoderate-low) and group size with the learning as the dependent variable, the analysis showed that there was no interaction $((\mathrm{F}=0.57$; df 2,$88 ; \mathrm{P}=0.567)$, and this is shown in Fig. 11.

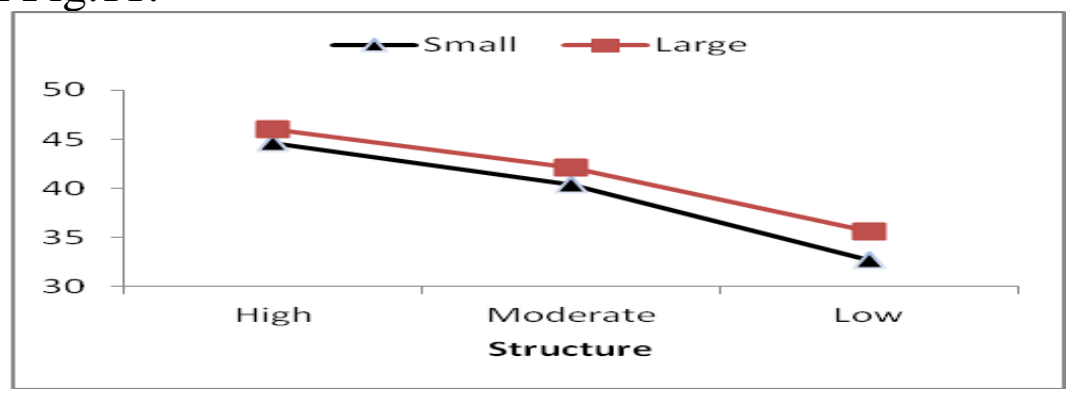

Fig.11: Interaction of learning by structure by group size

\section{Effects of Structure by Group Size by Satisfaction}

When the analysis of variance involved structure (highmoderate-low) and group size with the satisfaction as the dependent variable, the analysis showed a main interaction $((\mathrm{F}=5.064 ; \mathrm{df} 2,88 ; \mathrm{P}=0.008)$, with the large groups doing better than small groups with both high structure and low structure, and this is shown in Fig. 12.

\section{5}




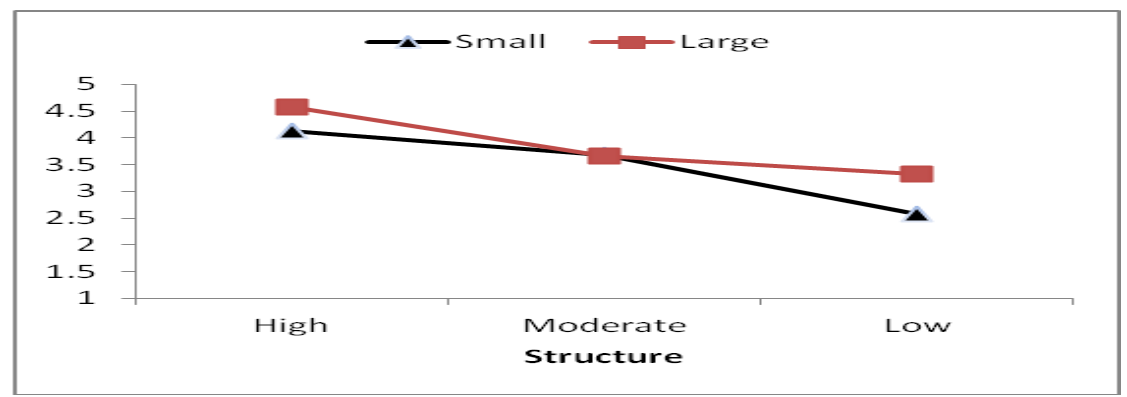

Fig.12: Interaction of satisfaction by structure by group size

\section{DISCUSSION OF RESULTS}

Most instructors seek ways to enhance student discussion and student participation and foster learning. This study sought to extend this notion to the online environment by determining whether structural elements of the discussion forums impacted student participation and learning in online discussion. The study also investigated student satisfaction of online discussion as an important factor affecting learning.

The purpose of the present study was to investigate the influence that instructor guidelines and group size in online discussion forums have on student participation, learning and satisfaction. The study examined whether differing levels of discussion structure and differing group size influenced the amount and type of student responses and whether online discussion forum structure and group size influenced student learning and satisfaction. This section presents the discussion of results and their implications for instructional designers of online discussion and learning. The discussion will be in the light of questions and hypotheses. The discussion will be presented in four sections:

- Quantity and Quality of Participation and Instructor Guidelines

- Quantity and Quality of Participation and Group Size 
- Learning and Instructor Guidelines and Group Size

- Satisfaction and Instructor Guidelines and Group Size Quantity and Quality of Participation and Instructor Guidelines

Study question one asked whether online discussion structure affected the amount and types of student participation. It was hypothesized that levels of instructor guidelines (high-moderate-low) would have no effect on student's amount and types of participation. Hypothesis one is not supported. The results showed that as the level of discussion structure increased from low to moderate to high, the amount of postings also increased. With the type of postings, the same pattern was observed, with the high structure group posted more on-topic responses than the moderate structure group and the low structure group. For off-topic responses, the results showed that unrelated-nonsubstantive responses were not affected by instructor guidelines.

Discussion structure, then, impacted the amount of student participation (quantity of participation) in the online discussion. This finding supports Gilbert and Dabbagh's study (2005), which reported that discussion increased the number of student postings. In addition, several studies may lend support to the present study (e.g., Khan, 2005; Stemwedel, 2005; Wallace, 2003; Xie et al., 2006) in that students participate more when they perceive that the discussions are valued by the instructor. For example, Khan (2005) confirmed that student participation increased when online discussions became mandatory than optional. Stemwedel (2005) maintained that incorporating participation into student's grades was essential to ensure that students submitted high-quality contributions to online discussions. Xie et al. (2006) suggested that when instructors placed greater value on online discussions and

\section{7}


explicitly encouraged participation, student participation and participatory behaviors (e.g., number of login times and responses) increased. They added that when instructors emphasized the value of online discussions, had explicit expectations for discussions, and encouraged active participation, students participated more and perceived the discussions as valuable and interesting.

In the present study, participants in high structure group posted significantly more responses on average than the moderate and low structure groups. Participants in the moderate structure group posted more on average than the low. As the level of structure increased, the guidelines for participation became more detailed. As a result, students may have perceived that the instructor placed greater value on the discussion and caused them to participate more. Additional research is needed to validate this result.

The second important finding of the present study is that instructor guidelines had a major effect on the types of responses students posted. In the high structure treatment group, participants posted more substantive responses than the moderate and low structure groups. Instructions students received before participation which showed the type and kind of posting may have increased the effort the student exerted to post a required response. Students in the high structure group were provided with instructions to post an opinion based on reading/research on the question or the topic discussed. They also were asked to pose a comment on their peer responses; as well as they were requested to visit sites and links to collect more information to enhance their contribution in the discussion. It seems that these instructions worked as framework for them to manage their participation in the discussion. As a result, the contribution was more controlled and was related to the question and the topic discussed. 
The results of the present study may support Hew and Cheung's (2003) notion that student ideas in online discussion often sound similar to one another. Therefore, students needed explicit guidelines (i.e., structure) in online discussions because without structure, students often participate at a surface level in online discussions. This finding is also in support of the need of structure guidelines in discussion which implied in Angeli et al. (2003) study. Angeli et al. (2003) indicated that students' participation in online discussions was mostly exchanges related to personal experiences, was not based on well-supported reasoning, did not show evidence of critical thinking related to studying course content, was conversational and opinionated. Gilbert and Dabbagh (2005) found that when the instructor presented guidelines, an increase in quality of responses and discussions was noted; participation guidelines increased the number of student postings, leading to more detailed and in-depth discussions and higher student interaction. In support of the results of the present study, Moore and Marra (2005) indicated that structure imposed constraints on communication systems and types of responses. The study by Due et al. (2005) also gives another support to the present result in that student were asked to post specific types of responses or formulate and post responses, critique peer's responses, and assist peers in developing their ideas. These structures were very helpful in enabling learners to post more comments related to the study topic. The results in this section are schematically displayed in Fig. 13.

Although, overall, structure has been reported to be beneficial in online discussions as found in the present study, there is still a need to further information about the relationships between structure and other variables related to online discussion. 


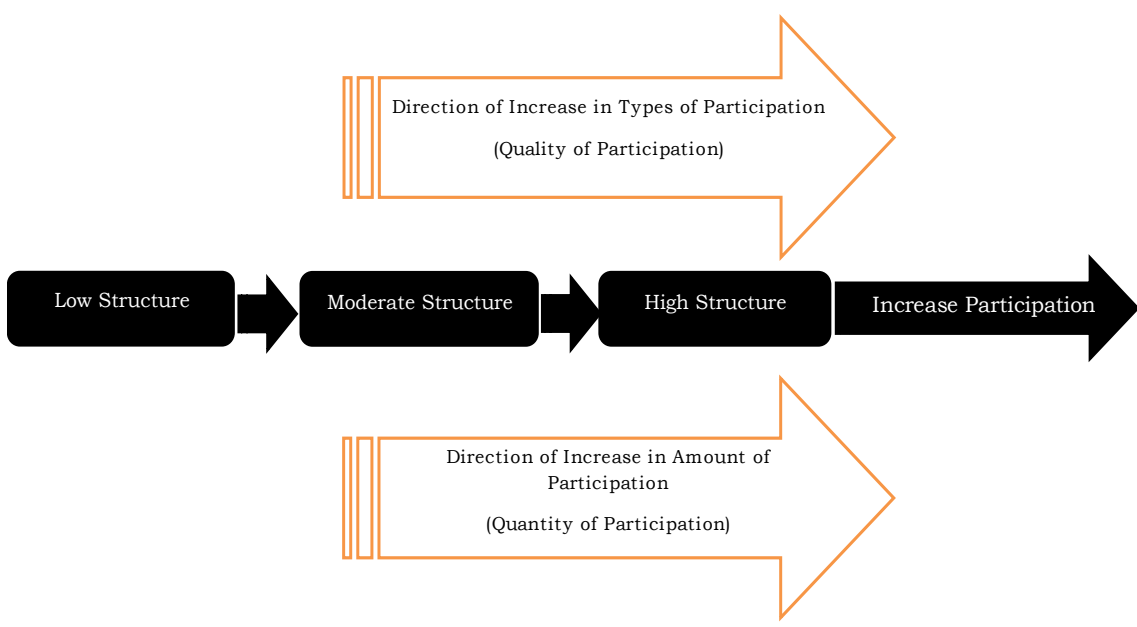

Fig. 13: Schematic diagram shows the direction of increase in amount and types of participation by instructor guidelines

Quantity and Quality of Participation and Group Size

Study question two asked whether online discussion group size affected the amount and types of student participation. It was hypothesized that group size structure (large versus small) would have no effect on student's amount and types of participation. Hypothesis two is not supported.

The results of the present study showed that, with the frequency of postings, large groups posted more responses than small groups. However, the average mean of posting was higher with the small groups than the large group. This means that the mean amount of postings was higher in the small groups. The pattern of results for the type of postings showed that small groups outperformed the large group in on-topic (substantive responses) but no differences were found in the off-topic (non-substantive responses). Further, the percentage of related postings (on-topic) was higher than the percentage of unrelated postings (off-topic) in the high and small groups. The results in this section are schematically displayed in Fig. 14. 


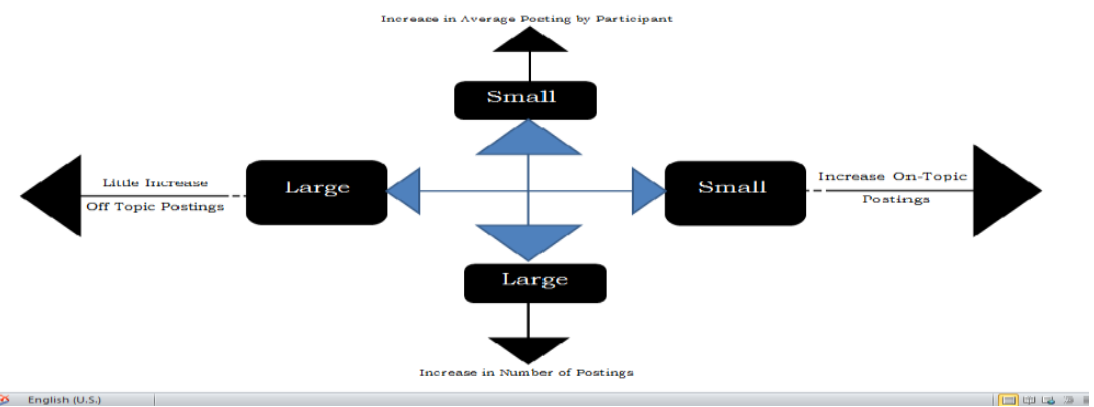

Fig. 14: Schematic diagram shows the direction of increase in amount and types of participation by group size

For the amount of postings, it seems that larger groups produced more numbers of postings than smaller groups. This result may be consistent with the increase in number of students, that is, increased number of students within the groups probably may have increased the possibility of having had more responses. However, this may not be a mirror of average posting by student. Students in smaller groups showed a higher average mean of postings than those in larger groups. This finding may be because smaller group discussions make it difficult for students to sit back or not to participate as it is noticeable if a student does not participate. In small groups, there may have been more peer pressure to contribute, because students knew that not participating means letting the group down. The students might feel that they were more accountable as sub-group members. When one student is missed a significant difference in contribution may be watched. Another important reason for the finding above is that smaller groups may represent closer relationships because they can interact more often and more confortable.

In terms of information overload, larger class size increase the amount of material that students are expected to read and process. This may have amplified information overload resulting in superficial level of processing. Too

\section{1}


many students in larger class may have resulted in more superficial discussions of many issues, rather than deep discussion of a few issues (Peter, 2005, 38). Lipponen (2001) has found that group work (especially larger groups) could actually increase the processing load on individuals. Wiley and Bailey (2006) pointed out that "in the end, individuals may be more burdened and enjoy less intact cognitive processing than when working alone" (300).

The results of the study by Hewitt, Brett and Peters (2007) are in support of the finding obtained in the present study. Hewitt, Brett and Peters (2007) suggest that larger classes were associated with an increase in the number of note written, a decrease in average note size, a decrease in the percentage of notes opened and an increase in note scanning. The present result is in line with this as the number of postings increased with the larger class size, but the average mean number of postings increased when the group sized was reduced.

Several studies also support the finding in the present study that small groups produced more on topic responses than larger groups. Some advocates of the large group suggest that the instructors who don not adopt a small group strategy have a common concern about the limited diversity of interests and knowledge in small groups. On the one hand, the small number of members might limit the information to which the members have to access; on the other hand, a lack of common interest and knowledge in small groups might make it difficult to establish a common ground for discussion. This may result in less contribution in small group. The result of the present study in this section does not support this idea.

Further, the results of the present study may support the idea that different groups may use different strategies in

\section{2}


postings during discussions. In larger groups, students may manage their processing of the many ideas and posting by using skipping strategy for some responses to save time for writing. This strategy can help students get higher participation. Hewitt et al (2007) hypothesized that some students are unable to follow what is going on in a mass discussion, might get disheartened and give up. This information overload in larger groups has deleterious influence on student learning and poses a greater threat to successful collaborative learning.

The present study indicated that on topic responses showed superiority with the small groups. Some students may have given up discussion as they felt that increase number of participants inhibited efficient in depth discussion because of repetitiousness or irrelevant "branching out" off topics. Since instructors assess students Reponses by number of postings contributed, many students appear compelled to write numerous but less thoughtful postings. The reverse may have been used by the small groups.

\section{Learning and Instructor Guidelines and Group Size}

Study question three and four asked whether learning (achievement) was affected by structure of online discussion and group size. It was hypothesized that achievement would not be affected by different structure guidelines and group size of the discussion. Results of the study showed that on achievement measure when the instructor guidelines differed, student achievement was significantly changed, with the high structure group outperforming moderate and low structure groups. An increase in achievement from low to moderate to high structure showed a continuum; with one pole achievement increased (high structure) but with the other decrease (low structure) in achievement was found.

\section{3}


Group size was also found to affect learning; with the large groups size outperforming the small groups. Based on this result, hypothesizes three and four were not supported. When involved group size by instructor guidelines, the results on achievement indicated no interaction; a similar pattern with observed with both small and large groups in high, moderate and low structure. These results are schematically presented in Fig. 15.

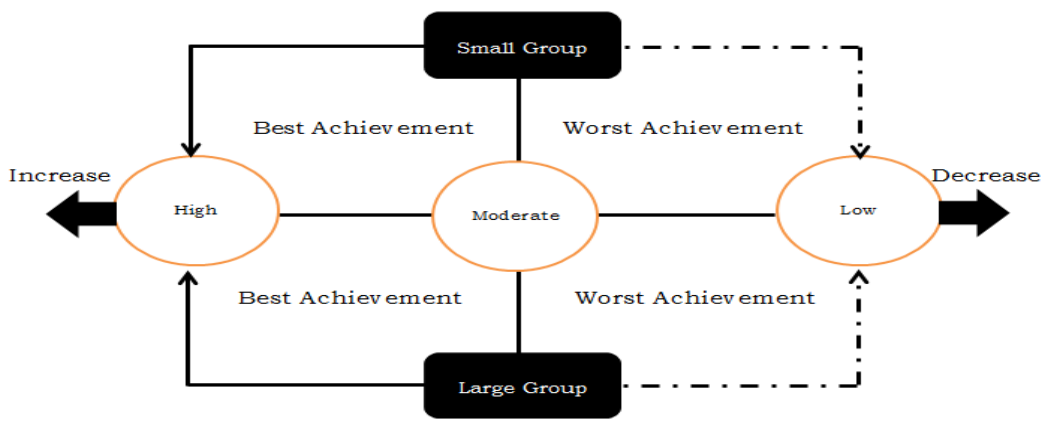

Fig. 15: Schematic diagram shows the direction of increase in achievement by structure by group size

Because group size by instructor guidelines showed no interaction effect, the discussion will focus on both structure and discussion group size separately. With respect to the instructor guidelines, it obvious that giving students explicit detailed guidelines had an impact on learning. Increasing guidelines was shown before that amount and types of participation increased as a result; with the high structure guidelines showing best effect on participation but worst participation being found with low structure guidelines. Taking both results into consideration may mean that increasing instructions on how students participate, what sort of response is required, number of response needed, may in some way affect both participation and learning. It is clear that with the higher instruction guidelines, students

\section{4}


were asked to give a related posting to the question provided and content topics; they were also asked to comment on their peers' comment to enhance their participation; and they were requested to visit links and website to validate their opinions. These requirements for the high structure groups might have had a better effect on learning plus participation.

When comparing the results of structure guidelines on amount and types of participation with the results of learning, it seems to be more attractive to say that both participation and learning are affected by structure guidelines. Possibly, when the structure is high or moderate, participation may be guided by this framework explicit detailed instruction, as a result, increase in amount and types of participation is likely to appear. In the same vine, learning may be affected by participation; when instructions were high participation was high, resulted in increase in learning. More research is needed to reveal the relationship of participation and learning.

With respect to the class size, large class size showed superiority over small class size in learning performance. However, previous results in this study showed that amount and types of student participation indicated a higher score for small groups' size over large groups' size. What the results suggest is that both types of group size might have different strategies for coping with the discussion. Larger groups appeared to have the opportunities to see several ideas, comments, and viewpoints. With the increase in number of students in online discussion, the likelihood that students had different viewpoints and different ideas and subjects related to the topic is expected. These variety of opinions and viewpoints on the discussed topics may have had richened students' experiences and knowledge which may have resulted in doing better on the achievement test. 
Students may have scanned the huge comments and responses and postings by selecting the ones related to the topics of questions. This strategy may have enabled them understand all aspects of the topic discussed. With respect to smaller groups, possibly less number of students dominated the discussion, with a lower number of comments, viewpoints and ideas were given; student, in this case, may have not been able to get in all sides of the topic discussed in the online discussion; and therefore, learning was affected and decrease in achievement was shown. Small numbers of students who participated in the online discussion may in this case prevent other students in the group to control over all aspects of the topics, this in turn, may have not assisted participants in formulated a good knowledge base in content topics, leading to decrease in performance on the achievement test.

\section{Satisfaction and Instructor Guidelines and Group Size}

Questions five and six of the present study are interested in studying learner satisfaction with the instructor guidelines and group size as independent variables. The interest in learner satisfaction was because online discussion forums are social environments in which a strong affective component exists. If learners are satisfied with the online discussion, they are more likely to engage in such experience again. Therefore, the focus of interest in this study was in examining two factors that affect learner satisfaction. With respect to the first factor-instructor guidelines, it was hypothesized that providing high, moderate, and low structure would not have an effect on student satisfaction. This hypothesis was not supported. With respect to the group size, it was hypothesized that different group sizes would not have an effect on learner satisfaction. This hypothesis was also not supported. 
Generally, the results showed that overall positive satisfaction was observed for all study groups. The mean score of the satisfaction questionnaire was 3.75 on a 5-point Likert scale. This finding from the study supported existing studies that have found positive satisfaction and perception of online discussion (Ellis, 2004; Sullivan, 2001). The findings from the present study suggested that students believed the online discussion had some utility in the course. In fact, approximately $78 \%$ of the participants who participated and completed the questionnaire responded with either strongly agree or agree to the statement, "I liked participating in the online discussions". Other researchers, such as Jin (2005), have also found that students in online courses commonly reported satisfaction with their experiences. Although the exact reasons that students enjoyed the discussions were not isolated in this study, $83 \%$ belived that the discussions were beneficial to learning experiences in online class. Existing research made similar claims; some reported that students perceive online discussions as beneficial to the learning process and to enhance student learning (Chen \& Hung, 2002). Some researchers have added that students enjoy online discussion and believe that these discussions are interactive and positively impact learning (Jin, 2005).

Some intervening variables could have impacted students' satisfaction of the online discussions. For example, because the use of the online discussions as an instructional strategy was not a common element in the course, it is possible that student satisfactions could have been impacted by the novelty effect. That is, because the online discussions were new to the learners, learners may have had more positive satisfactions of the discussions than if they had been using the discussions as part of their instruction for the other units in the course. 
Further, it is possible that the positive satisfactions may have been due to perceived expectations. In other words, students knew that they were participating in a study about online discussions, and, as a result, they may have assumed that their satisfactions were expected to be positive. The above discussion was concerned with general satisfaction. Next instructor guidelines and group size and satisfaction will be presented.

With respect to instructor guidelines, the results revealed that providing students with high structure guidelines enhanced student satisfaction. Learner groups who received high guidelines performed better on satisfaction measure than moderate and low guideline instructions. As shown in Table 14, the significant results of the ANOVA indicate differences in student satisfaction among the three structure of discussion comparing student satisfaction $(\mathrm{p}<0.000)$. Scheffe post-hoc comparisons revealed that the significant difference in satisfaction was between the high structure and the moderate and low structure and between the moderate structure and low structure (F.g.7). When looking at student satisfaction, there was a pattern of results the same as that in student learning. This may mean that student satisfaction is an indicator of successful learning (McFarland \& Hamilton, 2005; Parkhurst et al., 2008; York, 2008). It seems that when students report their satisfaction, they are assessing the quality of learning experience. A high level of student satisfaction can be an indicator of timely and substantive interaction among students and it may also indicate that the online discussion being used strongly reflect learning goals and student expectations. Additionally, student satisfaction can influence student motivation and attitudes, both of which may strongly influence how well students learn in a course (Moore, 2005). As with student performance, the link between student satisfaction and successful learning is

\section{8}


debatable, as students may report higher satisfaction with courses that they perceive as easy, fun, or less demanding, none of which are necessarily linked to successful learning. Still, sufficient reason exists to expect that student satisfaction may be higher in classrooms where successful learning is taking place.

When instructors provide structure guidelines, they need to take into consideration whether students enjoy online discussion or not. The findings suggest that a high structure guideline can be a viable option to maintain and may be even increase students' satisfaction. One possible explanation for the success of the high structure group on student satisfaction could be that instructions received allow students control their experiences in online discussion as requirements for successful learning. The instructor guidelines worked as external framework guided students' engagement in the learning tasks. The implicit meaning behind the superiority of the high structure and moderate structure groups over no structure group (low structure) may be explained by the supplantation hypothesis. If the coding elements of the online discussion are inconsistent with one's mode of internal representation and processing, it is likely that much more mental translation and transformation from external to internal is required. By providing learners with explicit high structure guidelines to go through the online discussion, it saves additional elaboration and mental translation required. In the present study, learners seemed to benefit from differing degrees from the same supplantation techniques (instructor guidelines). Further, a high structure provided to students appears to have the potential of accommodating some of the various learning needs of the students because of its advantages of adjusting students' participation and this may have led to more satisfied experiences. Leaving students with no instructions for

\section{9}


participation may have dropped student satisfaction with the online discussion experiences.

With respect to the class size, the results indicated a main effect, with the large class size group being more satisfied than the small class size group. More research is needed to inspect the reasons behind increase in satisfaction with the larger groups size while participation and learning being better for small groups size. One possible explanation is that larger group size provided students with diverse experiences, ideas and opinions not available to small group size, and this may have resulted in more satisfied experiences with the larger groups. This needs more investigation, and the schematic diagram below shows the results in this section.

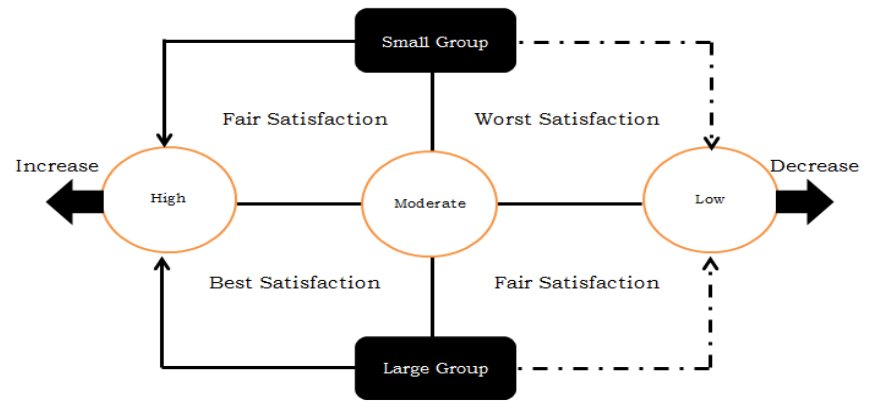

Fig. 16: Schematic diagram shows the direction of increase in satisfaction by structure by group size

\section{IMPLICATIONS FOR ONLINE DISCUSSIONS}

The results of the study have several implications for online discussion. There are some direct applications of the results in online discussions and there are others could be inferred from the findings.

Different structural elements such as instructor guidelines may have different effects on learner participation in online discussions; therefore instructors must be aware of the inherent differences that exist when using structure elements

\section{0}

Journal of Arabic Studies in Education \& Psychology (ASEP) 
in the discussion. It is recommended that clear guidelines of how, numbers and what types of responses needed from learner may contribute in enhancing the quality and quantity of learner participation in online discussions. Based on the results of the study, providing guidelines should be mandatory requirement. These guidelines should be connected with a grading system when instructors are in need for increasing participation. Instructors should make participation requirements explicit. It is not expected that all students know automatically how to participate in online discussions, neither in terms of the expected quantity nor in terms of the quality of participation. Therefore, clear guidelines and expectations in your syllabus should be given. Instructors should also post those guidelines as the first item in the board. Providing time guidelines such as weekly posts with exact deadlines for each task and question posted may probably help students manage their time for reading, thoughts and comments appropriately. In terms of grades, instructors should include online discussion participation in the course grade. If grades are not given for participation, learners typically do not use the discussion forum. Instructors should also decide how much of the course grade to give to discussions and whether they will assess the quantity or quality of postings, or a combination of the two.

Instructors should assist students to focus on on-topic responses, therefore it is important to get students involved in class discussion and explain the value of their participation and what they can expect to get out of their experiences. For helping students improve their focus on on-topic postings, it is worthwhile taking some time to teach the students how to read others' comments, how to paraphrase, and how to involve other members of the groups. Students need to understand that they share the

\section{1}


responsibility for making the discussion a worthwhile experience.

Results of the present study also indicated that group structure such as dividing large group into small sub-group may have direct influence on participation. Instructors should be aware of the suitable group size for different purposes; as in the present study, if the aim is to increase quality and quantity of participation, using small groups' size may be of main importance. When the aim is learning or satisfaction, probably using larger groups' size may be preferable as the results of the study showed. Based on this idea, to facilitate more deep and in-depth discussion, instructors have to divide large groups into small subgroups.

In order to motive students for discussions, instructors should use open-ended questions targeted toward higher order thinking skills. The present study used questions that may have needed direct responses, elaboration, evaluation of ideas and criticism. In successful discussion boards, all participants learn from and teach one another. In order to support a deep and meaningful conversation, the instructors should post an interesting initial discussion question which is controversial and allows for multiple perspectives that the students can provide from their own experiences.

\section{RECOMMENDATIONS}

Several follow up studies could be conducted either to improve upon the methods used in the present study, or to investigate a number of possible experiments that add to the current findings by manipulating completely different variables to those examined here. Possible research areas are listed and considered below.

The present study used a modified coding scheme to evaluate student participation in terms of quantity and

\section{2}


quality; this coding should be developed or create a new coding scheme and so the same study could be replicated.

An additional recommendation is to replicate this study to reevaluate the impact of structure on the number of substantive responses posted with a new controversial topic, and with a different sample such as postgraduate students.

The present study showed that increasing instructions for students in the online discussion showed improvement on participation and learning and satisfaction, more research is needed to reveal what amount of instructions is required to produce best participation.

The present study used a method to measure participation for students without the presence of instructor; future studies should also study the impact of instructor being a part of the discussion or not on student participation. One way to increase more and different kinds of substantive response and increase participation would be to include the instructor or a facilitator in the discussion, which in turn, promotes more meaningful connections in ideas (Topper, 2005).

Another important recommendation for suture research is to use the levels of structure used in the present study and add a control group. Adding a control group would help determine whether structure, regardless the level, impact student participation and learning.

One more important study could research the trends in student participation identified in this study; six on topic and four off topic codes were used to evaluate student postings. These codes may have impacted student learning. For example, one trend in participation discovered in this study was with the use of responses coded as chatting. Once one student posted this kind of response, all subsequent postings by other were likely also coded as chatting.

\section{3}


Chatting postings were non-substantive and did not appear to contribute to student knowledge and learning of the discussion topic and were irrelevant to the main topic. Future study should investigate types of responses in detail and their effect on enhancing participation and learning.

A time series analysis may also add in investigating the flow of student conversations. This type of analysis may look at the point at which students begins the post in offtopic ways, determine the probability that these kinds of responses will continue, and examine whether online structure influences the flow of off-topic postings.

For this study, the preparatory undergraduate year of University students may not have been accustomed to participate in independent discussions. As a result, such discussions may not have encouraged deep student leaning. With practice and feedback in discussions, students may be adept at participating in more substantive ways. Students may benefit from instructor participation in the discussions. The instructor could model good responses and provide examples and non-examples in the beginning of the course and then scaffold student responses as the course progresses. Therefore, another future study could include instructor modeling and participation in initial discussions. Such modeling may immerse in productive, successful discussions; and it is possible that effective student participation, which supports learning, could more naturally become an integral part of the course discussions.

\section{CONCLUSION}

This study was created to examine the moderating effects of instructor guidelines and group size in online discussion on quality and quantity of learner participation, learning and satisfaction. Learners were randomly assigned to one of three treatment groups with varying amount of structure students received: high structure, moderate structure and

\section{4}


low structure. 94 learners, preparatory year of Albaha University in Saudi Arabia, studying a communication course as a university requirement, participated in six-sub groups in six separated online forums. Three groups out of six, ranged in number from 21-23 participants, joined the large group discussions while the other three groups ranged from 6-8 students joined the small group discussions. Learners participated in the discussions for three successive weeks. Participation in the discussion was measured using a mean number of postings and a coding scheme measure to analyze the amount and types of student responses. Learning was measured using a 50-item achievement test and the satisfaction was evaluated using a 25-item survey measure. Data emerged from the participation measure, achievement test and satisfaction survey was analyzed using ANOVA followed by post hoc comparisons in order to figure out the effect of the independent variables of the study. The main conclusion of the study is summarized below in the light of expected outcomes of the hypotheses.

Hypothesis One: this hypothesis predicted that there would be no significant difference at $\alpha=.05$ level in amount and types of student participation as measured by the mean number of postings and participation rubric among the high structured online discussion group, moderate structured online discussion group and low structured online discussion group. The results of the study do not support this hypothesis. In terms of amount of postings, high structure guidelines group posted an average mean number of responses higher than the moderate and low structure groups. The moderate structure group posted more responses than the low structure group. With respect to the types of postings, the results showed a superiority of the high structure group over the moderate and low structure groups on the related on topic responses, but for the

\section{5}


unrelated irrelevant off topic responses the results showed no differences.

Hypothesis two: this hypothesis predicted that there would be no significant difference at $\alpha=.05$ level in amount and types of student participation as measured by the mean number of postings and the participation rubric between large group size and small group size. The results of the study showed a superiority of the smaller groups over the larger groups on the amount of postings and types of postings, with the small groups producing more substantive responses and average postings than the larger groups. For off-topic unrelated responses, the results showed no differences.

Hypothesis three and four: these two hypotheses predicted that no significant differences would be shown in learning as measured by the achievement test with respect to the varying levels of structure guidelines and group size respectively. The results of the study indicated that when the levels of structure differed from low to moderate to high, learning increased, with the high structure group doing the best. As for group size, the results revealed that larger groups did better than smaller groups on learning.

Hypothesis five and six: these two hypotheses predicted that no significant differences would be shown in satisfaction as measured by the satisfaction survey with respect to the varying levels of structure guidelines and group size respectively. The results of the study indicated that high structure guidelines group in online discussion were more satisfied with the discussion than the other two groups. In terms of group size, the larger groups were more satisfied with the online discussion than the smaller groups.

Hypothesis seven: this hypothesis predicted that there would be no interaction effect at $\alpha=.05$ level in

\section{6}


participation, learning and satisfaction with respect to instructor guidelines and group size. The results of the study showed that on quantity of postings, small groups did better than large groups particularly with the high structure guidelines. As for quality of postings, the results revealed that there was a crossover effect, with the small group did better on off-topic responses with the high structure guidelines but with the low structure guidelines, the larger groups produced more off-topic unrelated responses than the smaller groups. When learning was considered, the results revealed no interaction effect, but with satisfaction, the larger groups were more satisfied than the smaller groups. Overall, structural elements such as instructor guidelines and group size in online discussions are of main important and had a moderating effect on learning, participation and satisfaction.

\section{REFERENCES}

- Allan, M. (2004). A Peek into the Life of Online Learning Discussion Forums: Implications for Web-based distance learning. The International Review ofResearch in Open and Distance Learning, 5(2), 1-18.

- Anderson, M. A. (2009). Asynchronous discussion forums: Success factors, outcomes, assessments, andlimitations. Educational Technology \& Society, 12(1), 249-257.

- Angeli, C, Valanides, N., \& Bonk, C. J. (2003). Communication in a web-basedconferencing system: The quality of computermediated interactions. BritishJournal of Educational Technology, 34(1), 31-43.

- Aragon, S. R. (2003). Creating social presence in online environment.New Directions for Adultand Continuing Education, 100, 57-68.

- Atack, I. (2003). Becoming a web-based learner: Registered nurses' experiences.Journal of Advanced Nursing, 44(3), 289-297.

- Bailey, Y. S., \& Wright, V. H. (2000, November).Innovative uses of threaded discussiongroups. Paper presented at the annual meeting of the Mid-South Educational Research Association, Bowling Green, KY.

- Bales, R., \&Strodtbeck, F. (1951).Phases in group problem solving.Journal of Abnormal andSocial Psychology, 46, 485-495.

\section{7}




\section{Number 72, April , 2016}

- Barker, S. (2003). Online discussion boards: impacting the learning experience. In T. Greening \& R. Lister (Eds.), Proceedings of the fifth Australasian conference oncomputing education (Vol. 20, pp. 53-58). Adelaide, Australia: Australian Computer Society, Inc.

- Beaudoin, M. F. (2002). Learning or lurking? Tracking the "invisible" online student.Internet and Higher Education, 5, 147155.

- Bender, T. (2003).Discussion-based online teaching to enhance student learning. Sterling, VA: Stylus Publishing.

- Beuchot, A., \&Bullen, M. (2005).Interaction and interpersonality in online discussionforums.Distance Education, 26(1), 67-87.

- Bi, X. (2000). Instructional design attributes of web-based courses. Athens, OH: Ohio State University. (ERIC Document Reproduction Service No. ED 448746)

- Bielaczyc, K., \& Collins, A. (1999).Learning communities in classrooms: Areconceptualization of educational practice. In C. M. Reigeluth (Ed.), design theories and models: A new paradigm of instructional theory (pp. 397-424). Hillsdale, NJ: Lawrence Erlbaum.

- Bohlke, O. (2003). A comparison of students participation levels by group size and language stages during chatroom and face-toface discussions in German.CALICO Journal, 21(1), 67-87.

- Bonk, C. J. (2004). The perfect E-storm: Emerging technologies, enormous learner demand, enhanced pedagogy, and erased budgets. Part 2: Storms 3 and 4. London: UK: The Observatory on Borderless Higher Education. Retrieved December 14, 2006, from http://php.indiana.edu/*cjbonk/part2.pdf.

- Bonk, C. J., Wisher, R. A., \& Lee, J. Y. (2004). Moderating learner-centered e-learning: Problems and solutions, benefits and implications. In T. S. Roberts (Ed.), Onlinecollaborative learning: Theory and practice (pp. 54-85). Hershey, PA: Information Science Publishing.

- Bodzin, A. M., \& Park, J. C. (2000). Dialogue patterns of preservice science teachers using asynchronous computer-mediated communications on the world wide web. Journalof Computers in Mathematics and Science Teaching, 19(2), 161-194.

- Bodzin, A., \& Park, J. (2000).Factors that influence asynchronous discourse with preservice teachers on a public, web-based forum.Journal of Computing in Teacher Education, 16(4), 22-30.

- Bordia, P. (1997). Face-to-face versus computer-mediated communication: A synthesis of the experimental literature. The Journal of Business communication, 34, 99-120. 
- Branon, R. F., \& Essex, C. (2001). Synchronous and asynchronous communication toolsin distance education: A survey of instructors. TechTrends, 45(1), 36-42.

- Brewer, S., \& Klein, J. D. (2006). Types of positive interdependence and affiliation motive in an asynchronous, collaborative learning environment.Educational Technology Research and Development, 54(4), 331-354.

- Brookfield, S. D., \&Preskill, S. (2012). Discussion as a way of teaching: Tools and techniques fordemocratic classrooms (2nd ed.). San Francisco, CA: Jossey-Bass.

- Brown, J. S., Collins, A., \&Duguid, D. (1989). Situated cognition and the culture of learning.Educational Researcher, 18(1), 32-42.

- Bruner, J. S. (1985). Models of the learner.Educational Researcher, 14(6), 5-8.

- Bullen, M. (1998). Participation and critical thinking in online university distance education. Journal of Distance Education, 13(2), 1-32.

- Bruyn, L. L. (2004). Monitoring online communication: Can the development ofconvergence and social presence indicate an interactive learning environment? DistanceEducation, 25(1), 67-81.

- Campbell, N. (2004). Online discussion: A new tool for classroom integration?Communication Journal of New Zealand, 5(2), 7-26.

- Carr, T., Cox, G., Eden, A., \&Hanslo, M. (2004).From peripheral to full participation in a blended trade bargaining simulation.British Journal of EducationalTechnology, 35(2), 197-211.

- Chen, G., \& Chiu, M. M. (2006). Online discussion processes: Effects of earlier messages' evaluations,knowledge content, social cues and personal information on later messages. Computers \& Education.

- Chen, D., \& Hung, D. (2002).Personalised knowledge representations: The missing half of online discussions. British Journal of Educational Technology, 3, 279-290.

- Cheung, W. S., \& Hew, K. F. (2004). Evaluating the extent of illstructured problem solving process amongpre-service teachers in an asynchronous online discussion and reflection log environment.Journal ofEducational Computing Research, 30(3), 197-227.

- Cheung, W. S., \& Hew, K. F. (2005). Factors affecting learners' satisfaction on the use of asynchronous online discussion in a hypermedia design environment. Journal of Southeast Asian Education, 5(1\&2), 56-70.

- Cheung, W. S., \& Hew, K. F. (2007). Use of ground rules in online discussion.Paper Presented at the EDMediaWorld Conference on

\section{9}


Educational Multimedia, Hypermedia \& Telecommunications, Toronto:Canada.

- Choi, I., Land, S. M., \& Turgeon, A. J. (2005).Scaffolding peerquestioning strategies to facilitate metacognitionduring online small group discussion.Instructional Science, 33, 483-511.

- Clark, R. C., \& Mayer, R. E. (2002). E-Learning and the science of instruction: Provenguidelines for consumers and designers of multimedia learning. New York: John Wiley.

- Cohen, E. G. (1994).Restructing the classroom: Conditions for productive small groups. Review of Educational Research, 64(1), 3-35.

- Conrad, R. M., \& Donaldson, J. A. (2011).Engaging the online learner: Activities and resources forcreative instruction. San Francisco, CA: Jossey-Bass.

- Coomey M and Stephenson, J (2001) Online Learning: it is all about dialogue, involvement, support and control-according to the research, in Teaching and Learning Online: Pedagogies for New Technologies, ed. J. Stephenson, Kogan Page, London, UK

- Coomey, M., \& Stephenson, J. (2002).Teaching \& learning online: Pedagogies for newtechnologies. Online learning: It is all about dialogue, involvement, support andcontrol - according to the research. London: Kogan Page.

- Davidson-Shivers, G. V., Ellis, H. H., \&Amarasing, K. (2005). How do female studentsperform in online debates and discussion? In G. Richards (Ed.), Proceedings ofWorld Conference on ELearning in Corporate, Government, Healthcare, andHigher Education 2005 (pp. 1972-1977). Chesapeake, VA: AACE.

- Davidson-Shivers, G. V., Muilenburg, L., \& Tanner, E. (2001). How do studentsparticipate in synchronous and asynchronous online discussions? Journal ofEducational Computing Research, 25, 351-366.

- Davidson-Shivers, G. V., \& Rasmussen, K. L. (2006).Web-based learning: Design, implementation, and evaluation. Upper Saddle River, NJ: Pearson MerrillPrentice Hall.

- Davidson-Shivers, G. V., \& Taylor, L. L. (2006, April).Perspectives on gender and online discussion: Factors that influence participation. Paper presented at theannual meeting of the American Educational Research Association, SanFrancisco, CA.

- Davidson-Shivers, G. V., Tanner, E., \&Muilenburg, L. (2000).Online discussion: Howdo students participate? (ERIC Document Reproduction Service No. ED443410)

- Davie, L. (1988). Facilitating adult learning through computermediated distance education.Journal of Distance Education, 3(2), 55-69. 
- Davies, J. \& Graff, M. G. (2005) 'Performance in e-learning: Online participation and student grades. British Journal of Educational Technology, 36 (4), 657-663.

- Dennen, V. P. (2005). From message posting to learning dialogues: factors affecting learner participation in asynchronous discussion.Distance Education, 26(1), 127-148.

- Dennis, A. R., \& Williams, M. L. (2003). Electronic brainstorming: Theory, research, and future directions. In B. P. Paulus, \& B. A. Nijstad (Eds.), Group creativity: Innovationthrough collaboration (pp.160-180). New York: Oxford University Press.

- Dewey, J. (1901). Psychology and social practice. Chicago, IL: University of Chicago Press. Hubscher-Younger, T., \& Narayanan, N. H. (2003).Authority and convergence in collaborative learning.Computers \& Education, 41, 313-334.

- Dick, W., \& Carey, L. (2004).The systematic design of instruction (th ed.). New York: Harper Collins College Publishers.

- Dringus, L. P. (2002). Editor's choice 2002: Selected online learning resources. TheInternet and Higher Education, 5(4), 377397.

- Du, J., Havard, B., \& Li, H. (2005). Dynamic online discussion: Task-oriented interaction for deep learning. Educational Media International, 42, 207-218.

- Dunlap, J.C. (2005). Workload reduction in online courses: Getting some shuteye. Performance Improvement, 44(5), 18-25.

- Duschl, R. A., \& Osborne, J. (2002). Supporting and promoting argumentation discourse in science education. Studies in Science Education, 39, 39-72.

- Eisenberg, M. B., \& Small, R. V. (1993). Information-based education: An investigation of the nature and role of information attributes in education. Education Issues, 29(2), 263-275.

- Ertmer, P. A., Richardson, J. C., Belland, B., Camin, D., Connolly, P., Coulthard, G., et al. (2007). Using peer feedback to enhance the quality of student online postings: An exploratory study. The Journal of Computer-Mediated Communication, 12(2), 412-433.

- Ellis, A. (2004). Personality type and participation in networked learning environments.Educational Media International, 40(1-2), 101-114.

- Fauske, J., \& Wade, S. E. (2003-2004). Research to practice online: Conditions that foster democracy, community, and critical thinking in computer-mediated discussions. Journal of Research on Technology in Education, 36(2), 137-153.

- Ferdig, R. E., \&Roehler, L. R. (2003-2004). Student uptake in electronic discussions: Examining online discourse in literacy 
preservice classrooms. Journal ofResearch on Technology in Education, 36,119-136.

- Fisher, M, Thompson, G. S., \& Silverberg, D. A. (2004-2005). Effective group dynamicsin e-learning: Case study. Journal of Educational Technology Systems, 33, 205-222.

- Fung, Y. Y. H. (2004). Collaborative online learning: Interaction patterns and limiting factors. OpenLearning, 19(2), 135-149.

- Gagne, R. M., Wager, W. W., Golas, K. C., \& Keller, J. M. (2005).Principles ofinstructional design (5th ed.). Belmont, CA: Thomson/Wadsworth.

- Gall, M. D., \& Gall, J. P. (1976).The discussion method. In N. L. Gage (Ed.), Thepsychology of teaching methods (Seventy-fifth Yearbook of the National Society for theStudy of Education). Chicago: University of Chicago Press.

- Garvin, C. D. (1981). Contemporary group work. Englewood Cliffs, NJ: Prentice-Hall.

- Gilbert, P. K., \&Dabbagh, N. (2005). How to structure online discussions for meaningfuldiscourse: A case study. British Journal of Educational Technology, 36(1), 5-18.

- Cifuentes, L., Murphy, K. L., Segur, R., \&Kodali, S. (1997). Design considerations for computer conferences.Journal of Research on Computing in Education, 30(2), 177-201.

- Glass, G., \& Smith, M. (1979).Meta-analysis of research on class size and achievement.Educational Evaluation and Policy Analysis, 1, 2-16.

- Grady, D. B. (2003).Mapping online discussions with lexical scores.Journal ofInteractive Learning Research, 14 (2), 209-229.

- Golas, K. C. (2000). Guidelines for Designing Online Learning.Proceedings of the 2000Interservice/Industry Training, Simulation \& Education Conference, Orlando, FL

- Graham, C. R., \&Misanchuk, M. (2004). Computer-mediated learning groups: Benefits and challenges to using groupwork in online learning environments. In T. S. Roberts (Ed.), Online collaborative learning: Theory and practice (pp. 181-202). Hershey, PA: Information Science Publishing.

- Gunawardena, C. N., Lowe, C. A., \& Anderson, T. (1997).Analysis of a global online debate and the development of an interaction analysis model for examining social construction of knowledge in computer conferencing.Journal of Educational Computing Research, 17(4), 397-431.

- Guzdial, M., \& Turns, J. (2000).Effective discussion through a computer-mediated anchored forum.Journal of the Learning Sciences, 9(4), 437-469. 


\section{Number 72, April , 2016}

- Hakkarainen, K., \&Palonen, T. (2003). Patterns of female and male students' participation in peer interaction in computer-supported learning. Computers \& Education, 40(4), 327-342.

- Hammond, M. (2005).A review of recent papers on online discussion in teaching and learning in highereducation.Journal of Asynchronous Learning Networks, 9(3), 9-23.

- Harasim, L. (1990). Online education: An environment for collaboration and intellectual amplification. In L. Harasim (Ed.), Online education: Perspectives on a new environment (pp. 39-64). New York: Praeger.

- Harasim, L. (1997, May). Interacting in hyperspace: Developing collaborative learningenvironments on the WWW.Paper presented at the 1997 University of Maryland SystemInstitute for Distance Education and the International University Consortium Conferenceon Learning, Teaching, Interacting in Hyperspace: The Potential of the Web. Maryland,Ohio, USA.

- Havard, B., Du, J., \&Olinzock, A. (2005). Deep learning: The knowledge, methods, and cognitive process in instructor-led online discussion. The Quarterly Review ofDistance Education, 6,125135.

- Helic, D., Maurer, H., \&Scerbakov, N. (2004).Discussion Forums as LearningResources in Web-Based Education.

- Hewitt, J. (2003). How habitual online practices affect the development of asynchronous discussion threads. Educational Computing Research, 28(1), 31-45.

- Hewitt, J. (1996). Progress toward a knowledge-building community.Unpublished Doctoral dissertation, University of Toronto, Toronto, Ontario, Canada.

- Hewitt, J. (2005). Toward an understanding of how threads die in asynchronous computer conferences.Journal of the Learning Sciences, 14(4), 567-589.

- Hewitt, J., \& Brett, C. (2007). The relationship between class size and online activity patterns in asynchronous computer conferencing environments. Computers \& Education,49, 12581271.

- Hewitt, J., Brett, C. \& Peters, V. (2007). Scan Rate: A new metric for the analysis of reading behaviors in asynchronous computer conferencing environments. American Journal of Distance Education, 21(4), 1-17.

- Hew, K. F., \& Cheung, W. S. (2003a). An exploratory study of the use of asynchronous online discussion inhypermedia design.Journal of Instructional Science \& Technology, 6(1), 12-23.

- Hew, K. F., \& Cheung, W. S. (2003b). Evaluating the participation and quality of thinking of pre-serviceteachers in an asynchronous 


\section{Number 72, April , 2016}

online discussion environment: Part II.International Journal ofInstructional Media, 30(4), 355-366.

- Hiltz, S. R. (1990). Evaluating the virtual classroom. In L.M. Harasim (Ed.), Onlineeducation: Perspectives on a new environment (pp. 133-183). New York: Praeger.

- Hiltz, S. R., \&Turoff, M. (1985). Structuring computer-mediated communicationsystems to avoid information overload. Association of Computing Machinery, 28(7), 680-689.

- Hoadley, C. (2004). Fostering productive collaboration offline and online: Learning from each other. In M. C. Linn, E. A. Davis, \& P. Bell (Eds.), Internet environments forscience education. Mahwah, NJ: Lawrence Erlbaum Associates.

- Hoadley, C. M., \& Linn, M. C. (2000).Teaching Science through online, peerdiscussions: SpeakEasy in the Knowledge Integration Environment InternationalJournal of Science, 22(8), 839-857.

- Hrastinski,S. (2006). The relationship between adopting a synchronous medium and participation in online group work: An explorative study. Interactive Learning Environments,14(2),137152.

- Hron, A., \& Friedrich, H. F. (2003). A review of web-based collaborative learning: Factors beyond technology. Journal of Computer Assisted Learning, 19, 70-79.

- Hubscher-Younger, T., \& Narayanan, N. H. (2003).Authority and convergence in collaborative learning.Computers \& Education, 41, 313-334.

- Hummel, H. G. K., Burgos, D., Tattersall, C., Brouns, F., Kurvers, H., \&Koper, R. (2005a).Encouraging contributions in learning networks using incentive mechanisms.Journal of Computer Assisted Learning, 21, 355-365.

- Jeong, A. C ,\& Davidson-Shivers, G. V. (2006). The effects of gender interactionpatterns on student participation in computersupported collaborativeargumentation.Educational Technology Research and Development, 54, 543-568.

- Jin, S. H. (2005). Analyzing student-student and student-instructor interaction through multiple communication tools in web-based learning.International Journal ofInstructional Media, 32(1), 59-67.

- Johnson, D. W., Johnson, R. T., \&Holubec, E. J. (1994). Cooperative learning in theclassroom. Alexandria, VA: Association for Supervision and Curriculum Development.

- Johnson, C. G. (2005). Lessons learned from teaching web-based courses: The 7-year itch. Nursing Forum, 40(1), 11-17.

- Jonassen, D., \&Remidez, H., Jr. (2005). Mapping alternative discourse structures ontocomputer conferences.International Journal of Knowledge and Learning, 7,113-129. 
- Johnson, S. D., Suriya, C., Yoon, S. W., Berrett, J. V., \& Fleur, J. L. (2002). Team development and group processes of virtual learning teams.Computers \& Education, 39, 379-393.

- Jugdev, K., Markowski, C, \&Mengel, T. (2004).Using the debate as a teaching tool in the online classroom.Online Classroom, 4-7.

- Jung, I., Choi, S., Lim, C., \&Leem, J. (2002).Effects of different types of interaction on learning achievement, satisfaction and participation in web-based instruction.Innovations in Education and Teaching International, 39(2), 153-162.

- Kadushin, A. (1992). Supervision in social work. New York: Columbia University Press.

- Kachel, D. E., Henry, N. L., \& Keller, C. A. (2005). Making it real online: Distancelearning for high school students.Knowledge Quest, 34(1), 14-17.

- Khan, S. (2005). Listservs in the college science classroom: Evaluating participation and "richness" in computer-mediated discourse. Journal of Technology and Teacher Education, 13(2), 325-351

- Khine, M. S., Yeap, L. L., \&Lok, A. T. C. (2003).The quality of message ideas, thinking and interaction in an asynchronous CMC environment.Educational Media International, 40(1/2), 115-125.

- Kear, K. (2001). Following the thread in computer conferences.Computers \& Education, 37, 81-99.

- Kear, K., \& Heap, N. W. (2007).'Sorting the wheat from the chaff': Investigating overload in educational discussion systems.Journal of Computer Assisted Learning, 23, 235-247.

- Kerka, S. (1996).Distance learning, the Internet, and the World Wide Web. Columbus, OH: ERIC Clearinghouse on Adult, Career, and Vocational Education. (ERIC Document Reproduction Service No. ED395214)

- Kerr, N. (1989). Illusions of efficacy: The effects of group size on perceived efficacy in social dilemmas. Journal of experimental Social Psychology, 35, 287-313.

- Kerr, E. B., \&Hiltz, S. R. (1982).Computer-mediated communication systems: Statusand evaluation. New York: Academic Press.

- Kimball, L. (1995). Ten ways to make online learning groups work. EducationalLeadership, 53(2), 54-56.

- Kirk, J. J., \& Orr, R. L. (2003).A primer on the effective use of threaded discussionforums.2003 UNC Teaching and Learning with Technology Conference. March 28,Greensboro, NC. USA. (ERIC Document Reproduction Service No. ED472738).

- Klemm, W. R. (1998). Eight ways to get students more engaged in online conferences. The Higher Education Journal, 26 (1), 62-64. 
- Klemm, W. R. (2000). What's wrong with on-line discussions and how to fix it? Paper presented at the WebNet 2000 World Conference on the WWW and Internet, San Antonio, TX, USA, October, 2000. (ERIC Document Reproduction Service No. ED 448755)

- Kluwin, T. N., \&Noretsky, M. (2005).A mixed methods study of teachers of the deaf learning to integrate computers into their teaching.American Annals of the Deaf,150,350-357.

- Knowles, M., \& Knowles, H. (1959).Introduction to group dynamics. New York: Associated Press.

- Kuboni, O., \& Martin, A. (2004). An assessment of support strategies used to facilitate distance students' participation in a web-based learning environment in the University of the West Indies. Distance Education, 25(1), 7-29.

- Kukulska-Hulme, A. (2004). Do online collaborative groups need leaders? In T. S. Roberts (Ed.), Online collaborative learning: Theory and practice (pp. 262-280). Hershey, PA: Information Science Publishing.

- Kramer, R., \& Brewer, M. (1986).Social group identity and the emergence of cooperation in resource conservation dilemmas.In $\mathrm{H}$. Wilke, D. Messick, \& C. Rutte (Eds.), Experimental social dilemmas (pp. 205-234). Frankfurt am Main, NY: Verla Peter Lang.

- Larkin, T. L., \&Belson, S. I. (2005). Blackboard Technologies: A vehicle to promote student motivation and learning in physics. Journal of STEM Education, 6(1), 14-27.

- Larson, B., \&Keiper, T. A. (2002).Classroom discussion and threaded electronicdiscussion learning in two arenas.Contemporary Issues in Technology \& TeacherEducation, 2(1), 31-51.

- Lawhead, P. B., Alpert, E., Bland, C. G., Carswell, L., Cizmar, D., DeWitt, J., Dumitru,M., Fahraeus, E.R.,Scott, K.(1997). The Web and distance learning: what isappropriate and what is not (report of the ITiCSE '97 working group on the weband distance learning). The supplemental proceedings of the conference onIntegrating technology into computer science education: working group reportsand supplemental proceedings (pp. 27 - 37). Uppsala, Sweden: ACM.

- Lea, M., Rogers, P., \&Postmes, T. (2002). SIDE-VIEW: Evaluation of a system to develop team players and improve productivity in Internet collaborative learning groups. British Journal of Educational Technology, 33 (1), 53-63.

- Lehtinen, E. (2003). Computer-supported collaborative learning: An approach to powerful learning environments. In E. D. Dorte, L. 
Verschaffel, \& N. E. Entwistle (Eds.), Powerful learning environments: Unravelling basic components and dimensions (pp. 35-53). Oxford, UK: Elsevier.

- Linn, M. C. (1995). Designing computer learning environments for engineering and computer science: The scaffolded knowledge integration framework.Journal of ScienceEducation and technology, 4, 103-126.

- Linn, M. C., \&Slotta, J. D. (2006).Enabling participants in online forums to learn from each other. In A. M. O'Donnell, C. E. HmeloSilver, \& G. Erkens (Eds.), Collaborativelearning, reasoning, and technology (pp. 61-97). Mahwah, NJ: Lawrence Erlbaum Associates Publishers.

- Lipponen, L. (2001). Computer-supported collaborative learning: From promises toreality. Unpublished Doctoral Dissertation, University of Turku, series B, Humaniora, 245.

- Lipponen, L., \&Lallimo, J. (2004). Assessing applications for collaboration: from collaboratively usable applications to collaborative technology. British Journal ofEducational Technology, 35(4), 433-442.

- Lipponen, L., Rahikainen, M., Lallimo, J., \&Hakkarainen, K. (2003).Patterns of participation and discourse in elementary students' computer-supported collaborative learning. Learning and Instruction, 13(5), 487-509.

- Lu, L. L., \&Jeng, I. (2006). Knowledge construction in in-service teacher online discourse: Impacts of instructor roles and facilitative strategies. Journal ofResearch on Technology in Education, 39, 183-202.

- Masters, A., \&Oberprieler, G. (2004).Encouraging equitable online participationthrough curriculum articulation.Computers \& Education, 42, 319-332.

- Mazzolini, M., \&Maddison, S. (2004).Education without frontiers? International participation in an online astronomy program. In R. Atkinson, C. McBeath, D. Jonas-Dwyer, \& R. Philips (Eds.), Beyond the comfort zone: Proceedings of the 21st annual conference of the Australasian Society for computers in learning in tertiary education, ASCILITE 2004 (pp. 606-615). Perth, Australia: University of Western Australia.

- Mazzolini, M., \&Maddison, S. (2003).Sage, guide, or ghost?The effect of instructorintervention on student participation in online discussion forums.Computers andEducation, 40, 237-253.

- McAlpine, I. (2000). Collaborative learning online.Distance Education, 21(1), 66-80.

- McFarland, D., \& Hamilton, D. (2005). Factors affecting student performance and satisfaction: Online versus traditional course 
delivery. The Journal of Computer Information Systems, 46(2), 2532.

- McLoughlin, C., \& Luca, J. (2002).A learner-centred approach to developing team skillsthrough web-based learning and assessment.British Journal of Educational Technology, 33, 571582.

- Moore, J. C. (2005). The Sloan consortium quality framework and the five pillars. Retrieved from http://www.sloanc.org/publications/books/qualityframework.pdf

- Moore, J. L., \&Marra, R. M. (2005).A comparative analysis of online discussionparticipation protocols.Journal of Research on Technology in Education, 38 191-212.

- Mullen, B., Johnson, C., \& Salas, E. (1991). Productivity loss in brainstorming groups: A meta-analytic integration. Basic and Applied Social Psychology, 12, 3-23.

- Murphy, K. L., Mahoney, S. E., Chun-Ying, C, Mendoza-Diaz, N. V., \& Yang, X.(2005).A constructivist model of mentoring, coaching, and facilitating online discussions.Distance Education, 26,341-366,

- Murphy, E., \& Coleman, E. (2004). Graduate students' experiences of challenges inonline asynchronous discussions [Electronic Version]. Canadian Journal ofLearning and Technology, 30.

- Naidu, S. (1997). Collaborative reflective practice: An instructional design architecture for the Internet. Distance Education, 18(2), 257-283.

- Neo, M. (2003).Developing a collaborative learning environment using a web-based design.Journal of Computer Assisted Learning, 19, 462-473.

- Newman, D. R., Johnson, C., Webb, B., \& Cochrane, C. (1997). Evaluating the quality of learning in computer supported cooperative learning. Journal of the American Societyfor Information Science, 48(6), 484-495.

- Newman, P. S., \& Blitzer, J. C. (2003).Summarizing archived discussions: a beginning.Proceedings of the 8th international Conference on intelligent User interfaces(pp. 273-276). Miami, Florida, USA: ACM.

- Ng, C., \& Hung, D. (2003).Conceptualizing a framework for design of online communities.International Journal on E-Learning, 2(4), 60-71.

- Oliver, K. M. (2000). Methods for developing constructivist learning on the web.Educational technology, 30(6), 5-18.

- Oliver, M., \& Shaw, G. P. (2003).Asynchronous discussion in support of medical education.Journal of Asynchronous Learning Networks, 7(1), 56-67. 
- Olofsson, A. D. (2007). Participation in an educational online learning community.Journal of Educational Technology \& Society, 10(4), 28-38.

- Painter, C., Coffin, C., \&Hewings, A. (2003). Impacts of directed tutorial activities in computer conferencing: A case study. Distance Education, 24(2), 159-174.

- Palloff, R. H., \& Pratt, K. (1999).Building learning communities in cyberspace: Effectivestrategies for the on-line classroom. San Francisco: Jossey-Bass.

- Parkhurst, R., Barbara M. Moskal, G., Lee D., Juan L., Thomas B., \& Sharon E. (2008). Engineering Cultures: Comparing Student Learning in Online and Classroom Based Implementations.International Journal of Engineering Education, 24(5), 955-64.

- Paulus, P. B., Larey, T. S., \& Ortega, A. H. (1995).Performance and perceptions of brainstormers in an organizational setting.Basic and Applied Social Psychology, 7, 249- 265.

- Pena, C. M. (2004).The design and development of an online, casebased course in ateacher preparation program.Journal of Interactive Online Learning, 3(2), 1-18.

- Peng, T. (2004) Creating a knowledge building writing environment using computermediated communication technology: EFL students taking control of their learning.Unpublished doctoral dissertation, University of Toronto, Toronto, Ontario, Canada.

- Peters, V., \& Hewitt, J. (2005). An analysis of student practices in asynchronous computer conferencing environments. Proceedings of the ED-MEDIA 2005-WorldConference on Educational Multimedia Hypermedia \& Telecommunications, June 27- July 2, 2005, Montreal, Canada. CD ROM, 778-785.

- Peters, V. (2005).Towards an understanding of student practices in asynchronouscomputer conferencing environments.Unpublished master's thesis, University of Toronto, Toronto, Ontario, Canada.

- Piaget, J. (1932). The language and thought of the child. London: Routledge/Kegan Paul.

- Piaget, J. (1952). The origins of intelligence in children. New York: International Universities Press.

- Poole, D. M. (2000). Student participation in a discussion-oriented online course: A case study. Journal of Research on Computing in Education, 33(2), 162-177.

- Poscente, K. R., \&Fahy, P. J. (2003). Investigating triggers in CMC text transcripts. The InternationalReview of Research in Open and Distance Learning, 4(2).

- Puntambekar, S., \&Luckin, R. (2003). Documenting collaborative learning: What should be measured and how? Computers \& Education, 41, 309-311. 
- Richardson, J. C., \& Swan, K. (2003).Examining social presence in online courses in relation tostudents' perceived learning and satisfaction.Journal of Asynchronous Learning Networks, 7(1), 6888.

- Roberts, M. R., \& Hopewell, T. M. (2003).Web-based instruction in technology education.Council on Technology Teacher Education, 52nd Yearbook: Selectinginstructional strategies for technology education. McGraw Hill, Glencoe.

- Rodriguez Illera, J. L. (2001). Collaborative environments and task design in the university. Computers in Human Behaviour, 17, 481493.

- Rovai, A. P. (2002). Building sense of community at a distance.International Review ofResearch in Open and Distance Learning, 3(1). Retrieved September 20, 2014 fromhttp://www.irrodl.org/index.php/irrodl/article/view/79/152

- Scardamalia, M., \&Bereiter, C. (1999).Schools as knowledge building organizations. In D. Keating \& C. Hertzman (Eds.), Today's children, tomorrow's society: Thedevelopmental health and wealth of nations (pp. 274-289). New York: Guilford.

- Schrire, S. (2006). Knowledge building in asynchronous discussion groups: Goingbeyond quantitative analysis. Computers \& Education, 46, 49-70.

- Smith, M., \& Winking-Diaz, A. (2004). Increasing Students' Interactivity in an OnlineCourse.Journal of Interactive Online Learning, 2(3), 1-25. Retrieved on September 20,2014 from http://www.ncolr.org/jiol/issues/PDF/2.3.3.pdf

- Stathakos, J. (2003). Learning partners as an instructional design strategy to promotecollaboration and community building in the online classroom. Unpublished Doctoral Dissertation, University of Toronto, Toronto, Ontario, Canada.

- Stemwedel, J. D. (2005). Rubrics, roles, and successful online discussions.Online Classroom, 3-8.

- Strijbos, J. W., Martens, R. L., \&Jochems, W. M. G. (2004).Designing for interaction: Six steps to designing computersupported group-based learning.Computers andEducation, 42, 403424.

- Sullivan, P. (2001). Gender differences and the online classroom: Male and female college students evaluate their experiences. Community College Journal ofResearch and Practice, 25, 805-818,

- Sutton, L.A. (2001). The Principle of Vicarious Interaction in Computer-Mediated Communications. International Journal of Educational Telecommunications, 7(3), 223-242.

- Thaiupathump, C., Dawant, M., \& Bourne, J. (1998). An Automated FAQ system(AUTOFAQ): Building Frequently Asked Questions (FAQs) pages for ALNs[Electronic Version]. ALN 
Magazine, 2.Retrieved March 1, 2015, fromhttp://www.sloanc.org/publications/magazine/v2n1/choon.asp

- Topper, A. (2005).Facilitating student interactions through discursive moves: An instructor's experience teaching online graduate courses in educational technology. The Quarterly Review of Distance Education, 6(1), 55-67.

- Torrisi-Steele, G. (2002). 'Technology For The Sake Of Learning' A planning approach for integrating new technologies in tertiary learning environments [Electronic Version]. Retrieved January 15, 2014, from http://ausweb.scu.edu.au/aw02/papers/refereed/torrisi/paper.html

- Tu, C. H., \&Mclsaac, M. (2002).The relationship of social presence and interaction in online classes. The American Journal of Distance Education, 16(3), 131-150.

- Tucker, A. A. (2007). Leadership by the Socratic method. Air \& Space Power Journal, 21(2), 80-87,127.

- Vonderwell, S., Liang, X., \& Alderman, K. (2007).Asynchronous Discussions and Assessment in OnlineLearning.Journal of Research on Technology in Education, 39(3), 309-328.

- Vonderwell, S., \& Zachariah, S. (2005).Factors that Influence Participation in Online Learning.Journalof Research on Technology in Education, 38(2), 213-230.

- Vygotsky, L. S. (1978). Mind in Society. Cambridge, MA: Harvard University Press.

- Wallace, R. M. (2003). Online learning in higher education: A review of research on interactions among teachers and students. Education, Communication \&Information, 3,241-280.

- Watson, G., \& Johnson, D. W. (1972). Social psychology: Issues and insights (2nd ed.). Philadelphia: Lippincott.

- Wayne, J., \& Cohen C. S. (2001).Group work education in the field. Alexandria, VA: Council on Social Work education.

- Weasenforth, D., Lucas, S. B., \&Meloni, C. (2002). Realizing constructivist objectives through collaborative technologies: Threaded discussions. Language Learning \&Technology, 6(3), 5886.

- Webb, N. M., Troper, J. D., \&Fall, R. (1995). Constructive activity and learning in collaborative small groups. Journal of Educational Psychology, 8, 406-423.

- Wiley, J., \& Bailey, J. (2006).Effects of collaboration and argumentation on learning from web pages. In A. M. O'Donnell, C. E. Hmelo-Silver, \& G. Erkens (Eds.), Collaborative learning, reasoning, and technology (pp. 297-321). Hillsdale, NJ: Erlbaum.

- Xie, K., DeBacker, T. K., \& Ferguson, C. (2006).Extending the traditional classroom through onlinediscussion: The role of student 
motivation.Journal of Educational Computing Research, 34(1), 6789.

- Yang, Y. T. C., Newby, T., \& Bill, R. (2008).Facilitating interactions through structured web-based bulletinboards: A quasiexperimental study on promoting learners' critical thinking skills.Computers andEducation, 50(4), 1572-1585.

- Yang, Y. T. C., Newby, T. J., \& Bill, R. L. (2005).Using Socratic questioning to promote critical thinkingskills through asynchronous discussion forums in distance learning environments.American Journal ofDistance Education, 19(3), 163-181.

- Yeh, H. T., \&Buskirk, E. V. (2005).An instructor's methods of facilitating students' participation in asynchronous online discussion. In C. Crawford, D. A. Willis, R. Carlsen, I. Gibson, K. McFerrin, J. Price, \& R. Weber (Eds.), Proceedings of Society for Information Technology and Teacher Education International Conference 2005 (pp. 682-688). Chesapeake, VA: AACE.

- York, R. O. (2008). Comparing Three Modes Instruction in a Graduate Social Work Program. Journal of Social Work Education, 44(2), 157-71.

- Zhao, N., \& McDougall, D. (2005).Cultural factors affecting Chinese students' participation in asynchronous online learning. In G. Richards (Ed.), Proceedings of World Conference on E-learning in Corporate, Government, Healthcare, and Higher Education 2005 (pp. 2723-2729).Chesapeake, VA: AACE.

\section{垱垱溇潾潘}

